\title{
CHARACTERIZATION OF DISCONTINUITIES IN THE STRIPA
}

\section{GRANITE - TIME-SCALE HEATER EXPERIMENT}

\author{
Richard Thorpe \\ Lawrence Berkeley Laboratory \\ University of Cali fornia \\ Berkeley, California 94720 \\ July 1979
}

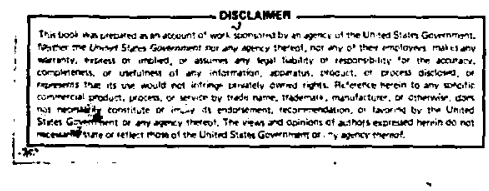

This report was prepared by the Lawrence Berkel ey Laboratory under the University of California contract W-7405-ENG-48 with the Department of Eneryy. Funding for this project is administered by the office of Nuclear Waste Isolation at Battelle Memorial Institute. 
PREFACE

This report is one of a series documenting the results of the Swedish-Amer ican cooperative research program in which the cooperating scientists explore the geological, geophysical, hydrological, geochemical, and structural effects anticipated from the use of a large crystalline rock mass as a geologic repository for nuclear waste. This program has been sponsored by the Swedish Nuclear Power Utilities through the Swedish Nuclear Fuel Supp Ty Company (SKBF), and the U.S. Department of Energy (DOE) through the Lawrence Berkeley Laboratory (LBL).

The principal investigators are L. B. Nilsson and 0. Degerman for SKBF, and M. G. W. Cook, P. A. Witherspoon, and J. E. GaTe for LBL. Other participants will appear as authors of the individual reports.

Previous technical reports in this series are 1 isted below.

1. Swedish-fmerican Cooperative Program on Radioactive Waste Storage in Hined Caverns by P. A. Witherspoon and 0 . Degerman.

(LBL-7049, SAC-01).

2. Large Scale Permeability Test of the Granite in the Stripa Mine and Thermal Conductivity Test by Lars Lundstrom and Haken Stille. (LBL-7052, SKCL-02).

3. The Mechanical Properties of the Stripa Granite by Graham Swan. (LBL-7074, SAC-03).

4. Stress Measurements in the Stripa Granite by H. Carlsson. (LBL-7078, SAC-04).

5. Borehole Drilling and Related Activities at the Stripa Mine by Pavel J. Kurfurst, T. Hugo-Persson, and G. RudoTph. (LBL-7080, SAC-05).

6. A Pilot Heater Test in the Stripa Granite by Hans Carisson. (LBL-7086, SAC-06).

7. An Analysis of Measured Values for the State of Stress in the Earth's Crust by Denn is B. Jamison and Neville G. W. Cook. (L.BL-7071, SAC-07).

8. Mining Methods Used in the Underground Tunnels and Test Rooms at Stripa by B. Andersson and P. A. Halen. (LBL-7081, SAC-08).

9. Theoretical Temperature Fields for the Stripa Heater Project by Tín Chan, Keville G. W. Cook, ard Chin-fu Tsang. (LBL-7082, SAC-09). 
10. Mechanical and Thermal Design Considerations for Radioactive Waste Repositories in Hard Rock. Part I: An Appraisal of Hard Rock for Potential Underground Repositories of Radioactive Wastes by Neville G. W. Cook; Part II: In Situ Heating Experiments in Hard Rock: The ir Objectives and Design by Neville G. W. Cook and Paul A. Witherspoon. (LBL-70̄73, SAC-10).

11. Full-Scale and Time-Scale Heating Experiments at Stripa: Preliminary Results by Neville G.W. Cook and Michael Hood. (LBL-7072, SAC11).

12. Geochemistry and Isotope Hydrology of Groundwaters in the Stripa Granite: Results and Preliminary Interpretation by P. Fritz, J.F. Barker, and J.E. Gale. (LBL-8285, SAC-12).

13. Electrical Heaters for Thermo-mechanical Tests at the Stripa Míne by R. H. Burleigh, E. P. Binnall, A. O. DuBois, D. U. Norgren, and A. R. Oritz. (LBL-7063, SAC-13).

14. Data Acquisition, Handling, and Display for the Heater Experiments at Stripa by Maurice B. McEvay (LBL-7062, SAC-14).

15. An Approach to the Fracture Hydrology at Stripa: Preliminary Results by J. E. Gale and P. A. Witherspoon. (LBL-7079, SAC-15).

16. Prel iminary Report on Geophysical and Mechanical Borehole Measurements at Stripa by P. Nelson, B. Paulsson, R. Rachiele, L. Andersson, T. Schrauf, H. Hustrulid, O. Duran, and K. A. Magnusson. (LBL-8280, SAC-16).

17. Observations of a Potential Size-Effect in Experimental Determination of the Hydraulic Properties of Fractures by $P$. A. Witherspoon, C. H. Amick, J. E. GaTe, and K. Iwaí (LBL-8571, SAC-17).

18. Rock Mass Characterization for Storage of Nuclear Waste in Granite by P. A. Witherspoon, P. Ne1son, T. Doe, R. Thorpe, B. Pautsson, J. Gale, and C. Forster (LBL-8570, SAC-18).

19. Fracture Detection in Crystalline Rock Using Shear Waves by K. H. Waters, S. P. Palmer, and W. E. Farre17 (LBL-7051, SAC-19). 
TABLE OF CONTENTS

Page

LIST OF FIGURES.

LIST OF TABLES . ABSTRACT

1. INTRODUCTION

2. BACKGROUND.

2.1 The Time-Scale Experiment.

2.2 Geology of the Stripa Mine

3. SOURCES OF DATA.

3.1 Floor Mapping . . . . . . . . . . 11

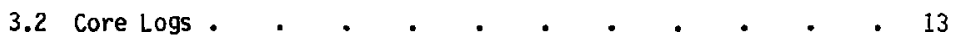

3.3 Comparison of Data Sources . • . • • • . 17

4. DETERMINISTIC CHARACTERIZATION OF DISCONTINUITIES . • . 20

4.1 Methodology . . . . . . . . . . 20

4.2 Results . . . . . . . . . . . . 23

5. STATISTICAL CHARACTERIZATION OF DISCONTINUITIES • • • $\quad . \quad 35$

5.1 Fracture Orientations . . . . . . . . 36

5.2 Fracture Sizes . . . . . . . . . . 39

5.3 Fracture Spacings . . . . . . . . . . 44

5.4 Fracture Infilling Characteristics . . . . . . 47

6. DISCUSSION $. \quad . \quad . \quad . \quad . \quad . \quad . \quad . \quad . \quad . \quad 53$

6.1 Origin of the Fracture System . • . • • . 53

6.2 Current Deformations. . . • • • • • . 56

6.3 Use of the Deterininistic Results . . . . . . 59

6.4 Limitations of Statistical Results . . • . . . 61 


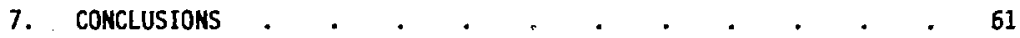

8. ACKNONLEDGMENTS . . . . . . . . . . . . . 63

9. RFFERENCES . . . . . . . . . . . . . 65

10. APPENDICES . . . . . . . . . . . . 67

A. Borehole Fracture Logs for
Tíme-Scale Experiment
. . . . . . . . . . . . 67

B. Photographs of Time-Scale
Experiment Core Samples . . . . . . . . . 89

C. Stereonet Plots of Fracture Poles for Time-Scale Experiment Boreholes . . . . . . 99 
1. Location of Stripa Mine . . . . . . . . . 2

2. General plan of test site. . . . . . . . . 5

3. Borehole layout in the time-scale drift . . . . . . 6

4. Sub-tijl geology at Stripa . . . . . . . . 8

5. Use of $1 \times 1 \mathrm{~m}$ reference frame in fracture mapping. . . 12

6. Detailed map of discontinuities in the floor of the time-scale experiment drift

7. Fracture frequencies from detailed floor map . . . . . 18

8. Core log fracture frequencies . . . . . . . . 18

9. Fracture frequencies for all fractures visible in core photographs 19

10. Generalized map of major discontinuities in the floor of the time-scale experiment drift . . . . . . . . 21

11. Subsurface profile along centerline of drift showing inajor discontinuities through the heater array. - . . • . 24

12. Three-dimensional views of the four continuous fractures passing through the heater array . . . . . . . 26

13. View of fracture no. 3 borehole locations, parallel to

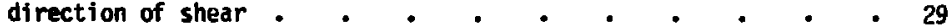

14. Contour diagram of fracture poles from time-scale experiment boreholes

15. Geniralized fracture set boundaries corresponding to 1.5 jercent contour ...$\quad$. . . . . .

16. Generalized fracture set boundaries for analysis of mapped fracture lengths

17. Fracture lerigth-frequency histograms for the three non-horizontal joint sets.

18. Cumulative lognomal iractuce length distributions. . .

19. Yertical fracture spacing-frequency histograms for all four joint sets. 
20. Cunulative lognomal distributions of fracture spacings

Page in vertical direction

21. Stereographic plots of poles of fractures with the three rajor types of mineralization. . . . . . . . 49

22. Stereographic plots of fractures with different thicknesses . . 52

23. Relationship of mean fracture set orientations and measured principal stress directions . . . . . . . 54

24. Resolution of shear and nomal stresses in the mean plane of fracture set 1 .

\section{LIST OF TABLES}

1. Subsurface coordinates of fracture 1 - . . . . 31

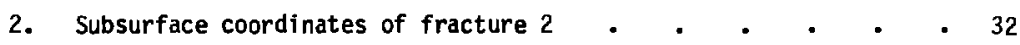

3. Subsurface coordinates of fracture 3 . . . . . . 33

4. Subsurface coordinates of fracture 4 . $4.0 . \quad$. $\quad$ - 34

5. Fracture length distribution parameters . . . . . . . 43

6. Fracture spacing distribution parameters. • . • . . 47

7. Fracture nineralization data for the Stripa core logs . . . 48

8. Statistical mineralization data fram Stripa fracture logs • . 52

9. Thickness data for fracture infillings . . . . . . 53

10. Shear and nomal stresses on the mean planes of the four fracture sets 
ABSTRACT

The report describes the methodology and results of a detailed study of geologic discontinuities associated with the time-scale heater test at the Stripa mine in Sweden. Mapping of the floor of the experiment tunnel coupled with observation of core samples from beneath the drift indicate that four $N$-striking shear fractures dip steeply through the $6 \times 10 \times 25-m$ rock mass. Oblique-thrust faulting has produced displacements of up to $2 \mathrm{~m}$ on one of the surfaces, and its inferred 3-D configuration is consistent with observed slickensiding. Resolution of locally measured principal stresses on the shear plane yields a theoretical shear direction that also coincides with the slickensiding.

Four distinct joint sets exist locally, one of wich coincides with the shear fractures. Another lies nearly horizontal, and two others are steeply inclined. Fracture length and spacing distributions for the four joint sets are shown to be lognomal. Two of the sets lie perpendicular to principal stress directions. The fact that one of these two joint sets apparently post-dates other fracturing and is normal to the minimum principal stress suggests that it is due to isostatic rebound. 


\section{INTRODUCT ION}

In June of 1977, Lawrence Berkeley Laboratory (LBL), and the Swedish Nuclear Fuel Safety Program (KBS) initiated a cooperative research program to study this suitability of crystalline rocks for storage of nuclear waste. Within the program are several different experimental projects, which are described by Witherspoon and Degerman (1978), Cook and Witherspoon (1978), and Gale and Witherspoon (1978). The field site for the research is located in south central Sweden (Fig. 1), at the Stripa mine. The history of mining
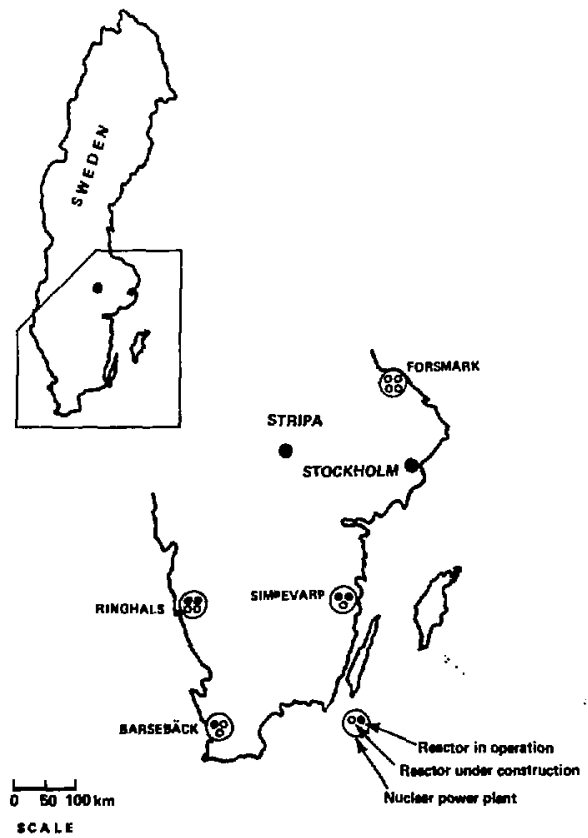

Fig. 1. Location of Stripa Mine. 
in the area and at Stripa is centuries old; iron ore production at the mine ceased earlir in 1977, however. Since that time the mine has been operated as an underground experimentation site under the auspices of the parent organization of KBS, the Swedish Nuclear Fuel Supply Company (SKBF).

The field studies involve two disciplines, subsurface hydrology and themomechanical behavior within massive fractured granite. Both aspects of the program require characterization of the fracture system because of its recognized importance to the stability of mined openings and the movement of fluids within the rock mass (Office of Waste Isolation 1977). The scope of characterization, however, depends on the extent of the rock mass influenced by the individual experiments. The heater experiments affect localized rock volumes of up to about a thousand cubic meters, whereas the hydrologic research involves volumes several orders of magnitude larger. While the latter requires a statistical approach to define the fracture network, the heater experiments require a more detailed study in which significant fractures are delineated in the subsurface. This report describes results. of such a study for the "time-scale" experiment, which is one of the two underground heater tests of Stripa. A similar report is being prepared concerning the other heater test, which is termed the "fullscale" experiment. The two experiments and their respective geological studies differ sufficientiy in scope, methodology, and results to warrant this separation. The common objective of the reports, however, is to define the position and nature of major discontinuities in the heated reyions. The ability to accomplish this depends largely on the quality and amount of subsurface geologic data available for each region. In a general 
sense, the deyree of detail which can be acquired is commensurate with the subsurface sampling, i.e., the "density" of instrumentation boreholes. Because the full-scale exi erilient is concerned with near-field effects, instrumentation drilling is dense near the heaters, and a detailed geological description can be made. For the time scale test, however, characterization is more general because although the zone of influence is larger, the sampling density is less.

In seeking to define the fracture system in the time-scale heater test, this report presents a limited amount of discrete discontinuity data coupled with a statistical evaluation of the local fracture network. In this manner the highly fractured rock between the delineated features can be represented stochastically. Throughout the report the general term "discontinuity" refers to natural fractures, joints, faults, dikes, or shear zones; "fracture" denotes any discontinuity except the dikes. Fractures without detectable displacement are termed joints; fractures with obvious silickensides are "shear fractures." Characteristics of the fractures, such as types and thicknesses of infilling, sizes, and spacings, will be discussed mainly statistically. Based on rather limiteci geological in imation about the Stripa area, some hypotheses regarding the origin of the fracture system will be offered. The potential influence of the discontinuities on local hydrology or the rock mass response to heating are beyond the scope of the report. 


\section{BACKGROUND}

\subsection{The Time-Scale Experiment}

The heater experiments are located approximately $335 \mathrm{~m}$ below the surface in massive granite adjacent to the Stripa ore body. A layout of the underyround site is shown in fig. 2. The time-scale experiment is designed to simulate the interactive themal effects of an array of waste canisters over a period of 12 years. Theoretically, this can be accom-

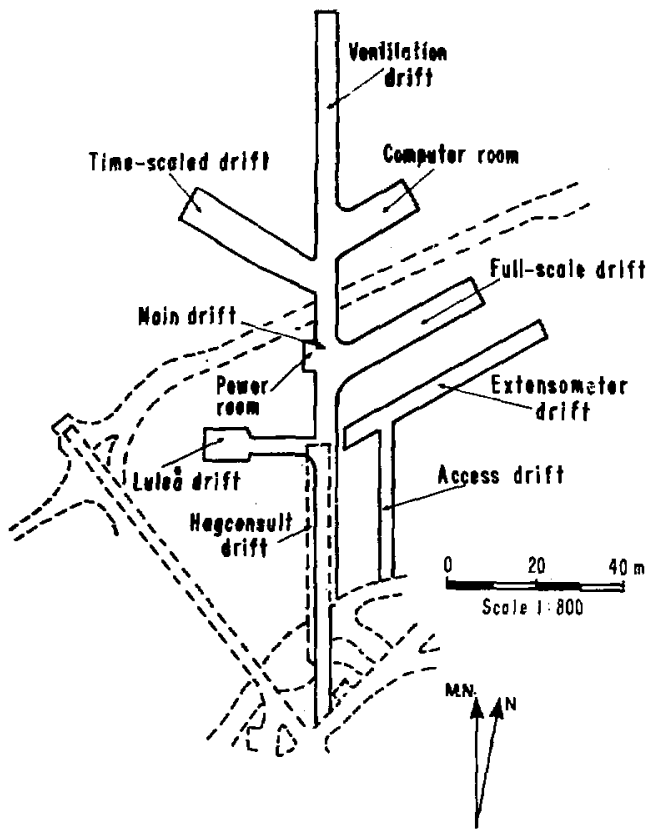

$X B L 787-1983$

Fiy. 2. General plan of test site. 
plished in a l-year period by scaling the dimensions and power outputs of the heaters by a factor of $1 / 3.5$. Since heat conduction involves the ratio of time to squared length, the laws of similitude correspondingly shorten the time scale by $1 /(35)^{2}$, or approximately $1 / 12$. The array consists of eight 1-m-long heatters arranged in the pattern shown in Fig. 3 . The midplane of the array is located approximacely $10 \mathrm{~m}$ below the drift floor,

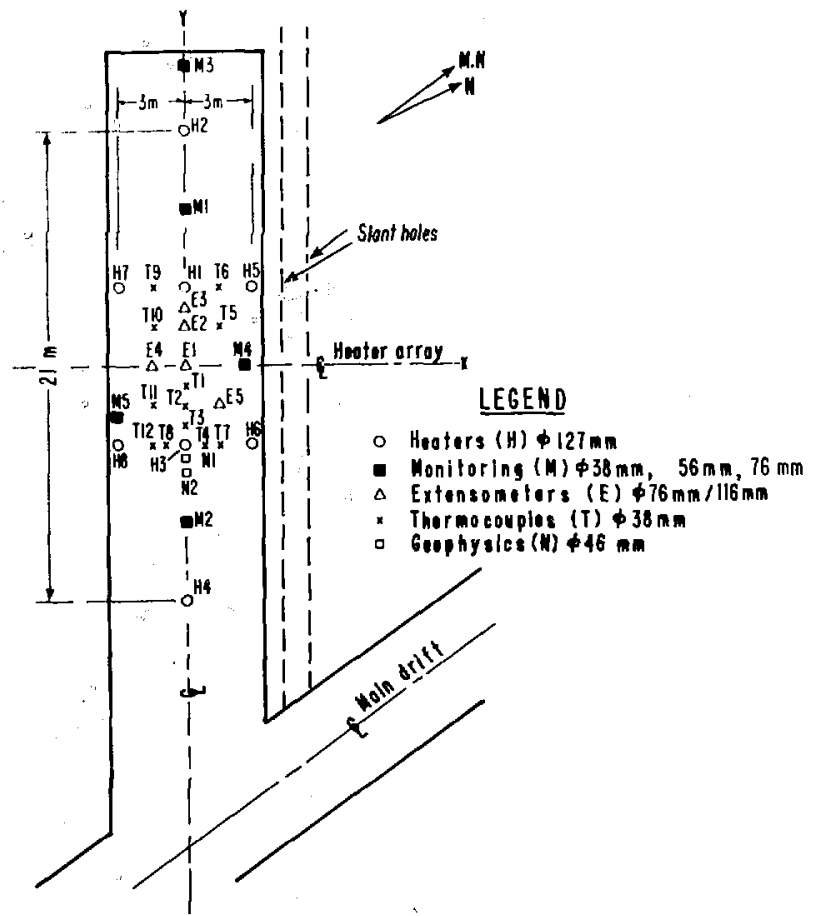

XBL 787-1986A

Fig. 3. Borehole layout in the time-scale drift. 
which should be outside the zone of stress alteration produced by the 5-rn-diameter tunnel. Over the life of the experiment, the outer isothenms produced by the heaters should approach flattened ellipsoidal shapes. The principal objective of the test is to investigate this simulated far-field response to heating and this improve numerical model'ing capabilities. Also of interest are the local effects between the heaters.

To monitor this rack mass behavior, a number of vertical displacemel., temperature, and stress-strain measurements are being recorded at various locations in the boreholes shown in Fig. 3. The most pronounced deformations in the rock mass should nccur in the central portion of the heater array where temperatures will be the highest; therefore, instrumentation is concentrated in that area.

In addition to the geomechanical instrumentation, in situ fluid pressures are being monitored in two $45-m$ boreholes situated alongside, the heater array, as shown in Fig. 3. As described by Gale and Witherspoon (1978), each borehole is separated into five equal intervals by hydraulic packers so that any change in the fluid pressure profile can be detected and recorded electronically. The vertical $\mathrm{N}$ - and M-holes of Fig. 3 are used for periodic geophysical monitoring of the heated rock mass. For a complete discussion of this aspect of the instrumentation, refer to Nelson et al. (1979).

\subsection{Geol ogy of the Stripa Mine}

The Stripa mine geology has been studied by the Swedish Geological Survey (SGU), and reported by 0lkiewicz et al. (1978). Figure 4 shows 


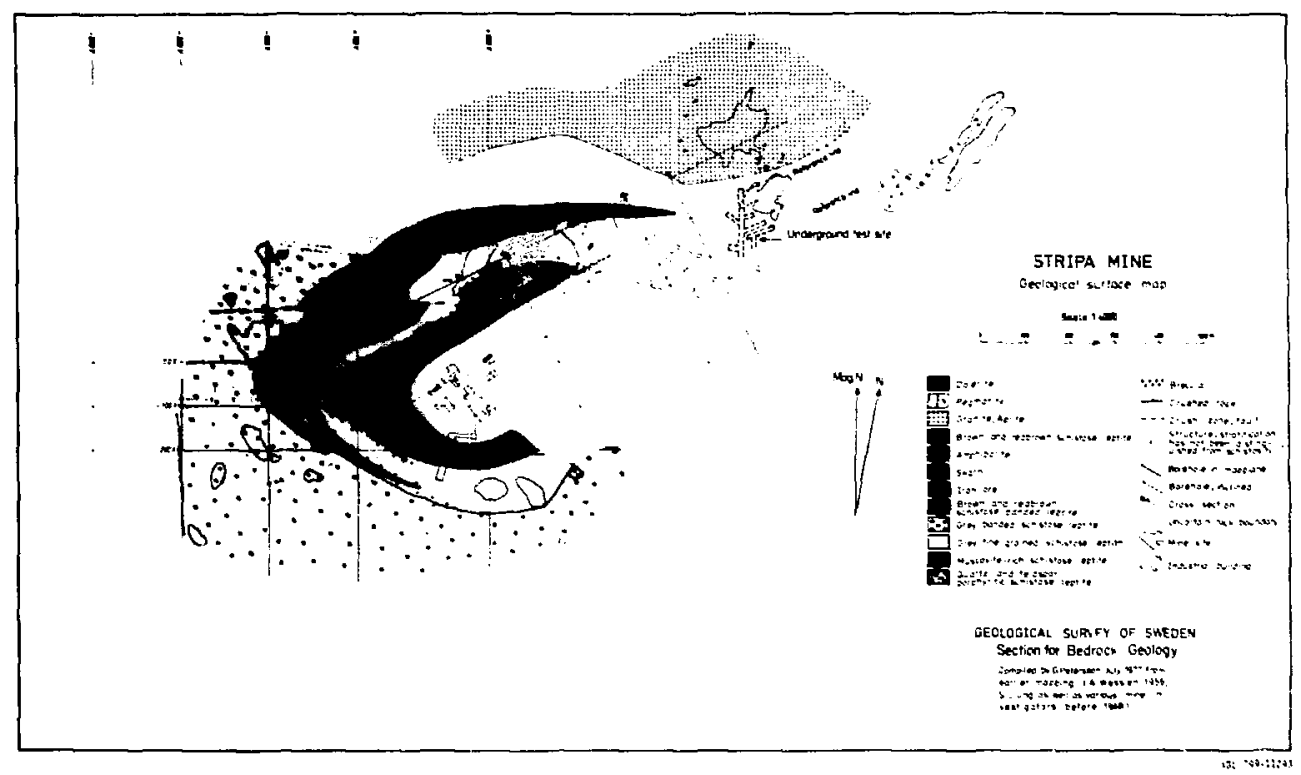

Fig. 4. Sub-till geology at Stripa. 
: the surficial geologic setting in the area of the mine. The ore body lies in a synclinal trough whose axis plunges about $20^{\circ}$ to the ENE. The ore has a relatively high iron cortent, and is composed predominantly of interbanded hematite ond quartz with some magnetite concentrations. It is stratiformly bound within gray io browmish Precambrian metavolcanic rock, which in European teminology is broadly classed as "leptite." A smaller ore body lies parallel to the main ore and stratigraphically below it. The southern limb of this parallel are is missing above the 200-m mine level, while below that depth both limbs are present. Just below each of the ore bodies the leptite is clearly layered, while above it is not. The iron ore is the youngest component of the leptite and occurs as reddish brown masses. A number of diabase and amphibolite dikes transect the leptite and are visible in the mine levels.

The underground test site is located in a massive granite body in contact with the north limb of the leptite syncline. The contact is quite irregular, but in its area in the mine it strikes ENE and dips steeply to the SE. The actuai heater experiments are being conducted approximately 150 m within the granite, at a depth of about $340 \mathrm{~m}$. The granite most likely post-dates the leptite and is probably connected with one of several postorogenic Precambrian plutons in the region. Due to relatively mild tectonism since the intrusion, there are no gneissic structures in the granite. The granite is yenerally unfoliated and varies from gray to light red in color. Composition of the reddish variety has been reported by olkiewicz et al. (1978). 


$\begin{array}{lc}\text { Quartz } & 44 \% \\ \text { Plagioclase } & 39 \% \\ \text { Microcline } & 12 \% \\ \text { Chlorite } & 3 \% \\ \text { Muscovite } & 2 \% \\ \text { Accessory Minerals: } & \text { zircon, opaques }\end{array}$

The gray type of granite which predominates in the test areas has a somewhat higher microcline percentage and less plagioclase. Grain sizes vary from 1 to $5 \mathrm{~mm}$, with an average of $3 \mathrm{~mm}$. Associated with the granite are widely spaced pegmatite and aplitic dikes less than $1 \mathrm{~m}$ in thickness. The youngest dikes are diabase, nearly vertical, and strike NNE.

Although little has been written on the tectonic features in the mine, previous investigations at Stripa (Geijer 1938) have differentiated the fractures in the ore body into two categories. One category is related to shearing between layers produced by the fold deformation, and the other is descrited by Geijer as more recent and "steeply dipping" (no average strike direction mentioned). The fold-re]ated fractures in the ore body tend to be steeply inclined and strike in an ENE direction, although these are also nearly horizontal faults.

Major fractures throughout the various drifts in the granite formation have been broadly surveyed by SGU and reported by 01kiewicz et al. (1978). Compilations of fractures over an extensive area show a clear dominance of those that dip steeply to the north, except in the heater experiment areas, where many fractures dip to the south. Two general strike directions 
persist, according to 0lkiewicz et al. (1978). One is evenly distributed fras north to east; and the other is concentrated between northwest and west. These surveys indicate that the great majority of the fractures are visibly closed, and water seepage consists only of damp surfaces or slow arips. Fracture filling materials are primarily chlorits, and occasionally calcite.

\section{SOURCES UF DATA}

The work of 0lkiewicz et al. (1978) provides : ieral description of yeologic discontinuities in the underground test area. The interpretation of the time-scale experiment, however, demands a more detailed characterization. over a smaller area. Locating the positions of discrete major features beneath the drift floor required (1) a detailed floor map of surficial discontinuities, and (2) comp? ete core logs describing subsurface features. The majority of the subsurface interpretation for the time-scale drift could not be perfomed on site, hence secondary information included (a) stereophotographs of the floor and walls of the drift, and (b) color photographs of the logged core samples taken from the drift. The data bases are described further below.

\subsection{Floor Mapping}

Underyround-fracture surveys typically involve mapping features from the walls and roofs of drifts (Knill and Jones 1965; Kendorski and Mahtab 1976). In order to trace individual features beneath the drift, it was necessary to inspect the floor-a task that required much preparatory work. First, the newly excavated $6 \times 6 \times 32-m$ entry was scaled of loose rock and thoroughly cleaned to facilitate geological mapping. Next, a $1 \times 1-m$ horizontai 
yrid was painted on the floor, oriented parallel to the drift centerline, and nence tied into the overall mine survey systen. Mine elevations were measured at the painted coordinates to provide some representation of the irregular floor topography, which has a relief of $0.5 \mathrm{~m}$ or less.

The floor was mapped square-by-square, starting at the end of the drift and progressing back toward the entrance. To facilitate the process and improve accuracy, a $1 \times 1-m$ square frome, with $0.1-m$ graduations along its side, was positioned over the grid points, as depicted in Fig. 5. This allowed fracture positions to be visually estimated within each square

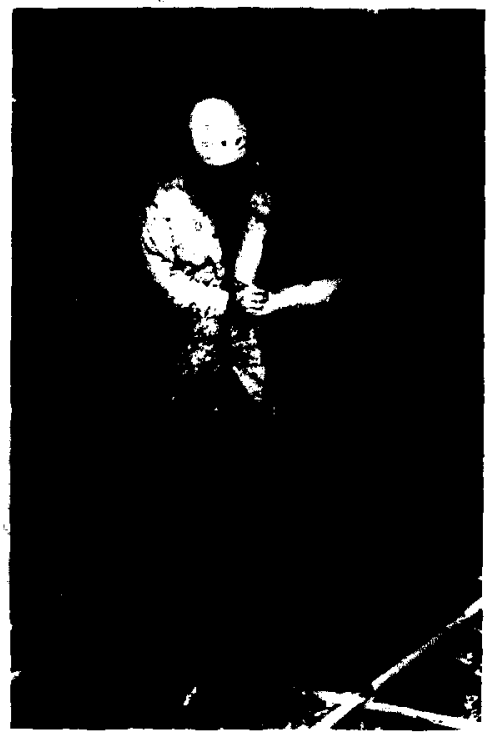

Fig. 5. Use of $1 \times 1-m$ reference frame in fracture mapping. 
to an accuracy of about $\pm 5 \mathrm{~cm}$. Features were sketched onto a 20:1 base map, which represents the outcrop boundaries of fractures, veins, and dikes. The map thus corresponds to what. could be traced directly from a photomosaic, except that much more detail can be recorded in field mapping. With this silethod the topography of the drift floor tends to be reflected in the irregular traces of mildly dipping fractures. In most cases of nearly horizontal features, however, much of the coated surface was exposed and mapping in two dimensions was troublesome. For this reason, and also because of geometrical biasing, nearly horizontal features (less than about $30^{\circ}$ dip) were not included in the floor map.

Virtually all other steeply dipping features with trace lengths greater than about 0.3 in were mapped. Normally, the dip angles of major discontinuities were determined; for minor fractures only relative dip directions were recorded. The mapped traces of all fractures represent average strikes, assuming nild surface relief. Type and thickness of fracture coating and changes in rock were briefly noted during mapping. The resulting detailed floor map is shown in Fig. 6 and discussed further in Section 4.

\subsection{Core Logs}

Thirty-two instrumentation and heater boreholes were drilled vertically in the time-scale drift to an average depth of about $12 \mathrm{~m}$. Core samples oriented with respect to the drift centerline were taken from seventeen of the holes that were $76 \mathrm{~cm}$ or greater in diameter. These include the $E, M$, and $H$ holes, concentrated in the central portion of the heater layout (Fig. 3). In addition to the vertical boreholes, two inclined 76-mm-diameter 
holes are drilled downward alongside the heater array such that they cross the transverse axis of the array at the heater midplane. A complete discussion of the drilling and sampling process is given by Kurfurst, Hugo-Persson, and Rudolph (1978).

Fracture logs of all core samples were prepared in tabular form and contain the following data.

-- rock description

-- depth and types of discontinuities

-- surface characteristics of discontinuities, including planarity, roughness, and weathering

- orientations of discontinuities with respect to core axis and drift centerline direction (excepting non-oriented core).

Loys for the oriented core are included in Appendix A. Thin sealed fractures, typically filled with chlorite, were not usually logged. For this work, fractures that were open in the core were assumed to be relatively weaker than all others, and hence more significant from an engineering standpoint. However, this apparent weakness probably was also a function of tive drilling and handing technique. To fllustrate, several fractures that were opened by rough handling showed distinct slickensiding, which should represent plones of makness in the rock mass. It is reasonable that the cohesion of a fracture can vary acruss its surface, so a fracture sealed in the core suple wy not necessarily be closed elsewhere. Hence, important features may not always be sapled consistently when drilling technique varies and only open fractures are logged. The significance of this bias in the fracture logging remains to be investigated. 

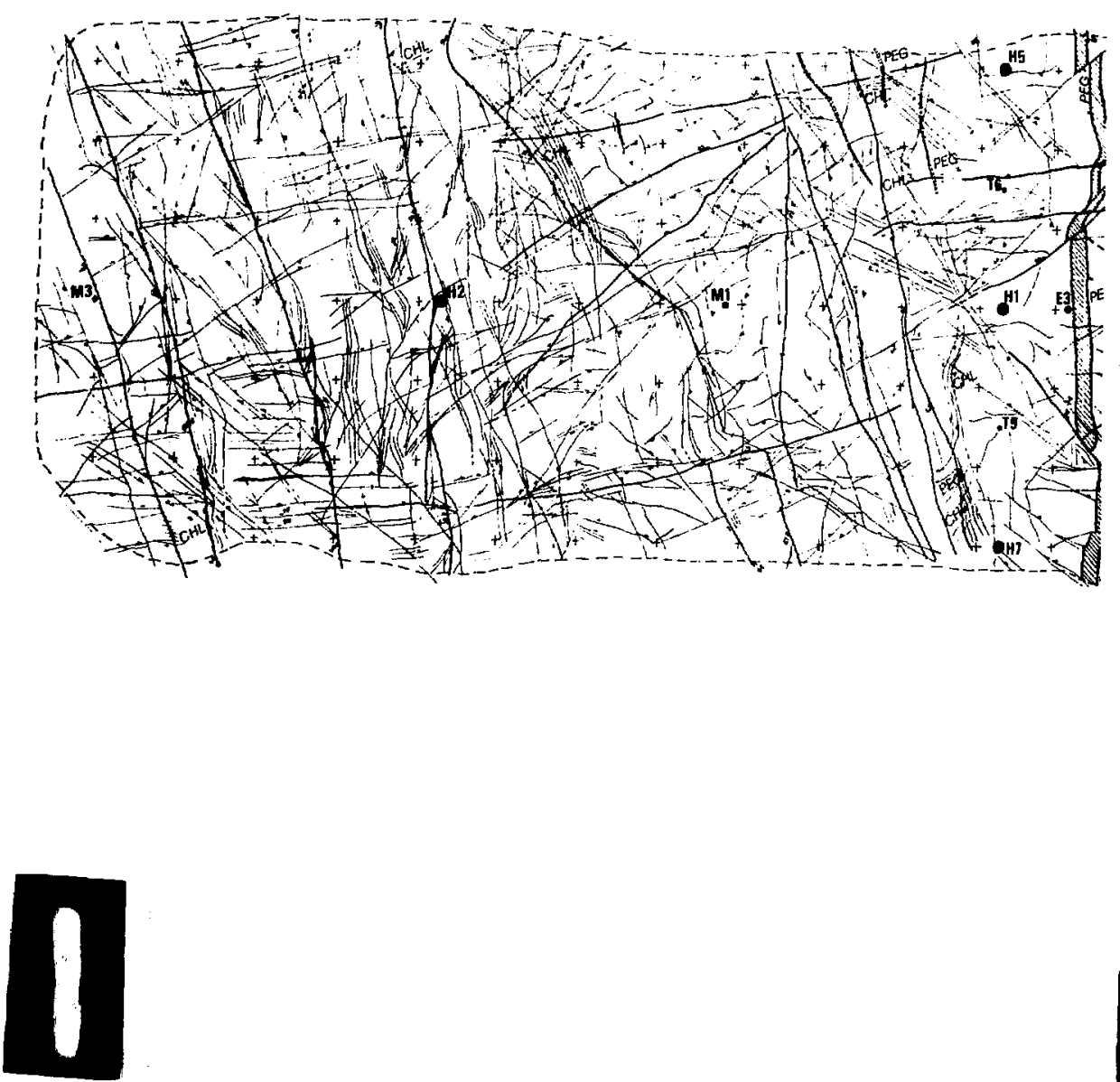


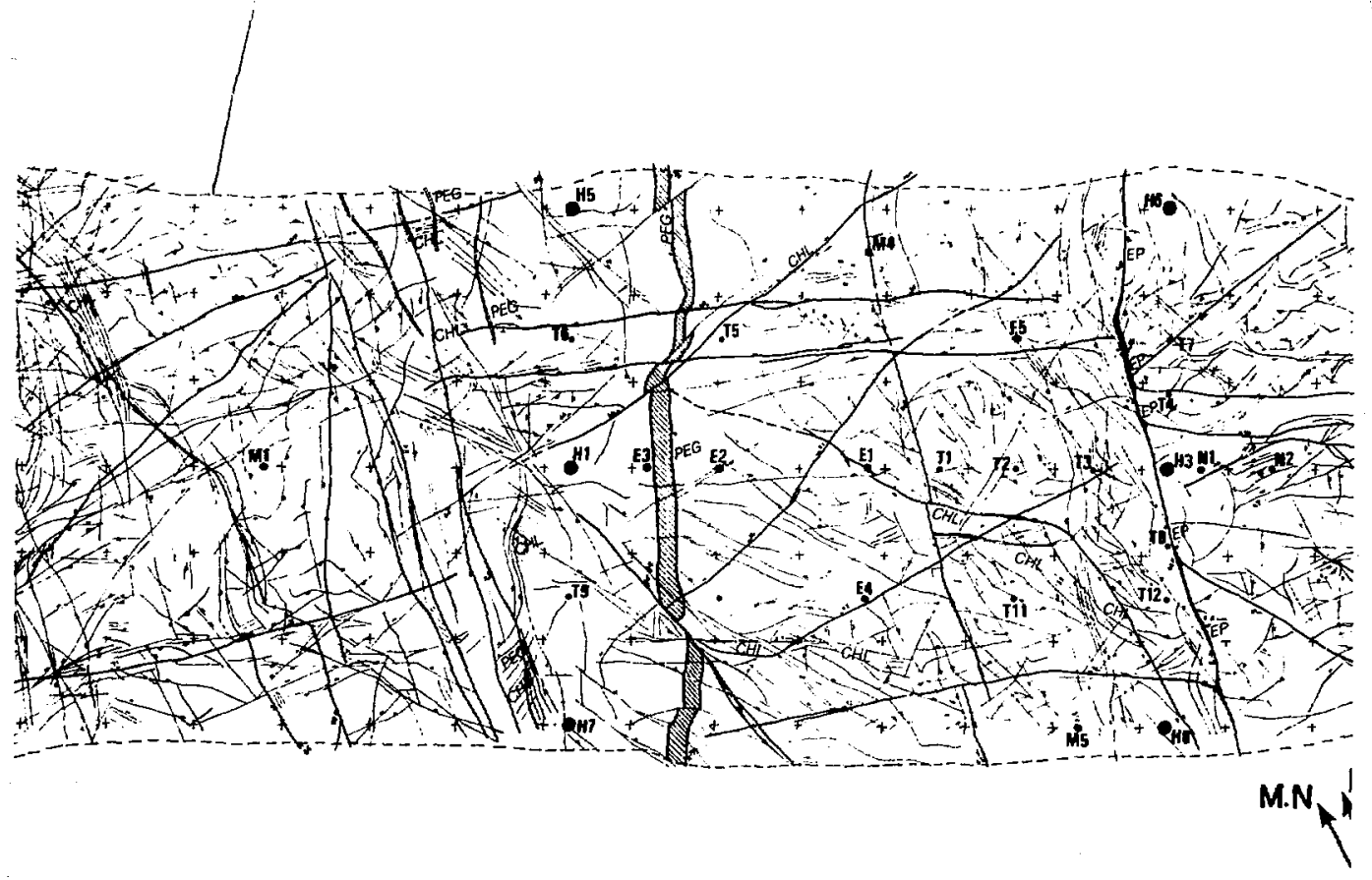



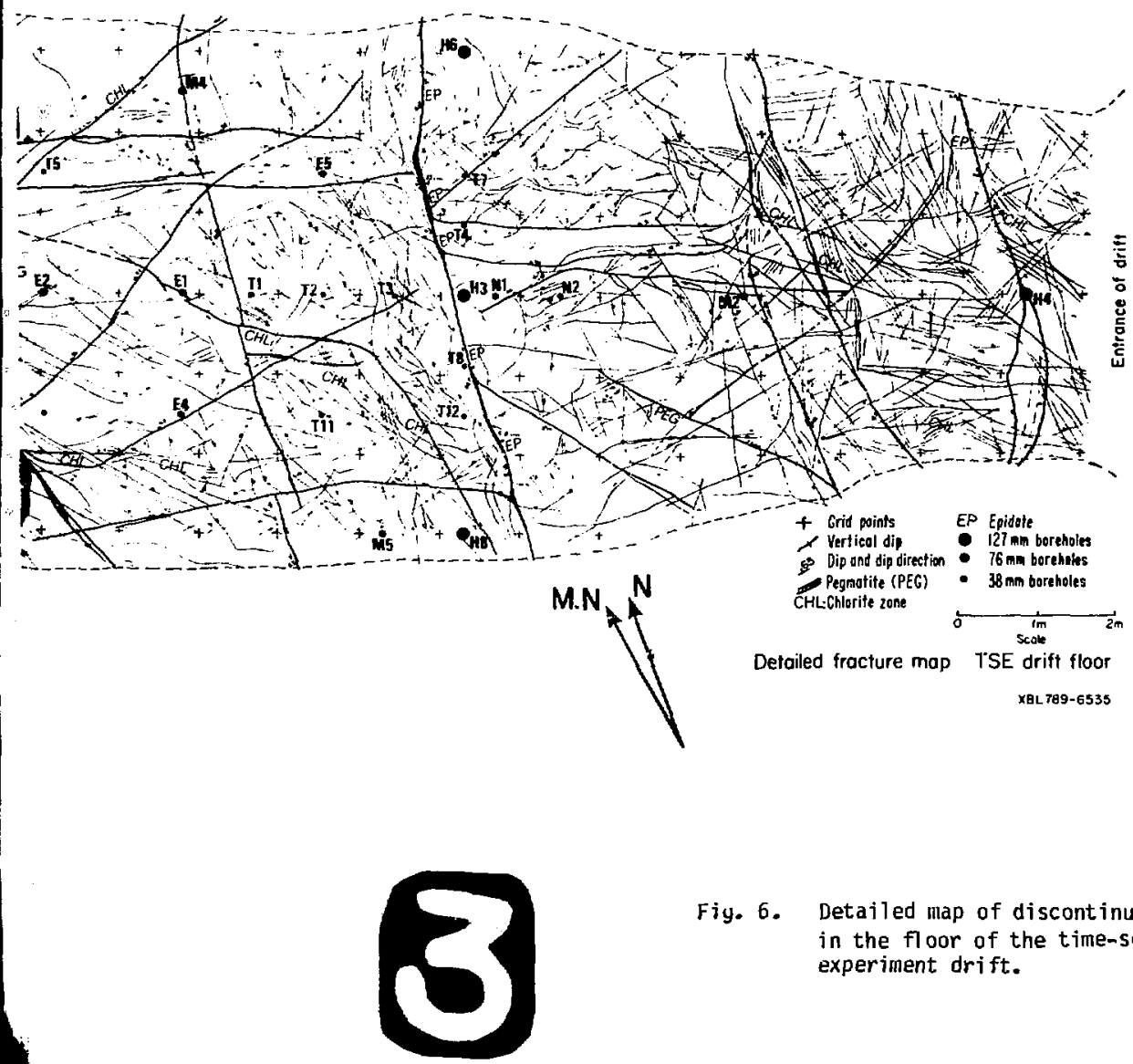

Fig. 6. Detajled map of discontinuities in the floor of the time-scale experiment drift. 
Since the interpretive part of this study was not conducted at the test site, the sealed fractures in the core could be identified later only by exanining photographs of the cores. Reduced copies of these photographs are shown in Appendix B. Several of these pictures provided crosshole correlations of major sealed discontinuities, as discussed further in Section 4.

\subsection{Comparison of Data Sources}

In synthesizing surface and subsurface information, it is desirable to nave data Dases that are consistent in terms of their relative fracture frequency. It is assumed here that if sampling frequencies are similar, the same class of fracture is being compared. To demonstrate the compatibility between the fracture mapping and the core logging, the average fracture frequency was plotted for various sample lengths. For the detailed fracture map, sample lines were taken $1 \mathrm{~m}$ apart in the langitudinal and transverse directions, which is comparable to the spacing of the boreholes. Fracture frequency was computed as the total number of fractures counted over a given sanple length, divided by the sample length. For example, if a 2-m sanple line had five fractures crossing it over the first meter and seven over the second, three frequencies would be recorded: five and seven fractures per ineter for two $1-m$ sample lengths and 12/2, or six fractures per weter for the overall $2-m$ length. Results from the floor map are presented in Fiy. 7, which shows a maximum frequency of about fourteen fractures per meter, and an average frequency of about six fractures over the entire floor.

A similar plot of the borehole fracture log data has been developed 
by dividing the number of consecutive logged fractures by the distance between the first and last. In this instance the measurement length is variable. If, for example, a log showed three fructures at successive depths of $1.0,1.2$, and $1.5 \mathrm{in}$, three frequencies would be calculated:

(a) $2 /(1.2-1.0)=10$ fractures/meter (0.2 m measurement length)

(b) $2 /(1.5-1.2)=6.67$ fractures/meter $(0.3 \mathrm{~m}$ measurement length)

(c) $3 /(1.5-1.0)=6$ fractures/meter $(0.5 \mathrm{~m}$ measurement length $)$.

If the nunber of consecutive fractures is varied from two up to the total number in a particular log, a distribution of frequencies is obtained for that hole. Figure 8 is a composite plot of such data for all of the timescale fracture logs. The peculiar shape of the data near the origin results froul dividing a discrete number of fractures by randon lengths; i.e., $f(x)=$ $n / x$. The vimodal shapes of both distributions are probably due to variations in drilling techniques and borehole sizes, which cause different nunbers of fractures to open upon retrieval of the core. The maximum

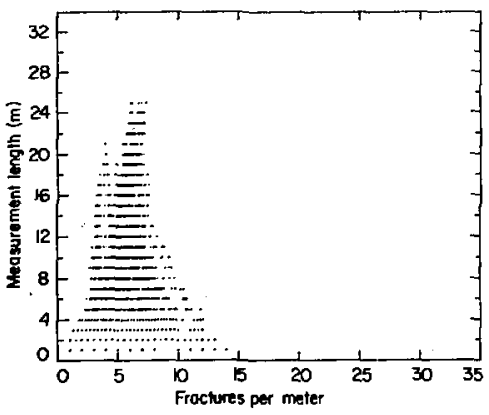

14. 799-31313

Fig. 7. Fracture frequencies from detailed floor map.

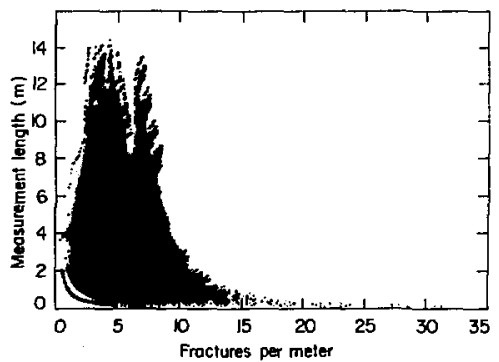

Ja: 799.11314

Fiy. 8. Core log fracture frequencies. 
frequency for measurement lengths of $1 \mathrm{ki}$ is about 14, which is commensurate with the frequency shown in Fig. 7. Bath distributions have similar overall shapes and average frequencies of about six fractures per meter--hence the data bases are judyed to be compatibie. Neither can give an indication of the actual fracture frequency in the granite, however. This can be accomplished by examining the core photographs in detail, counting all fractures, reyardless of length, thickness, or degree of openness. All visible fractures in the photos were counted over random core lengths, and the computed frequencies are plotted in Fig. 9. Comparing Fig. 9 with the previous figures indicates that the actual fracture frequency in the rock mass is likely to be two to three times greater than that observed in the core logs or fracture map. The disparity can be rationalized by recognizing that both data bases used in this study preferentially sample the more significant fractures, that is, those which are longer $(>0.3 \mathrm{~m})$ and weaker (open in the core).

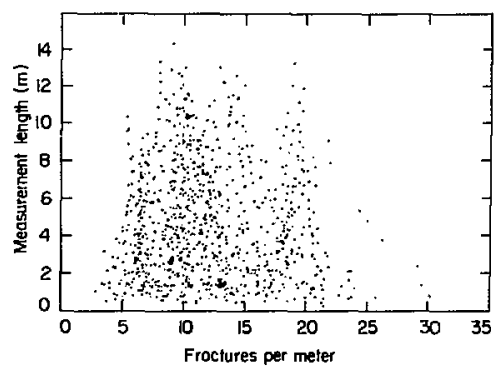

1日L $795+11315$

Fig. 9. Fracture frequencies for all fractures visible in core photographs. 
4. UETERMINISTIC CHARACTERIZATION OF OISCONTINUITIES

\section{2 iHethodoloyy}

Ueteriitination of the three-dimensional netwark of discontinuities was basically a process of correlatiny major observed surface features with the cure information. Because of the discontinuous nature of rock Joints, this was considered possible for only a few prominent and continuous features, i.e., the fractures and the single pegmatite dike shown in Fig. 10. Trese were therefore delineated first in the detailed surficial map of the floor (Fig. 6). Criteria for this designation were length, surficial continuity, and filling thickness. Fractures which extended over many weters or which were sraceable throughout the floor, walls, and roof of the orift were considered significant and likely to extend to depths comparable to tiseir observed or mapped lengths. Fractures which tend to off set other features, as well as being relatively long, were considered to be most extensive in ared. The fractures in Fiy. 10 typicalty have mineraiization thicknesses ranging fron several millimeters to several centimeters, as opposed to a millineter or less for the majority of the fractures shown in Fiy. 6 .

The subsurface (subfloor) pasitions of the major features in the floor Hap were estilnated by assuming the surfaces were planar, then calculating expected positions in the nearby boreholes. The equation of such a fracture plane in cartesian coordinates is given by

$$
A\left(x-x_{0}\right)+B\left(y-y_{0}\right)+C\left(z-z_{0}\right)=0,
$$

where $x_{0}, y_{0}$, and $z_{0}$ are coordinates of a known, or mapped point in a plane and $A, B$, and $C$ are the direction cosines of the normal vector to 


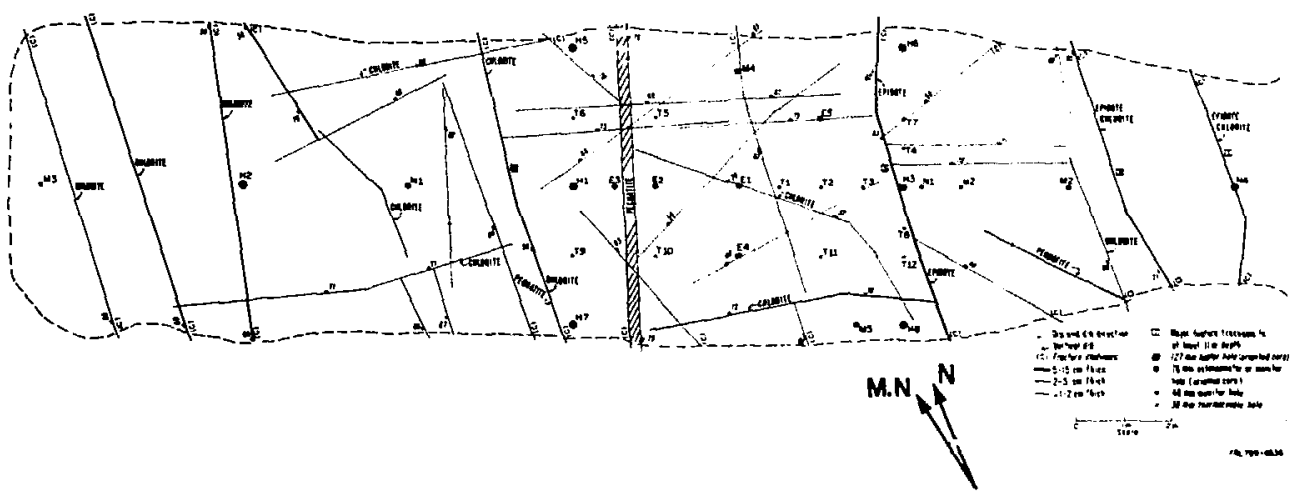

Fiy. 10. Generalized map of major discontinuities in the floor of the time-scale experiment drift. 
trle plane. Lettiny $x$ and $y$ be the horizontal coordinates of a particular vertical burehole, then solving for $z$, gives the elevation at which the plane should intersect the borehale. Fractures described in the core log or ouserved in the core photographs could then be compared with the extrapolation. Since fractures generally are nat perfectly planar, the actual intercept (if present) was usually some distance above or below the extapolated pusition. To account for a fracture's waviness and to help delineate the zone ifl which it might be found, the extrapolation was made from several different points alony the mapped fracture trace. Selection of the most reasonable candidate fracture in the core was a trial-and-error process based on (1) its proximity to the extrapolated positions, (2) similarity of surface and subsurface orientations, and (3) similarity of filling characteristics. Further correlation of a fracture to deeper locations was made in the same manner, using local borehole orientations and hole-to-hole extrapolation. Fractures were projected to a maximum depth of about $13 \mathrm{~m}$ below the drift floor, or $3 \mathrm{~m}$ below the midplane of the heater array. Since few boreholes extended to this depth, further extrapolations would have been speculative at best. Likewise, the lateral extent of fractures was extrapolated only 1 in beyond the periphery of the heater array. Boundary coordinates for the fractures were estimated as the mean of mathematical projections froin nearby mapped or correlated locations.

Surface-to-subsurface correlations provided what can be considered "first order" attempts to find inajor continuous features. The second and more speculative type of correlation attempted to delineate major fractures not intersecting in the drift. Because of the vertical orien- 
tation of boreholes, these types of fractures would be primarily subnurizontal. Despite the large number of fractures in the core samples, reasonable evidence of single fractures continuing from one borehole to the next was difficult to find.

\section{2 kesults}

Following the trial-and-error procedure described above, it was possible to delineate the subsurface locations of four of the major throughyoiny fraccures shown in the floor map. These are members of a set which strikes $11-S$ and dips $55^{\circ}$ to 700 to the west. The boxed numerals in fig. 10 indicite the four fractures in the floor map. In general, they tend to offset or truncate other features. The most prominent feature, a fracture labeled 3 , is visible near the $\mathrm{H} 3$ borehole and strikes transverse to the centerline. The outcrop of this fracture is marked by a relatively thick cuatiny of epidote chlorite. Over rrost of its expression the infilling is 1 to $2 \mathrm{cill}$ thick, but in at least two areas where other fractures intersect it, the epidote thickness reaches 5 to $15 \mathrm{~cm}$. Slickensides are visible on the fracture walls, oriented at roughly S60W. Because of this clear evidence of movenent, it is designated here as a "shear fracture."

The other three fractures which were traced into the subsurface are similar in orientation and infilling mineralogy. Their mapped expressions are thinner and more irregular, however, and may actually represent narrow zones of fracturing. Figure 11 shows the four fractures in a vertical profile through the centerline of the heater array. This is perhaps the simplest and most useful profile, since the apparent dip of the fractures is 

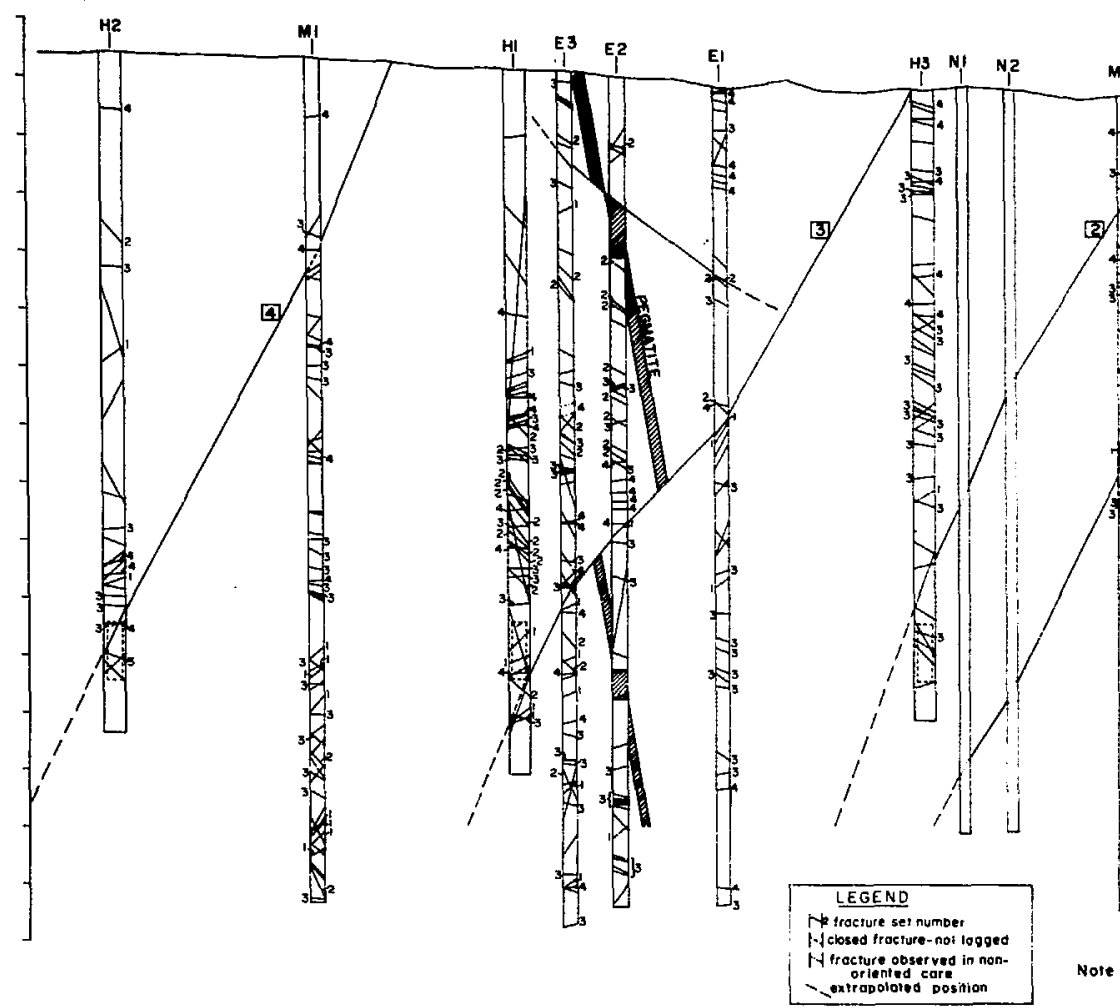

WEST

$[336$

me
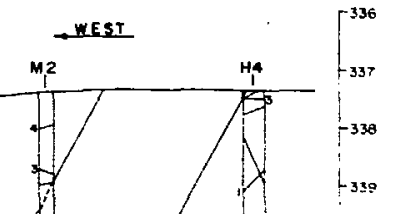

$-329$

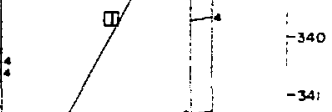

S 先 -30

(4) E

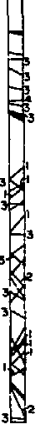

Dosition

XBL $7811-12833$

Fig. 11. Subsurface profile along centerline of drift shewing major discontinuities through the heater array. 
very near the true dip, and their spatial ralationship to the majority of the heaters and instrumentation boreholes can be seen easily. Correlated intercepts from boreholes not on the centerline can be combined with points on the centerline profile to produce three-dimensional representations of the fracture surfaces. The correlated borehole locations and the extrapolated boundary points for a particular fracture form the vertices of contiguous triangles, whose conposite gives an approximation of the overall surface waviness.

Figure 12 shows a series of orthographic projections of the four fractures. Beginning with the plan view oriented as shown in Fig. 12a, the figure is rotated about the observer's horizon in Figs. 12b and 12c. The horizontal axis of rotation has been selected approximately perpendicular to the direction of shearing ubserved on fracture 3. At an inclination of about $45^{\circ}$ above the horizontal the projected width of this fracture reaches a minimum, which is consistent with the small amplitude of waviness one would expect to observe in the direction of shearing. The amplitude does not appear to be zero, however, because (1) the boundary points are only extrapolated, and (2) the lines connecting the points have been arbitrarily assigned. Since the boundary points were determined from local (borehole) fracture orientations, they nlay not confornl well with the average trend of al 1 borehole intercepts. Hence, the true linearity of the surface in the direction of shearing can be better assessed by ignoring the extrapoiated points. This has been done in Fiy. 13 for the $45^{\circ}$ view in Fig. 12c. The overlap of points in Fig. 13 suggests that sliding is kinenatically possible in the viewing direction 


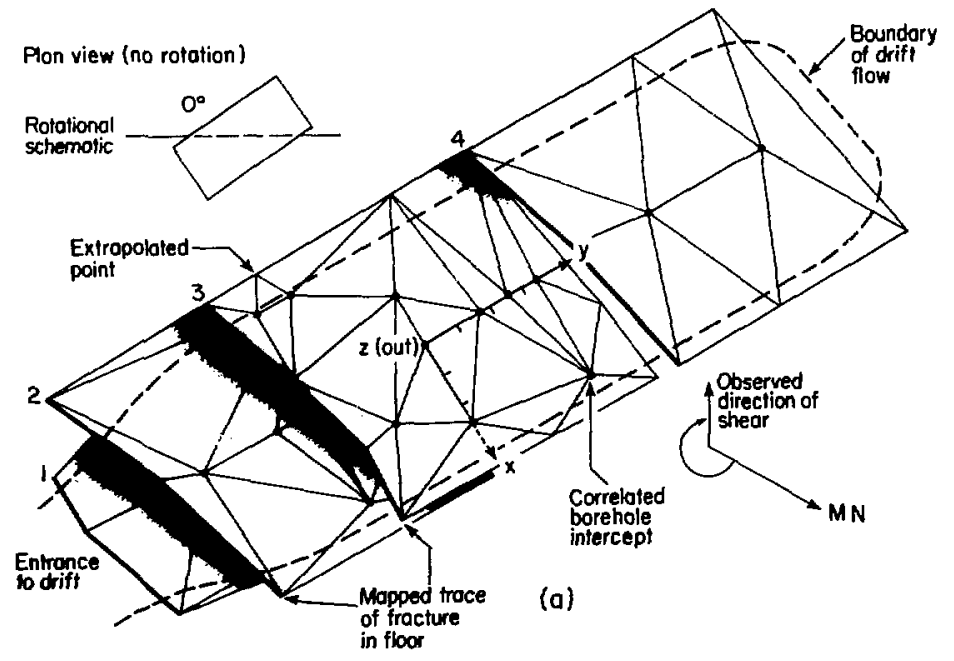

XBL 799-11316

Fig. 12. Three-dimensional views of the four continuous fractures passing through the heater array. 


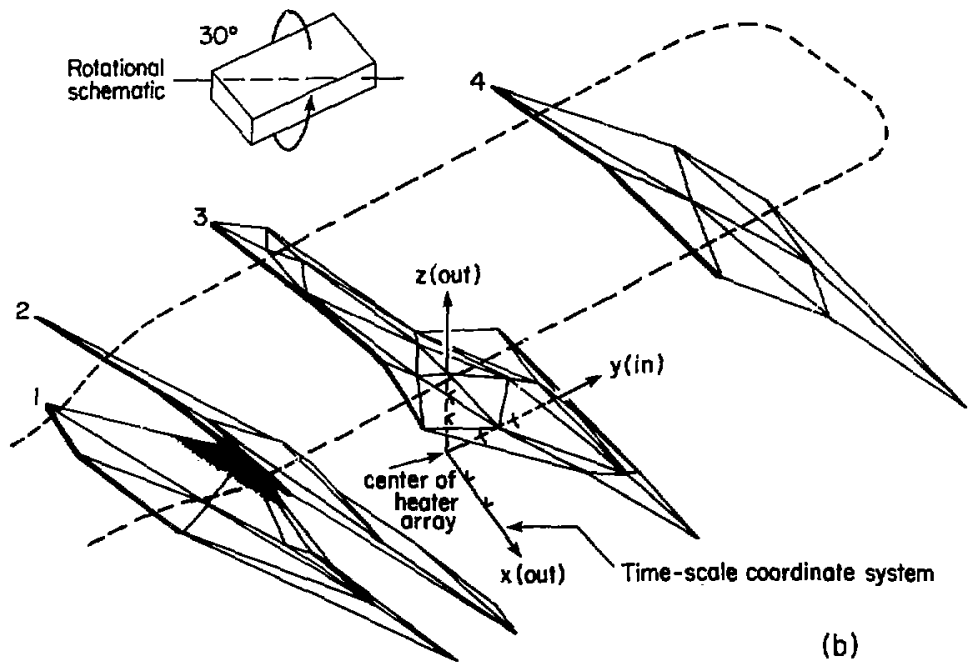

IBL. 795-11317

Fig. 12 (continued) 


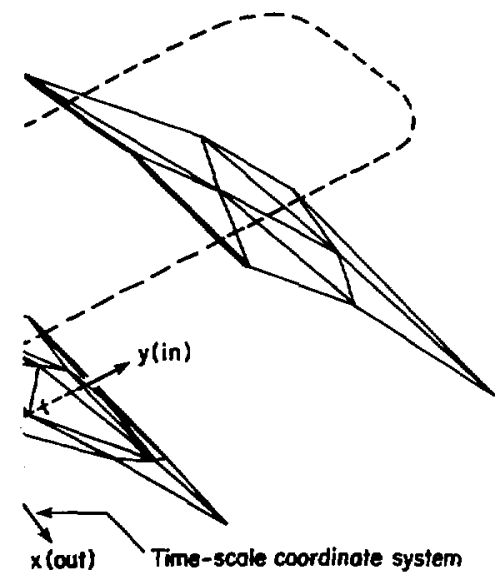

(b)
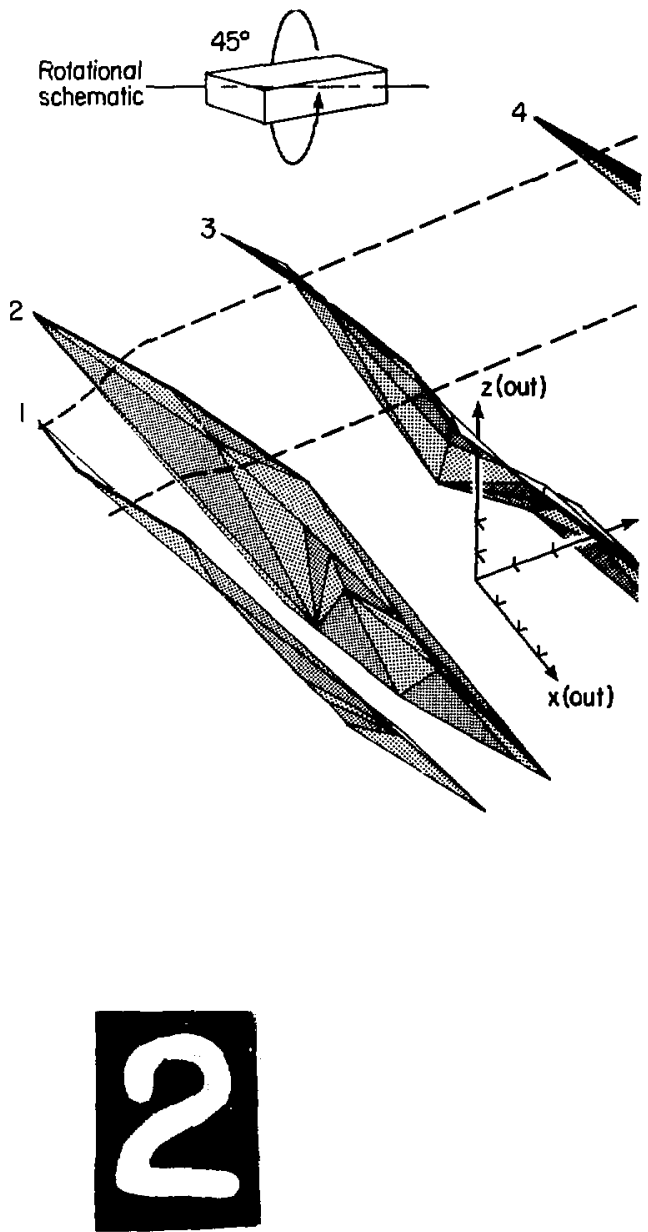


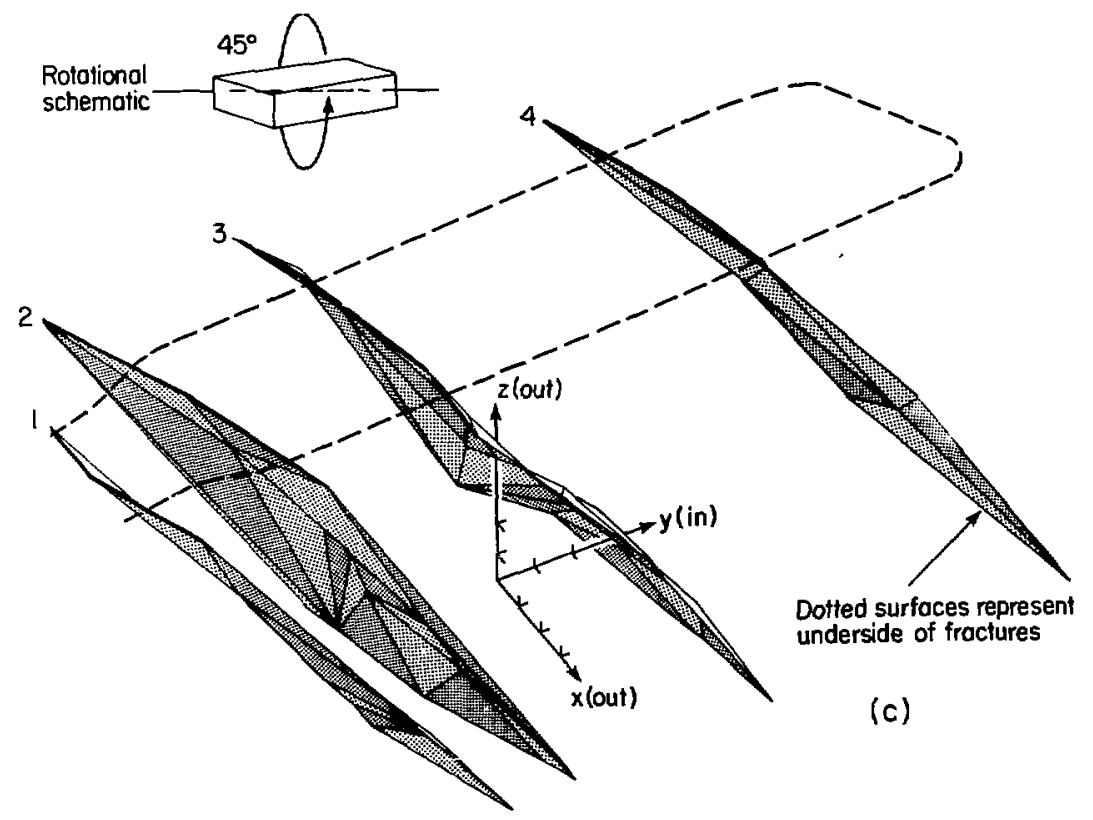

XBL 799-1131B 


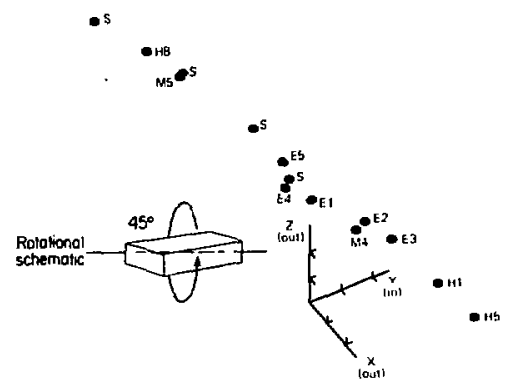

xBL $799-11319$

Fiy. 13. View of fracture no. 3 borehole locations, parallel to direction of shear. Extrapolated points are excluded. points labeled "S" represent mapped surface locations.

and, therefore, the credibility of the three-dimensional configuration shown is strenythened.

Along with the four major fractures, a $20-\mathrm{cm}-$ thick pegmatite dike passes transversely through the time-scale heater array, as shown in Fiys. 6,10 , and 11 . It is one of a series of widely spaced dikes which strike NNE and dip steeply to the east. Grain size of the pegmatite averages about $1 \mathrm{~cm}$. Much of the fracturing post-dates the pegmatite, as seen by the offsets in jts detailed mapping. Most of the offsets are less than about $20 \mathrm{~cm}$ and, at depth, it is difficult to infer such small jrregularities fron available borehole data. However, from hole-to-hole correlation, it is evident that an offset of about $2.0 \mathrm{~m}$ in the pegmatite must occur at a depth of about $8 \mathrm{~m}$. Fracture 3 is most likely responsible for this faulting, as depicted in Fig. 11. Based on the offset and slicken- 
siding, the type of movement is oblique-thrust, with the direction indicated in Figs. 12 and $13:$

A conpilation of all subsurface points that define the four major fractures is given in Tables 1 through 4. The fact that some sealed fracture locations and orientations were estimated from core photographs makes the results no less reliable in light of the previous discussion concerning cohesive strength of a fracture surface. This is illustrated by the intersection of fracture 3 with the $H 8$ borehole (Table 3). Al though the surface expression of the fracture near $H 8$ is extremely clear, and one would expect to find a very prominent trace of it at a depth of 1 to $2 \mathrm{~m}$ in the core, only a sealed, unlogged fracture of the appropriate orientation was discovered in that interval. This observation and similar occurrences shown in the tables, indicate that what may appear to be a significant discontinuity in one area may be less obvious a short distance away.

The three-dimensional fracture delineations described above may not represent reality, however. Major features could actually be composed of one or more closely spaced fractures, as evidenced by the many fracture zones shown in Fiy. 6. Our lintited subsurface information allows us to assurne only discrete, single-surface representations of the major features. More detailed data fram future in situ hydrologic or geophysical tests in the time-scale drift could either confirm or refute this assumption.

The four continuous faults certainly do not constitute a complete characterization of the fracture system. Virtually thousands of other fractures can be identified in the drift, most of them discontinuous with 
Table 1. Subsurface coordinates of fracture 1.

observed location

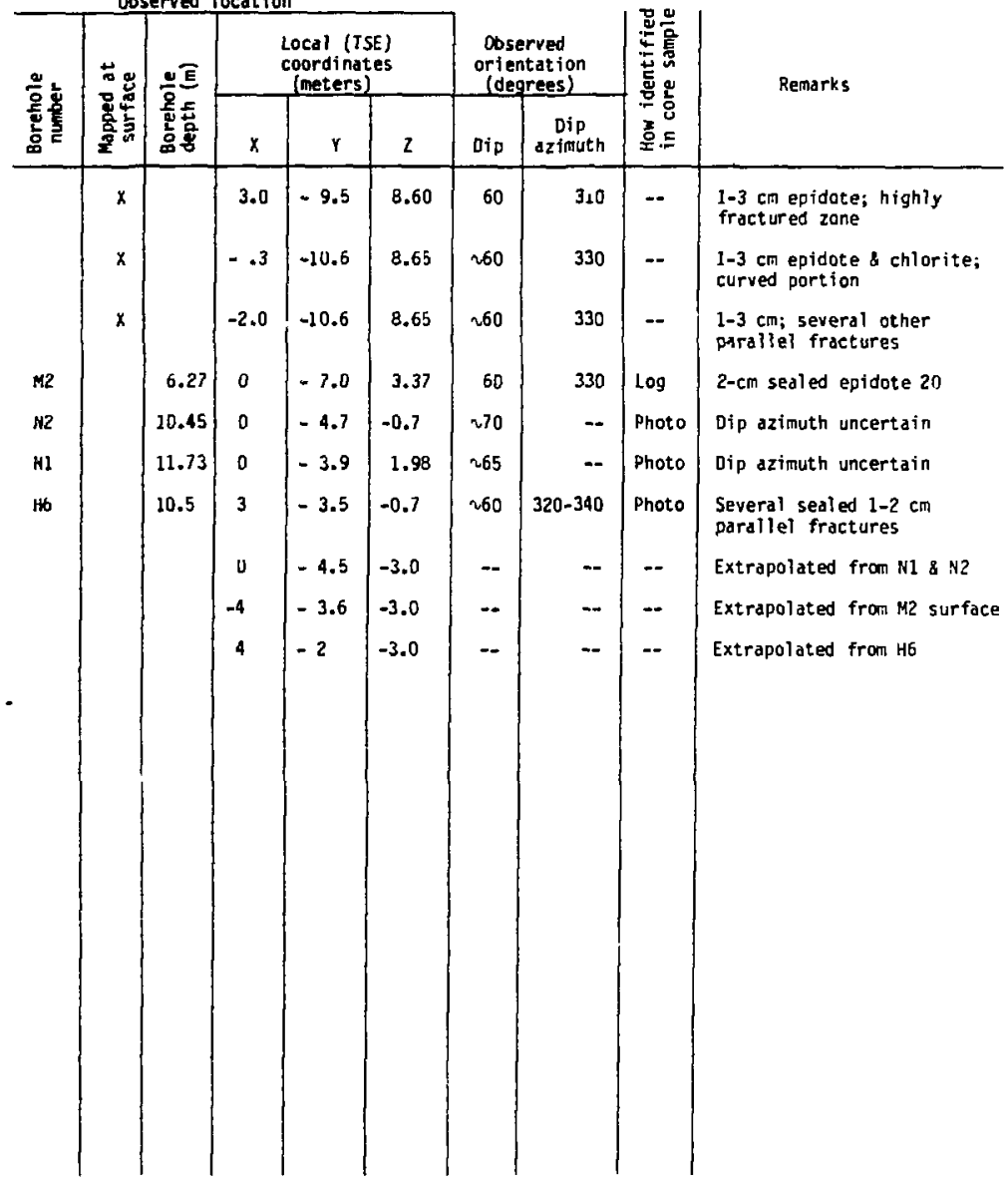


Table 2. Subsurface coordinates of fracture 2.

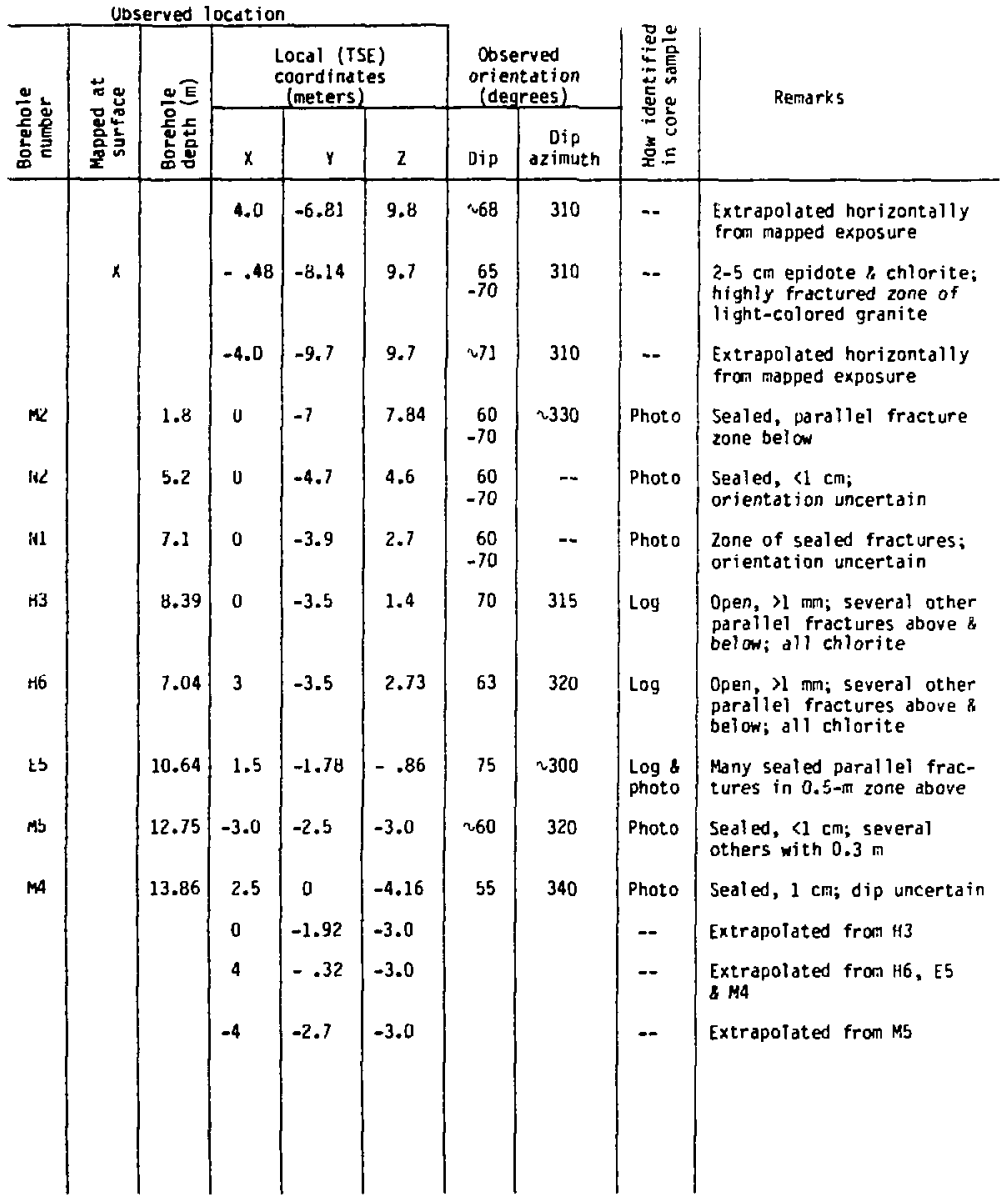


Table 3. Subsurface coordinates of fracture 3.

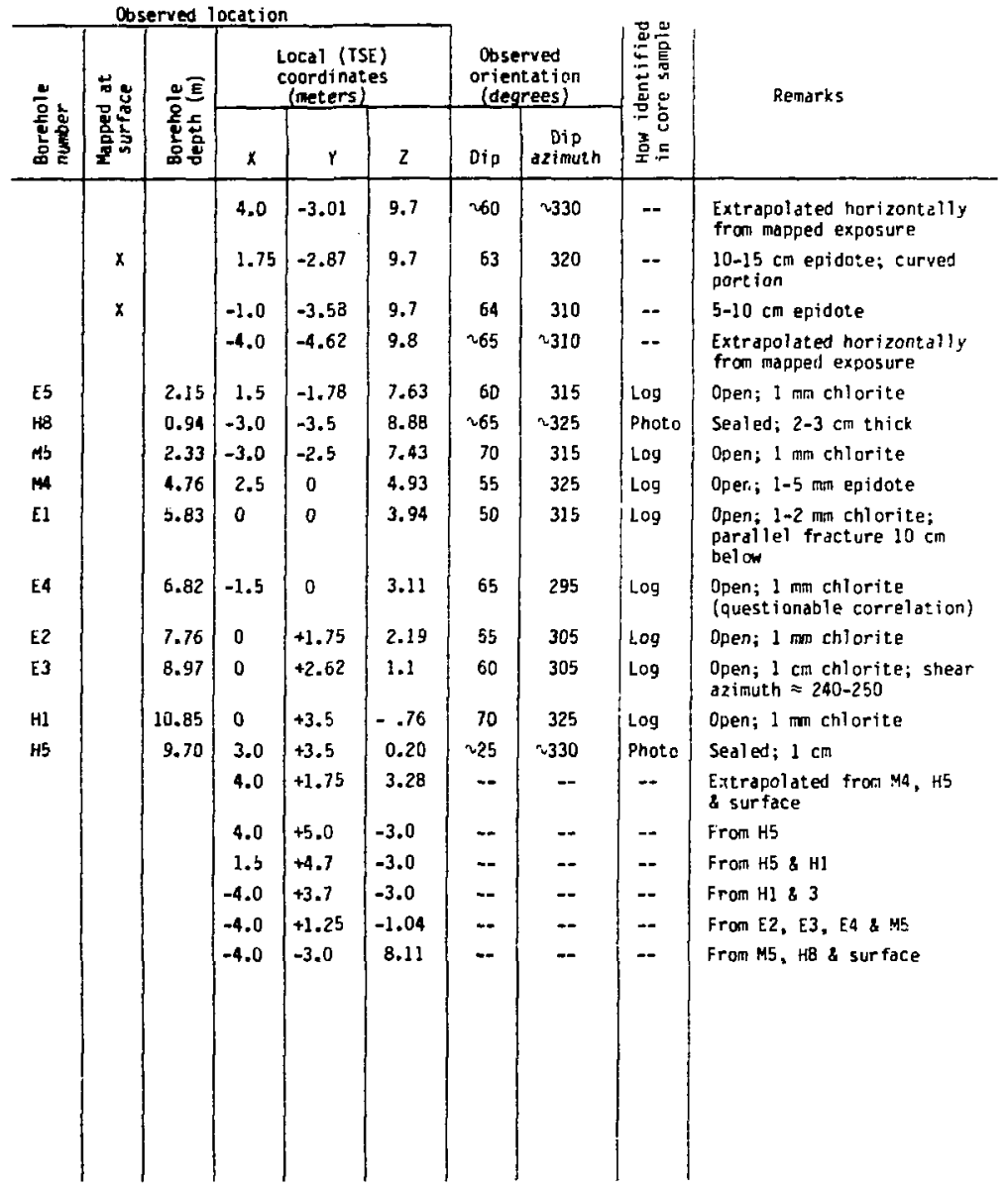


Table 4. Subsurface coordinates of fracture 4.

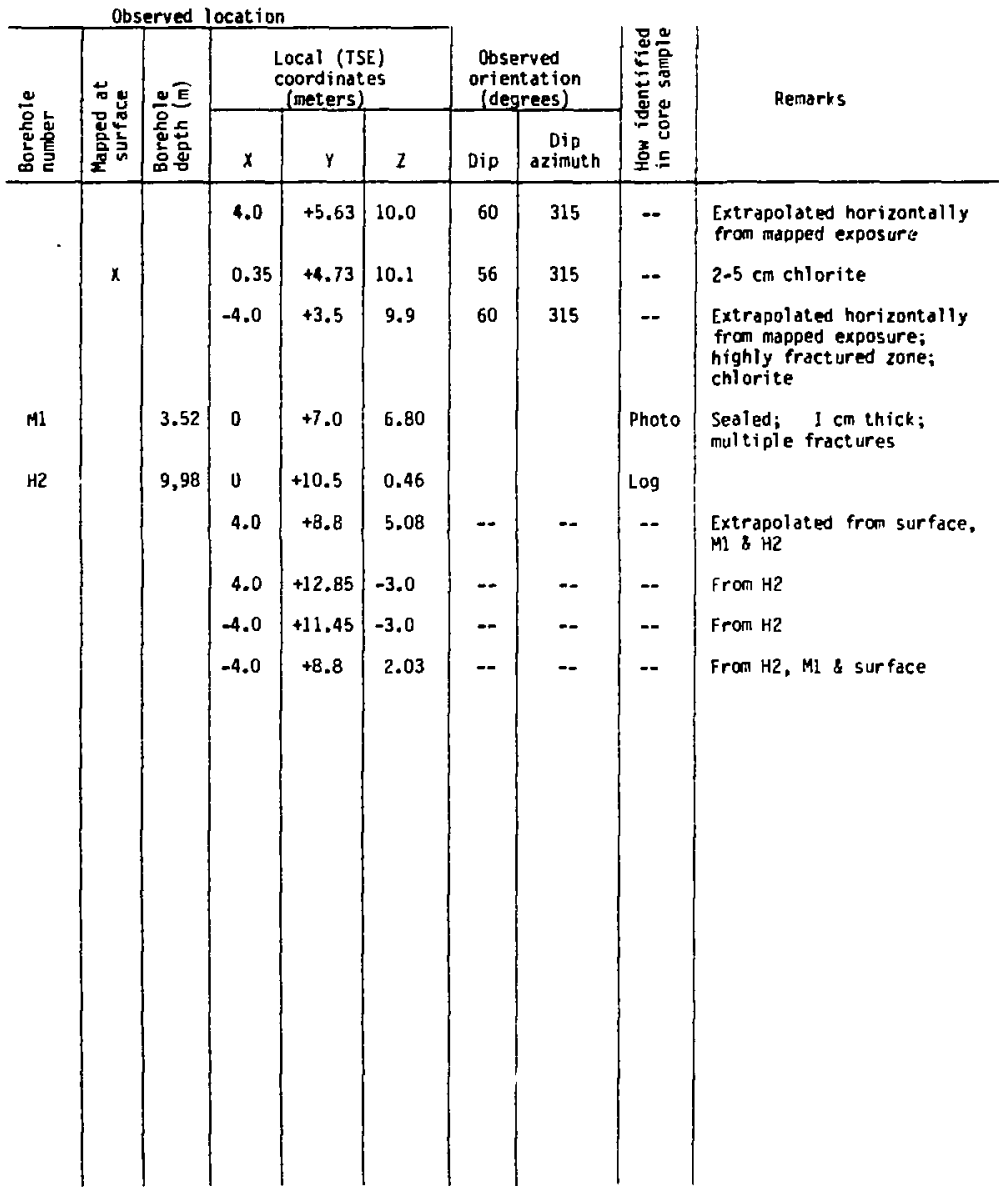


respect to the four shear fractures. Although subsurface correlation of the secondary features is, thus, difficult, attempts were made in this study to detemine the subsurface expressions of all features shown in fig. 10. This proved very difficult below about $5 \mathrm{~m}$ from the surface. The Ilajurity of the discontinuous surficial features were either truncated, or they extended out of the zone of heating by that depth, and thus their delineation near the surface would be largely superfluous. Alternatively, the steeply dipping fractures shown in Fig. 10 that strike paralle! to the drift were impossible to detect at depths of 8 to $12 \mathrm{~m}$, since they seldom intersected the vertical boreholes. As mentioned previously, mathematical and graphical attempts to correlate sub-horizontal features between boreholes were unsuccessful. While this supports the claim that few continuous fractures pass through the experiment, it is clear that a more general approach is required to characterize the local rock mass. Accordingly, fracturing in the regions between the four main faults will be described statistically in the following section.

\section{STATISTICAL CHARACTERIZATION OF DISCONTINUITIES}

In lieu of precise determination of actual fracture locations in the subsurface, the best approach is to combine all available data into a statistical model of the fracturing by describing the discontinuous fractures between the major continuous features according to distributions of size, spacing, and orientation. To provide an adequate sampling base, all vertical borehole data have been combined, and therefore possible variations in the discontinuous systern are not represented. Using the results presented here--that is, by combining the four continuous features, 
the peynatite dike, and a discontinuous fracture network--a generalized undel of the local rock mass can be synthesized. It is beyond the scope of this report to formulate a numerical simulation, which properly belongs with the interpretation of themomechanical or hydrological test data. Three important fracture parameters, orientation, size, and spacing, as well as infilling characteristics are discussed below.

\section{S.1 Fracture urientations}

A distribution of orientations can be developed by stereographically plotting the nornal vectors (poles) of all fracture planes logged in the bortholes. Using a counting circle of $10^{\circ}$ radius ( 1.5 percent area) on the surface of the unit sphere, the original plot of poles can be discretized and contoured. Fig. 14 shows the resulting contour map, plotted on an equal-area projection, for 827 fractures in the time-scale vertical boreholes. Contour intervals represent the percentage of fractures per 1.5 percent area. As labeled in the figure, there are three distinct fracture sets, plus a fourth which is less certain. Although localized statistical variations in fracture orientations are not analyzed here, stereonet plots of fracture planes fran individual core logs are provided for reference in Appendix $C$.

Set 1, though poorly defined, is significant because it roughly corresponds in orientation to the four major features described above. Set 2 also corresponds to fractures al ready identified by the surface mapping, that is, those striking nearly parallel to the drift centerline and dipping steeply to the nurtheast. While most joints in set 2 are clustered about the mean pole as shown, the distribution is noticeably skewed toward the south. This 


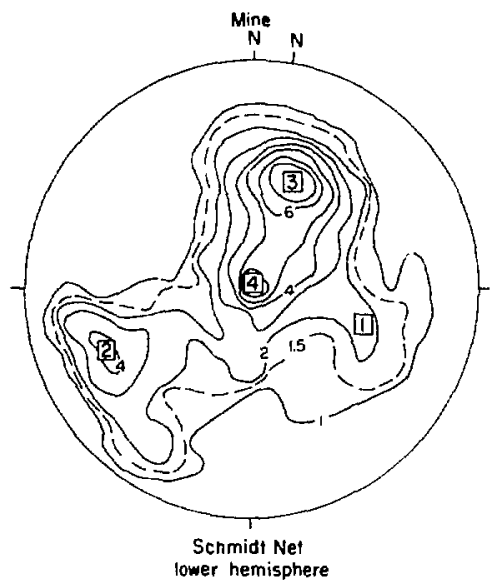

7BL $799-11320$

Fig. 14. Contour diagram of fracture poles from time-scale experiment boreholes. Contour intervals represent percentage of points per 1.5 percent area (10 degrees counting radius), based on a total of 827 points. Numbers in boxes show mean orientations of respective joint sets.

"shoulder" could actually be a fifth joint set, but for simplicity it is considered part of set 2. Sets 3 and 4 are more evenly distributed about their means. Set 4 is yenerally parallel to the floor, and therefore it is not represented in floor mapping. Visual inspection of the walls of the underyround site, however, has shown this set to be pervasive throughout the granite. Joint set 3 is the predominant cluster in Fig. 14 in terms of sampling frequency, yet relatively few of these fractures appear in the detailed fracture map. This lack of correspondence probably arises from the luwer-bound lenyth of fractures in the map; that is, most joints in this set 
probably have trace lengths less than $0.5 \mathrm{~m}$, and thus they were not routinely mapped. Fracture lengths are discussed further in Section 5.2.

Mathenatical distributions for the four fracture-set orientations have not yet been developed. Although their mean pole directions are evident, it is clear that sets 1 and 2 do not conform to a simple spherical nonnal distribution; that is, there is covariance between the solid angle and azimuth of poles relative to the mean pole direction. In contrast, sets 3 and 4 dppear to be normally distributed, but their contours overlap to form a bimodal distribution. Because of these non-uniformities, a more complete statistical analysis of the four fracture-set distributions will be reported in the future.

Several simplifying assumptions can be made in order to study fracture size and spacing variations. First, it is possible to approximate the boundaries of each cluster in Fig. 14. The average, or random, density of 827 poles on the henisphere is 12.5 poles per contouring circle, which corresponds to the 1.5 percent interval in Fig. 14. This is taken as the "significance threshold" of the clusters, and forms a logical boundary. The individual cluster boundaries are therefore comprised of the 1.5 percent. contour plus arbitrary boundaries drawn between sets. In this manner, the signficant concentration of poles ( $>1.5$ percent contour) is delimited into the four sets, as shown in Fig. 15. The boundaries have been linearized in order to facilitate the assignment of appropriate set numbers to fractures in the core logs and floor map. The major assumption here is that the fracture sets do not overlay. Note that orientation distribution functions 


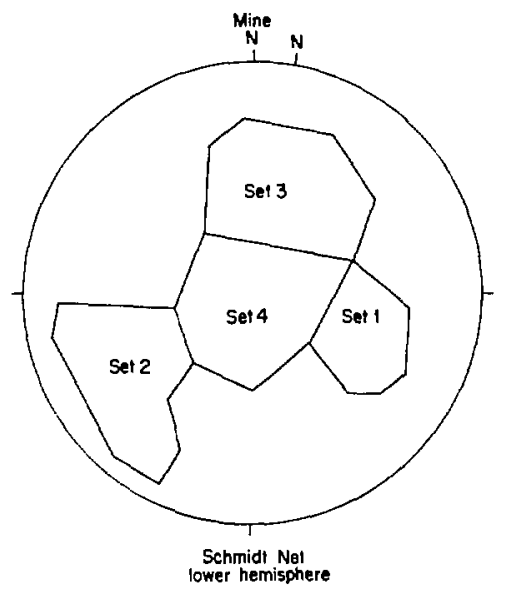

$x: 1299-13331$

Fig. 15. Generalized fracture set boundaries corresponding to 1.5 percent contour.

have not been defined for the sets; the sizes and spacings of fractures within a set are assumed to be independent of orientation.

\subsection{Fracture Sizes}

In order to estimate their sizes, discontinuous fractures are assumed to be disc-shaped with a distribution of diametral lengths. This characterization has previously been adopted for analysis of joint traces (Barton 1978). The detailed fracture nap supplies trace lengths, provided that fracture set yroupings can be made according to the following discussion. The angles of dip for minor fractures were not routinely measured during the floor mapping. However, sets can be generalized according to dip direction, 
and hence pole direction. Using Fig. 15 to indicate the appropriate ranges of pole azinuths, fracture set boundaries can be broadened as shown in fig. 16. Lip angles of fracture planes range from about $30^{\circ}$ to $80^{\circ}$ for each of sets 1,2 , and 3, which yield limits on pole inclinations as shown. These anyular limits a"ose fron the fact that (1) subhorizontal fractures were not usually mapped, and (2) dips of $80^{\circ}$ to $90^{\circ}$ were considered vertical and were so desiynated in the map. Using Fig. 16, the fracture sets in the flour can be identified to within $10^{\circ}$ to $20^{\circ}$ oi their configurations in Fiy. 15. Wue to the bias against subhorizontal fractures, set 4 was not included in this survey.

Trace lengths of fractures falling within the Fig. 16 boundaries were

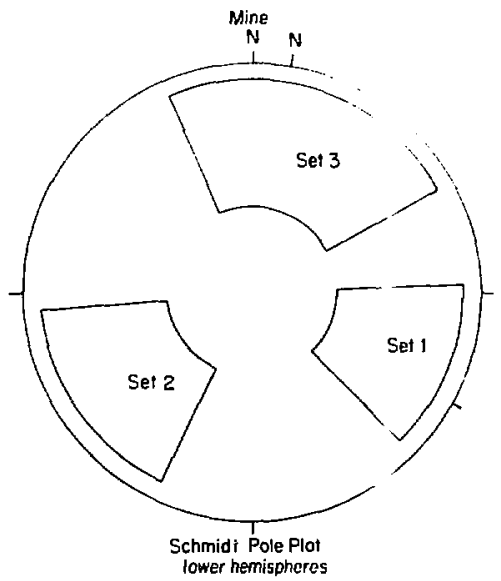

XBL 799-11322

Fig. 16. Generalized fracture set boundaries for analysis of mapped fraciure iengths. 
scaled from Fig. $b$ to the nearest $0.1 \mathrm{~m}$. Length-frequency histograms for tiiese tabulated data are shown in Figs. $17 a, b$, and $c$ for sets 1,2 , and 3 , respectively. The probability $p$ of equaling or exceeding each of the yiven fracture lengths can be calculated according to the Weibull plotting position formula:

$$
p=\frac{m}{n+1}
$$

where $n$ is the number of observations, and in is the rank of the fracture lenyth, the longest having lil $=1$ and the shortest having $n=n$. Dlatting these data in lognormal probability forlil yields the cumulative frequency distributions shown in Fig. 18. The best linedr fit through the datd is provided by the lognorial distribution function, the equation for which is yiven by Chow (1964):

$$
\log x=\overline{\log x}+k \cdot \log x
$$

The variable $x$ is the fracture length in meters, $\overline{\log x}$ is the $\log -$ arithilic mean, and the standard deviation for the distribution is ${ }^{\circ} \log x^{*}$ The $k$ tenil is related to the nomial probability function by

$$
P(x \geq x)=\frac{1}{\sqrt{2 \pi}} \int_{-\infty}^{k} \exp \left(-k^{2} / 2\right) d k
$$

Values of the exceedence probability, $P(X>x)$, for various values of $k$ can be found in numal probability tables from most statistical handbooks. For clarity, the linear $K$ axis is plotted alonyside the probability axis in Fig. 18. Noninearity at the ends of each set of data is due to the lower bound on mapped fracture lengths (about $0.3 \mathrm{~m}$ ) and the upper 

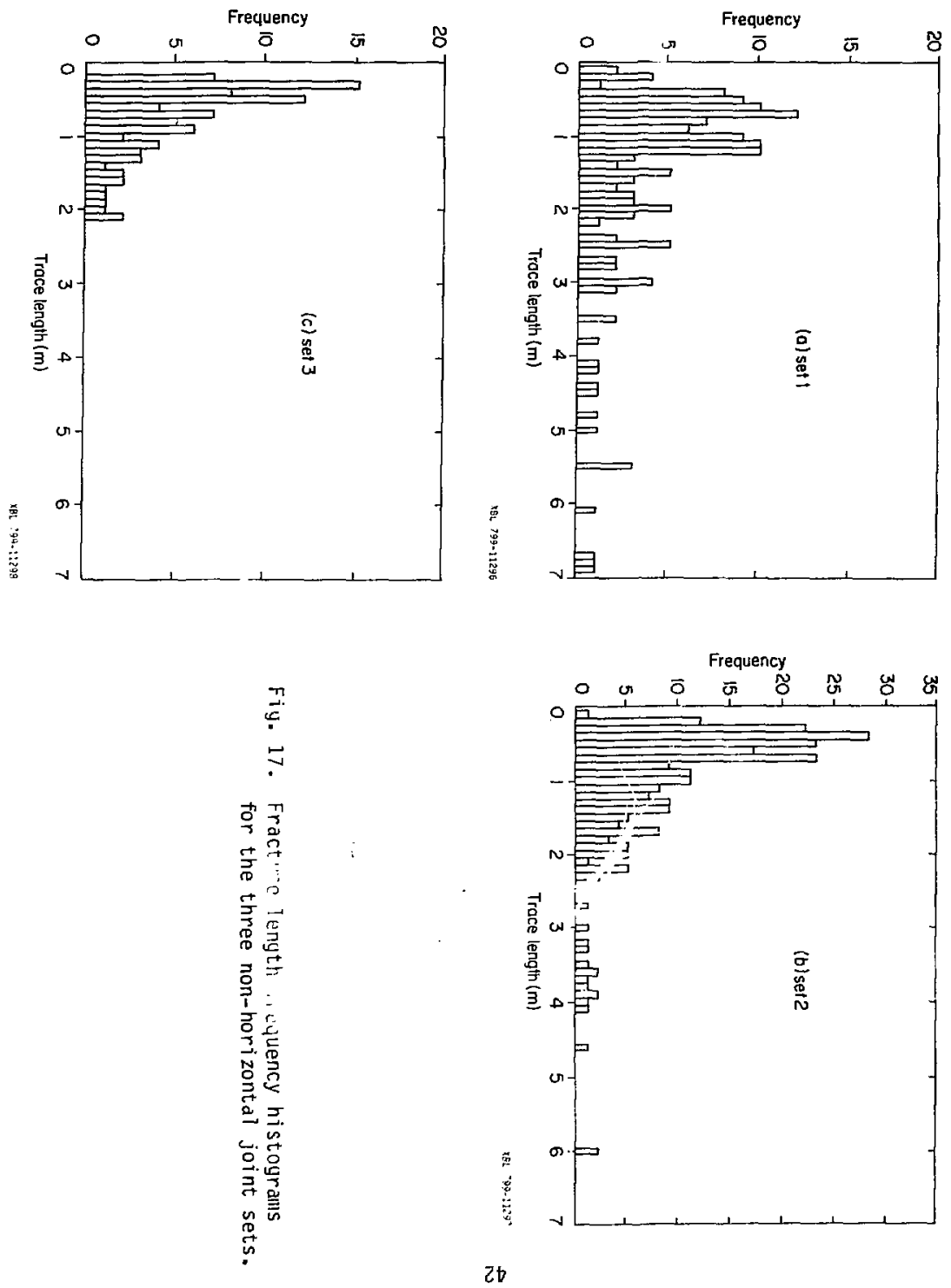


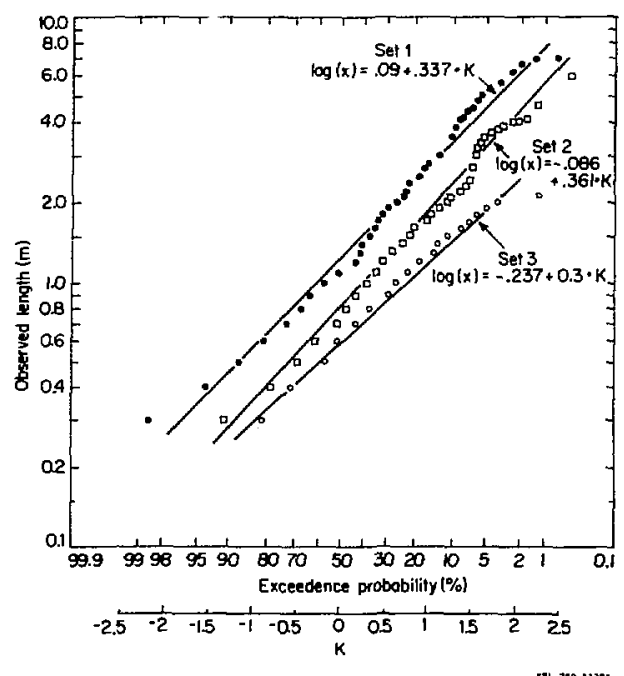

xa4. $749-2132]$

Fiy. 18. Cunulative lognomal fracture length distributions.

Dound set by the dimensions of the drift (e.g., about $7 \mathrm{~m}$ for set 1). For purposes of representing the local fract ring, however, the relevant range of lengths is given adequately by the three distributions. As shown in fig. 18, least squares fitting of Eq. (1) to the sets of data gives the respective mean and standard deviation values listed in Table 5.

Table 5. Fracture length distribution parameters.

Set no. Mean length (m) Standard deviation (m)

$\begin{array}{lll}1 & 1.25 & 2.20 \\ 2 & 0.81 & 2.29 \\ 3 & 0.58 & 2.00\end{array}$


The cumulative distributions of $F i g .18$ give the exceedence probabilities, rather than the discrete probabilities, for given lengths of fractures. In other words, Fig. 18 shows that there is a 50 percent chance of finding a fracture in set 1 whose length is greater than $1.25 \mathrm{~m}$, but only a 10 percent chance of finding one greater than about $3.4 \mathrm{~m}$. To determine the probability of finding a fracture of some given length, the probability density function

$$
p(x)=\frac{1}{\sigma_{y} e^{y} \sqrt{2 \pi}} \exp \left[-(y-\bar{y})^{2} / 2 \sigma_{y}^{2}\right]
$$

(uist be used, where $y=\log x$ and $\sigma_{y}$ and $\bar{y}$ are from Table 5 .

\subsection{Fracture Spacings}

Fracture data from the vertical boreholes were used ax; a basis for analyzing the spacings between fractures of the four sets. For each core loy, spacings relative to the core axis (1.e., vertical) were computed for consecutive fractures of the same set. For the analysis, fracture sets were delimited according to the boundaries show in Fig. 15. For example, if tirree successive fractures in set 4 were found at depths of $1.5,2.0$, and $3.0 \mathrm{~m}$ in a yiven borehole, two spacings, $0.5 \mathrm{~m}$ and $1.0 \mathrm{~m}$, would be recorded. Fractures of any other set lying within 1.5 to $3.0 \mathrm{~m}$ would, of course, be iynored. Following this computation procedure for all core logs, the histogram plots shown in Figs. 19a-d were developed.

Aggain using the lognormal probability distribution, the exceedence probabilities are represented by Figs. $20 \mathrm{a}$ and $\mathrm{b}$. In order to determine 

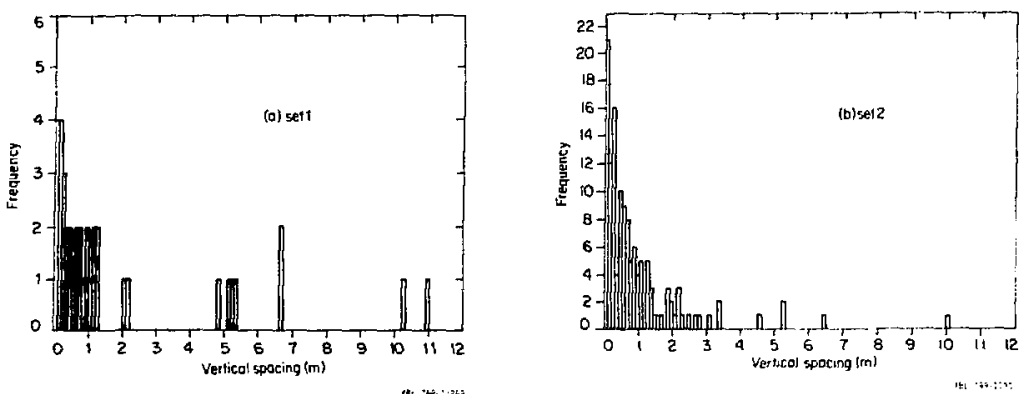

$146 \cdot+79: \div$
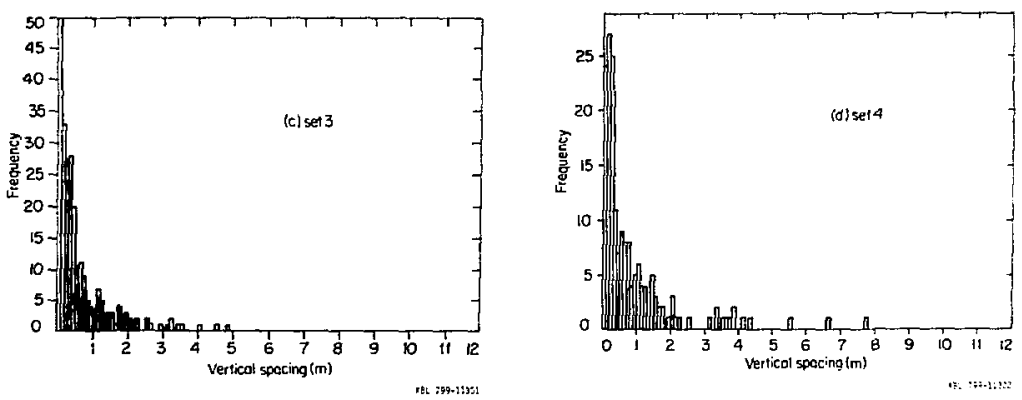

Fig. 19. Vertical fracture spacing-frequency histograms for all four joint sets. 

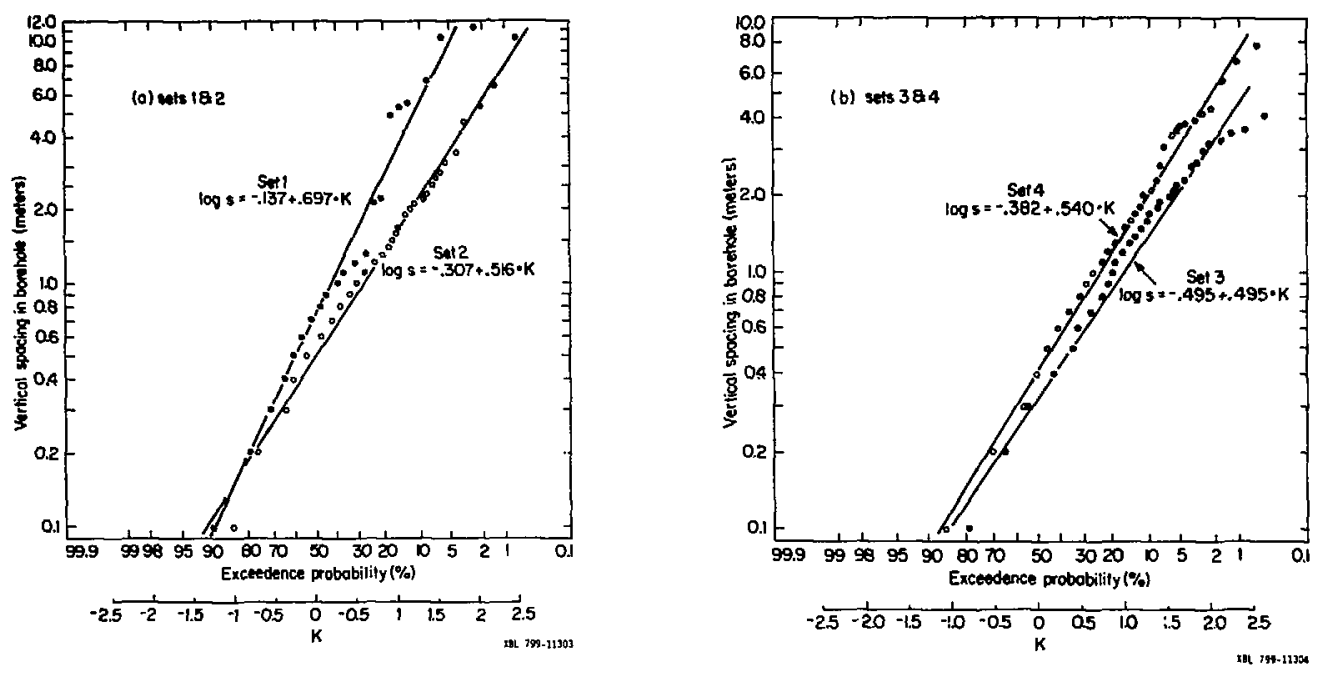

Fiy. 20. Cumulative lognomal distributions of fracture spacings in vertical direction. 
the perpendicular spacings between parallel-dipping fractures it is necessary to multiply the observed spacings by the cosine of the dip angle (Terzaghi 1965). Since the orientations of fractures vary within a set, however, the dip of the mean fracture plane must be used to estimate the correct spacing. Parameters describing the vertical and corrected spacings are listed in Table 6.

Table 5. Fracture spacing distribution parameters.
Stt no.
$\begin{array}{ccccc}\begin{array}{c}\text { Mean vertical } \\ \text { spacing (ii) }\end{array} & \begin{array}{c}\text { Standard } \\ \text { deviation }\end{array} & \begin{array}{c}\text { Medn dip } \\ \text { angle ( })\end{array} & \begin{array}{c}\text { Nomal } \\ \text { spacing }\end{array} \\ 1 & 0.73 & 4.98 & 41 & 0.55 \\ 2 & 0.50 & 3.28 & 59 & 0.25 \\ 3 & 0.32 & 3.13 & 39 & 0.25 \\ 4 & 0.42 & 3.47 & 0 & 0.42\end{array}$

Vertical spacing distributions in Figs. 20a and b appear to be less linear than fracture length distributions in Fig. 18. This nonlinearity and the more pronounced irregularities in the plotted data are most probably due to the sampling bias of the core logs; that is, sealed fractures were not routinely logged. The lognormal distributions fit the data well enough, nowever, to be useful in statistical representations of fracturing. Equation (3) should be used as the stochastic generator for discrete fracture spacings.

\subsection{Fracture Infilling Characteristics}

The wost common nineralization observed in the fractures is chlorite, second is calcite, and third is epidote.* Other minerals identified in the 
core loys include mica, pyrite, and fluorite. Based on the 827 natural fractures logyed in the vertical boreholes, the percentage occurrences are yiven in Table 7. It is common for a fracture to have two or more types of mineralization, and no predaninance of a filling in a particular fracture is indicated.

In order to correlate the types of infilling with the fracture sets, equal-area stereonet plots of poles to fracture exhibiting the three major types are yiven by Figs. 21 a, b, and c. Percentage occurrence data for each set are summarized in Table 8 . Chlorite is common to all four fracture sets, while calcite tends to be most concentrated in sets 2 and 3. Epidote is must conmonly associated with sets 1 and 2 , but less frequently found in sets 3 and 4.

A similar presentation of fracture infilling thicknesses shows that the yreat majority are less than a millimeter wide. Figure 22a, b, and $c$ shows the orientation distributions of fractures of increasing thickness. These data are summarized in the form of exceedence, or cumulative probabilities, in Table 9. Comparison of Figs. 15 and $22 \mathrm{c}$ indicates that set 1

Table 7. Fracture nineralization data for the Stripa core logs.

\begin{tabular}{lcc} 
iuineralization & $\begin{array}{c}\text { Number of } \\
\text { occurrences }\end{array}$ & $\begin{array}{c}\text { Percentage } \\
\text { of 827 (\%) }\end{array}$ \\
\cline { 2 - 3 } Chlorite & 758 & 91.7 \\
Calcite & 406 & 49.1 \\
Epidote & 62 & 7.5 \\
nica & 16 & 1.9 \\
Pyrite & 9 & 1.1 \\
Flourite & 7 & 0.8
\end{tabular}




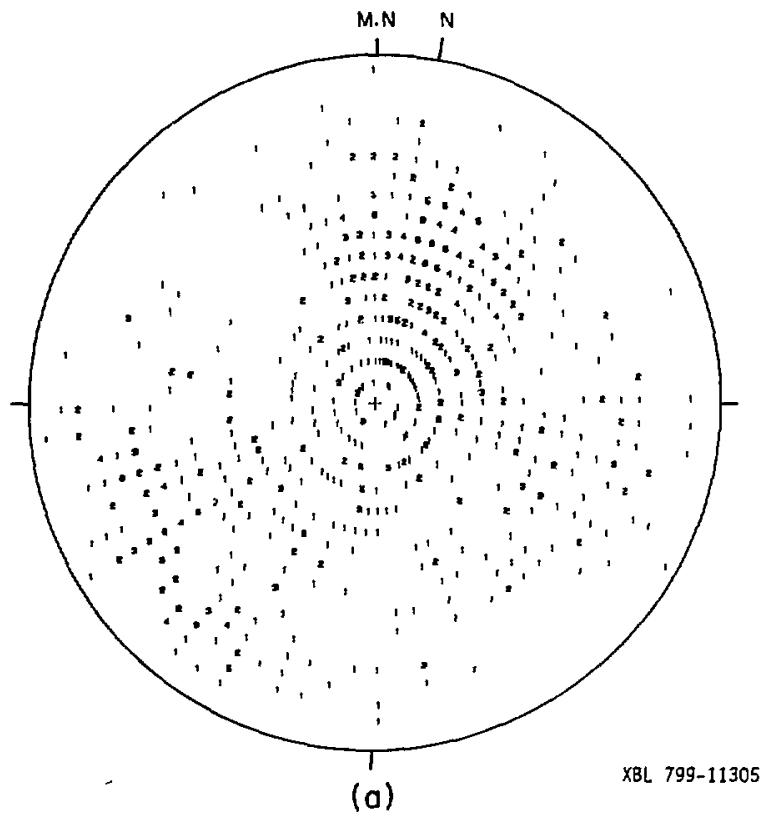

Schmidt equal-areo pole plot Chlorite mineralizatian Lower hemisphere

758 points

Fig. 21. Stereographic plots of poles of fractures with the three major types of mineralization. 


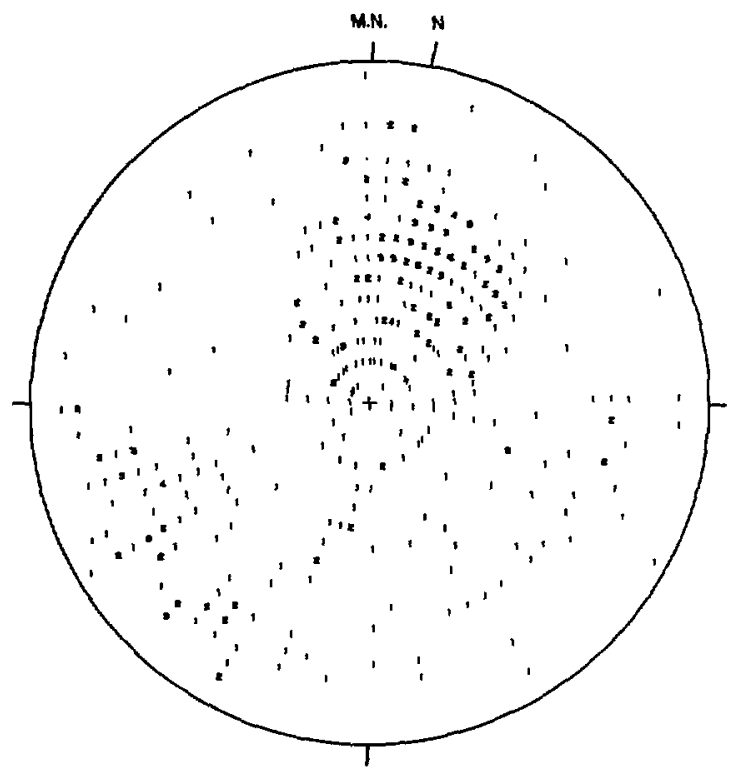

(b)

XBL 799-11306

Schmidt equal-ared poleplot

Colcite minarolization

Lower hemisphere

406 points

(Fig. 21 continued) 


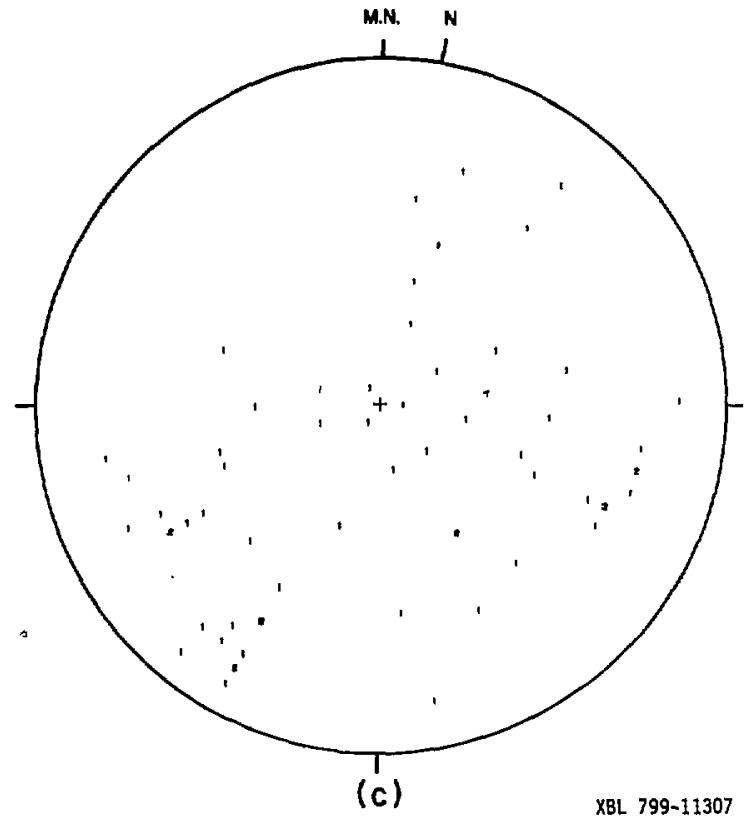

Schmidt equal - orea pole plot

Epidole mineralization

Lower hemisphere

62 point:

(Fig. 21 continued) 
Table 8. Statistical mineralization data from Stripa fracture logs.

\begin{tabular}{ccccc}
$\begin{array}{c}\text { Set } \\
\text { number }\end{array}$ & $\begin{array}{l}\text { Iotal } \\
\text { number } \\
\text { in 5et }\end{array}$ & & \multicolumn{3}{c}{$\begin{array}{c}\text { Number } \\
\text { Chlorite }\end{array}$} & $\begin{array}{cccc}\text { Calcite } \\
1\end{array}$ & 53 & $46(87 \%)$ & $14(26 \%)$ & $7(13 \%)$ \\
2 & 154 & $147(95 \%)$ & $72(47 \%)$ & $20(13 \%)$ \\
3 & 254 & $244(96 \%)$ & $151(63 \%)$ & $7(3 \%)$ \\
4 & 191 & $172(90 \%)$ & $83(43 \%)$ & $11\langle 5 \%)$
\end{tabular}
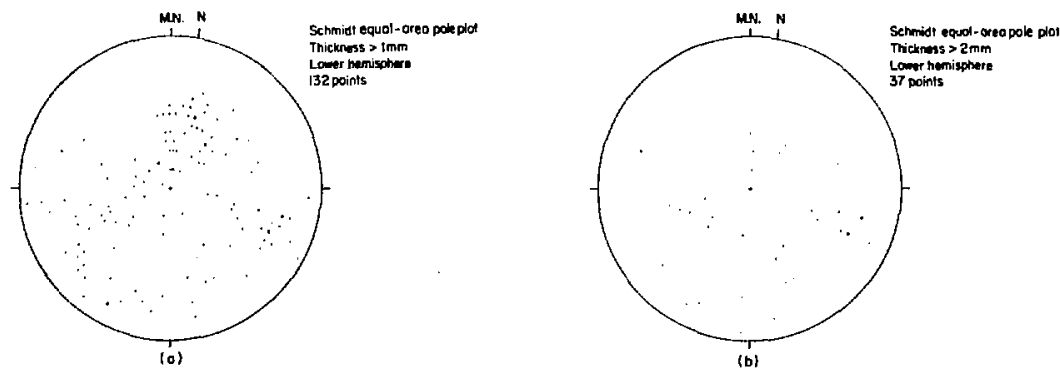

HB. .19-315

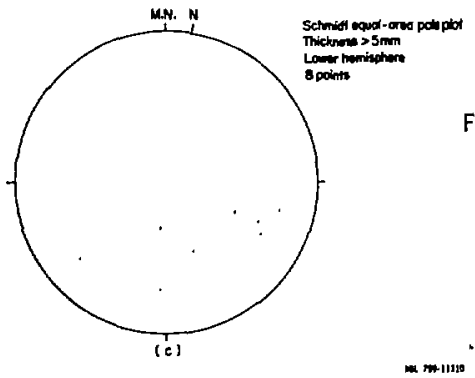

Fig. 22. Stereographic plots of fractures with different thicknesses. 
Table 9. Thickness data for fracture infillings.

\begin{tabular}{|c|c|c|c|c|}
\hline \multirow{2}{*}{$\begin{array}{c}\text { Set } \\
\text { nullour }\end{array}$} & \multirow{2}{*}{$\begin{array}{l}\text { Tutal } \\
\text { number } \\
\text { in set } \\
\end{array}$} & \multicolumn{3}{|c|}{ Number and percentage of occurrences } \\
\hline & & $1 \mathrm{~mm}$ & $2 \pi n$ & 5 ing \\
\hline 1 & 53 & $13(25 \%)$ & $8(15 \%)$ & $3\langle 6 \%\rangle$ \\
\hline 2 & 154 & $30(193)$ & $7(5 \%)$ & $1(1 \%)$ \\
\hline 3 & 254 & $35(14 \%)$ & $5(2 \%)$ & $0(0 \%)$ \\
\hline 4 & 191 & $21(11 \%)$ & $4\langle 2 \alpha\rangle$ & $1(1:)$ \\
\hline
\end{tabular}

conprises the thicker fractures, which also agress with the delineation of major features from the floor inap (Fig. 10). Sets 3 and 4 generally have the smallest percentages of fractures thicker than $1.0 \mathrm{~mm}$.

\section{UISCUSSION}

\subsection{Urigin of the Fracture System}

The yeoloyy and tectonics of the granite mass at Stripa are complex and difficult to interpret due to the lack of previous study from which to draw. An understanding of the regional geological setting and a general idea of the inorphojogy of the rock mass are necessary in order to theorize on the origin of the fracture system, and are currently being investigated. Although discussion of possible origins of the discontinuities is very speculative at this time, the following information might stimulate study into possible connections between the existing stresses and fracture pattern in the underground test area.

Carlsson (1978) has reported the results of stress measurements in the OV1 drift (Fig. 2), whose average principal stress components show a close directional relationship with the fracture sets in the time-scale drift (Fig. 
14). A plot of mean fracture-set poles and the major principal stress vectors is shown in Fig. 23. The mean poles of sets 1 and 3 are about perpendicular to the major principal stress direction, $\sigma_{1}$, and the pole of set $s$ corresponds to the minimum principal stress, $\sigma_{3}$. Furthermore, the mear. plane of set 2 is oriented virtually perpendicular to the major principal itress. Such orthogonalities are common in fracture networks in rock (Rart ey 1967), but because of historical changes in the tectonic regime, the sbserved fracturing need not be morphologically related to the existing stat $\geqslant$ of stress. Nevertheless, the following speculation about joint oriy ns is an attempt to explain the close correlation of the local stress fiel 1 with the extensive fracturing in the time-scale drift.

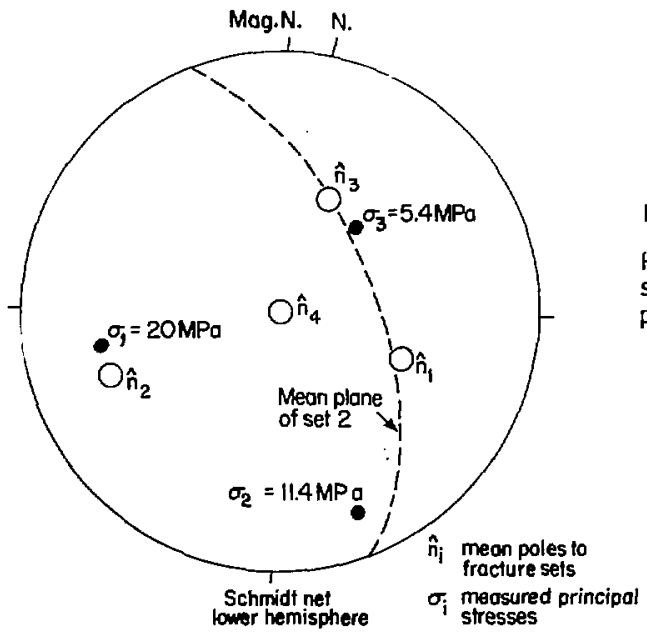

Fig. 23.

Relationship of mean fracture set orientations and measured principal stress directions. 
It can be reasoned that joint sets 1,2 , and 4 are related to the intrusion and subsequent cooling of the granite body. The presence of epidote and chlorite on these fractures, as opposed to only calcite, sugyests such a hydro-thermal environment. The core samples and floor map show that the surfaces of the joints of set 2 are generally irregular and rough, iridicating that they are extension (tension-related) features. Such fracturing should occur parallel to the maximum compressive stress. Here, the opposite is true and, therefore, the stresses which initiated these fractures inst have been diffurent from the stress which has been measured. Although it is speculative to reconstruct this previous stress field, the orientation of set 2 implies that the major principal stress should have been learly orthogonal to that which now exists. It is visualized that such a large shift in the local state of stress could have been associated with cooling isotherins in the pluton, which in turn would have been related to the overall shape and orientation of the body. For example, if a mass of cooling granite were striking parallel to the maximum principal stress, then the Iraximum stress within the rock mass due to cooling should be perpendicular to the long dimensions of the body. Of course, the applicabitity of such a model here is uncertain because very little is known at this time about the intrusion process or the geometry of the rock mass at Stripa. A11 that can be stated now is that the granite-leptite contact appears t? strike roughly parallel to the mean pole of joint set 2 and $\tau_{1}$, which may be indicative of such a themal fracture mechanism.

The above discussion does not imply that the existing state of stress is the salle as that at the time of intrusion. The most recent change in 
stress resulted from glacial loading, consisting of 2 to $3 \mathrm{~km}$ of ice (Press and Siever 1974). Certain factors indicate that fracture set 3 may be associated with the current isostatic uplift from this loading: (1) the set's orientation with respect to $\sigma_{3}$, (2) the predominance of only calcite fracture infillings, as opposed to hydrothermal minerals, (3) the relatively short trace lengths and close spacings of joints, and (4) the observation that these joints tend to pass continuously across the other fractures in the core samples. An alternate explanation of joint set 3 is that it results fram a distorted stress field produced by the mine itself. Verification of this mechanisin depends on further stress measurements and fracture studies far from the mine stopes.

\subsection{Current Deformations}

Defomation within the Stripa granite is continuing, as evidenced by the faulting of certain fractures in set 1. It has been shown in Section 4 that the configuration of at least one of these faults is consistent with the observed direction of slickensiding. The relationship between this shearing and the existing state of stress can be analyzed by resolving the principal stress vectors in Fiy. 23 into shear and normal components on the mean plane of set 1 . This is done stereographically in Fig. 24 by first finding the resultant stress direction, ${ }_{r}$; then passing a plane through this resultant and the mean nornal of set $1, \hat{n}_{1}$. The intersection of this $\mu$ lane and the set 1 plane (containing the dip vector, $\hat{d}_{1}$ ) is the direction of the shear stress, $\hat{s}_{1}$, on the joints. The azimuthal direction of $\hat{s}_{1}$ is yiven by the vertical plane containing it, and this turns out to be $242^{\circ}$, which ayrees with the observed diraction of shearing $\left(240^{\circ}\right.$, see Section 4). Stress magnitudes on this mean plane have been calculated, 


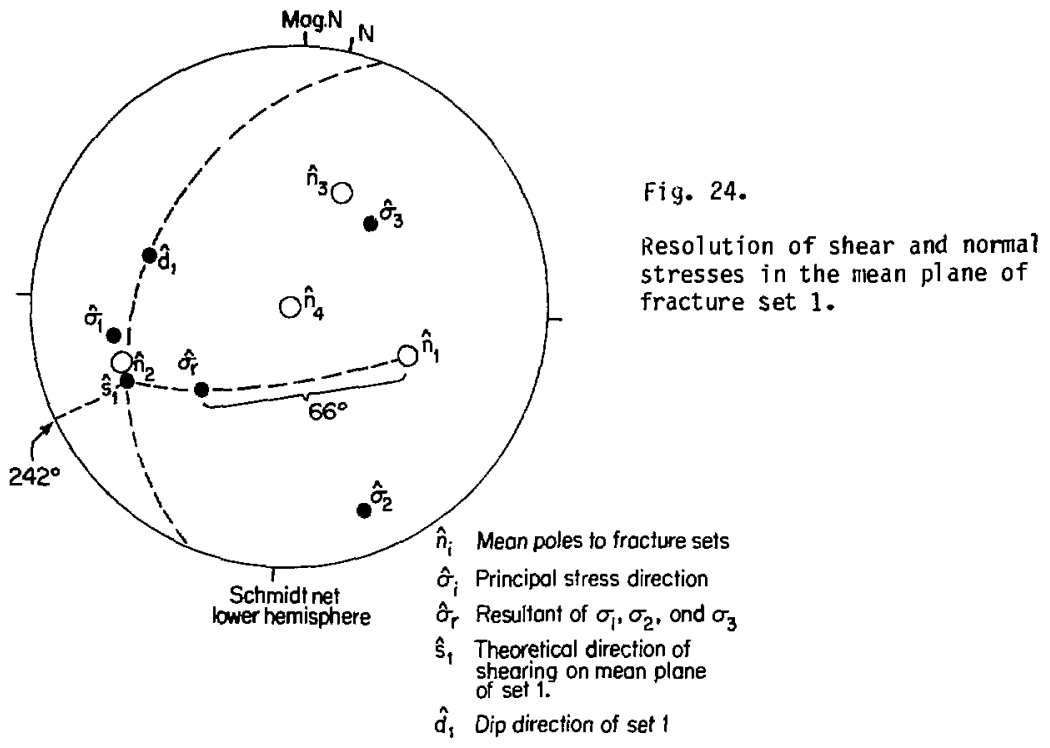

XBL 799-113!2

and the resultiny ratio of shear-to-normal stress is 2.25. For sliding equilibriun the friction angle of the set 1 faults must be at least arctan $(2.25)=66^{\circ}$, assuming no cohesion. The friction angle must be somewhat less, however, because a certain amount of cohesion does indeed exist on the faults, as discussed in Section 4.

Stresses on the mean $p l$ anes of the other three fracture sets can be simjlarly resolved, and their magnitudes are given in Table 10. The highest strear-to-normal stress ratio is found on set 3 , which indicates that the friction anyle and/or the cohesive strength is high enough to maintain equilibriull. Recognizing that set 3 is relatively discontinuous, its "cohesion" derives from the strength of the intact granite. Table 10 also 
Table 10. Shear and nomal stresses on the mean planes of the four fracture sets.

\begin{tabular}{|c|c|c|c|c|}
\hline $\begin{array}{c}\text { Set } \\
\text { newber }\end{array}$ & $\begin{array}{c}\text { Shear stress } \\
\left(\mathrm{PPa}^{\mathrm{a}}\right)\end{array}$ & $\begin{array}{c}\text { Normal stress } \\
(\text { MPD }) \\
\end{array}$ & $\begin{array}{l}\text { Theoret ical } \\
\text { azimuth of } \\
\text { shearing }\left({ }^{\circ}\right)\end{array}$ & Shear/normal \\
\hline 1 & 21.56 & 9.60 & 242 & 2.25 \\
\hline 2 & 10.35 & 21.21 & 127 & 0.49 \\
\hline 3 & 23.08 & 4.91 & 218 & 4.70 \\
\hline 4 & 15.17 & 18.03 & 224 & 0.84 \\
\hline
\end{tabular}

lists the theoretical azimuths of shearing on all of the mean planes. Many of the fractures logged in the core samples show signs of slickensiding and, based on a limited re-examination of the core, the actual directions do not ayree with those in Table 10. The observed azimuth directions vary from about $230^{\circ}$ to $280^{\circ}$, which is generally in the direction of shearing on set 1. While these directions need not be precisely aligned with the major faulting, it is clear that the present tectonic movements are being controlled by the set 1 shear fractures. This is to say, when sliding occurs along a set 1 fault, the stresses on the other fracture planes are temporarily altered from those shown in Table 10 until new equilibrium positions are reached.

Rather than conclude that none of the fractures were formed by shear failure, we hypothesize that the existing shear planes originated as tensile failure surfaces, wich were then propagated by tectonic stresses until those oriente in ;imilar directions became interconnected and formed faults. While : $:$ predominant faulting is currently associated with set 1 fractures, propayation of the set 3 surfaces due to the current state of stress might create an entirely new mode of shear deformation in the distant future. This is plausible in light of the high shear-to-normal stress ratio on these 
planes. Alternatively, if the local state of stress were substantially altered (e.g., by large-scale heating or further mining), such that set 3 fractures would be propagated, the likelihood of faulting along these planes would be enhanced.

The degree to which certain fractures are currently open may be indicated not only by the occurrence of slickensides, but also by the type of infilling. As discussed previously, epidote is probably a post-intrusion product of hydrothemal solutioning. Chlorite is common to virtually all fractures, and is thought to be deposited as an alteration product of the feldspars and muscovite on the fracture walls. Of the three predominant ininerals, calcite is probably the most recently deposited (Wollenberg 1979), and aight indicate the location of the main hydraul ic flow paths. The calcite fractures are clustered in sets 2 and 3 . The shear fractures extending through the time-scale experiment al so hive significant calcite coatings in addition to chlorite and epidote, so it is probable that major fractures in set 1 also constitute flow channels in the rock mass.

\subsection{Use of the Deterministic Results}

We envision that the major features in the time-scale experiment can be analyzed numerically by modeling individual discontinuities to simulate the mechanical behavior of a rock mass (as discussed by Goodman 1976), provided their strength properties are known.

As discussed in Chapter 4, because of the paucity of subsurface inforsnation near the ends of the heater array, the configurations of the major fracture surfaces are not completely indisputable: fracture number 3 has been delineated with the most confidence; fractures 1,2 , and 4 are less 
certain. The surficial expressions of fractures 1, 2, and 4 are more complex, and are most likely associated with zones of fracturing which have undergone relatively less sheariny.

Fracture 3 shows the most pronounced shear deformation, and is undoubtedly the most significant discontinuity through the experiment. Due to the observed and inferred waviness, however, its made of shear deformation is limited mainly to slip along an azimuth of about $240^{\circ}$ from true north. Considerably more energy would be required to shear the fault in other directions, because the anount of dilation (aperture opening) would be yreater. Because the infilling thickness is quite irregular, which may be due to the dilation fron past shearing, the relative amounts of mineralization vary over the surface. Calcite and chlorite are pervasive, but the epidote thickness can vary from less than a centimeter to about $15 \mathrm{~cm}$, with an average thickness of about $2 \mathrm{~cm}$, based on the data in Table 3 . Epidote is harder than chlorite, however, and probably has less influence on the ilechanical behavior of the rock mass.

The pegmatite dike shown in Fig. 6 is obviously a discontinuous feature, although the small-scale offsets of less than about $20 \mathrm{~cm}$ should be neylected, since they cannot be accurately defined at depth. It is therefore recommended that the dike be modeled as a $10-$ to $20 \mathrm{~cm}$-wide tabular body striking perpendicular to the long axis on the array, as shown in Figs. 10 and 11. The only major offset in the dike which can be confidently inferred from the borehole data is that caused by shear fracture number 3. 


\subsection{Limitations of Statistical Results}

The statistical data reported here are lacking in certain respects. First of all, to be useful in a stochastic analysis, the non-uniform distributions of the fracture plane orientations should be quantified. Secrndly, the major assumption of the fracture size and spacing analyses is that these parameters are independent of each other. In fact, the detailed fracture map shows that this is not exactly correct because of the occurrence of fracture zones. In these areas, for example, it is possible to find closely spaced long fractures. For proper representation, this relationship needs to be investigated. Thirdly, the statistical data represent the whole experimental area, rather than selected areas. The data base used here is probably insufficient for a proper statistical analysis; potential variations in the orientation, length, and size parameters over different zones in the drift should be investigated. Fourthly, the relationship between fracture size or spacing and infilling characteristics needs attention. Ideally, a complete statistical characterization should facilitate the simulation of fracture networks in the areas between the major continuous features. Until such a characterization can be reported, it is suggested that the mean orientation, size, and spacing values reported in Section 5 be adopted for purposes of modeling or interpretation of themal data.

\section{CONCLUSIONS}

on the basis of available data, four major continuous fracture surfaces and a faulted pegmatite dike have been delineated to a depth of about $13 \mathrm{ml}$ bel ow the experiment drift. The most prominent of these features is a shear fracture which dips steeply through the central portion of the 
heater array, and obliquely thrust-faults the pegmatite at a depth of about $8 \mathrm{in}$. The inferred offset is about $2 \mathrm{~m}$, N60w.

The methodology by which these continuous features were identified, outlined in this paper, appears sound in light of the consistency of the fracture configurations and the observed shearing direction. Based on the available subsurface data, however, the method cannot be expected to yield detailed information on the network of discontinuous fractures. This aspect has required a statistical approach, from which it is concluded that there are four principal sets of fractures. The mean orientations of these sets have been determined, and the distributions of fractures about the means are described qualitatively. The spacing and size distributions of fractures of the given sets have been shown to conform to the lognormal probability distribution, assuming that these parameters are independent.

Speculations have been made concerning the origins of the fracture sets. Because of the close alignment of the fracture sets and the locally measured principal stress directions, it is reasoned that some fracturing results from cooling of the granite following emplacement and other fracturing is due to much more recent isostatic uplift. The local state of stress has probably changed over time, and it is hypothesized that the current stresses have induced the most recent extension fracturing, as well as faulting along the major continuous fractures in the time-scale drift. Mine excavaijons may also have some influence on the stress field, but this is unsubstantiated at present. 


\section{ACKNOWLEDGMENTS}

A number of persons must be recognized for their help in preparing this report. Individuals who participated in the fracture mapping included

S. Abrahansson, K. Almén, L. Andersson, T. Dauggard, L. Jacobsson, and U. Jacobsson. B. Kanehiro, W. Klauber, and D. McCarthy provided assistance in the interpretation of the fracture data. T. Pfeiffer did the fine illustration work for the eport. The contributions of all these individuals are gratefully acknowl edged. A special note of thanks is given to Dr. J. E. Gale for his continuing guidance in the project. 


\section{REFERENCES}

Barton, C.M. 1978. Analysis of Joint Traces. Proceedings, 19th U.S. Symposium on Rock Mechanics, Reno, Nevada.

Carlsson, Hans. 1978. Stress Measurements in the Stripa Granite." Lawrence Berkel ey Laboratory report LBL-7078, SAC-04. Berkeley, Cal i fornia.

Chow, V.T. 1964. Handbook of Applied Hydrology. New York:. McGraw-Hi11, Inc.

Cook, Neville G.W., and P.A. Witherspoon. 1978. Mechanical and Thermal Design Considerations for Radioactive Waste Repositories in Hard Rock. Part [1: In Situ Heating Experiments in Hard Rock: Their 0bjectives and Design. Lawrence Berkeley Laboratory report LBL-7073, SAC-10. Berkeley, Cal i fornia.

Lidle, J.E., and P.A. Witherspoon. 1978. An Appproach to the Fracture Hydrojoyy at Stripa: Prel iminary Results. OEDC Seninar on In Situ Heat iny Experiments in Geological Fomations, Stripa, Sweden, Sept. 12-15. Also Lawrence Berkeley Laboratory report LBL-7079, SAC-15. Berkeley, California.

Geijer, P. 1938. Stripa Odalfaeltsgeologi (Stripa Mine District Mapping). Stripa Mine Archives, Stripa, Sweden.

Goodilan, R.E. 1976. Methods of Geological Engineering in Discontinuous Rocks. St. Pdul, Minnesota: West Publishing Company.

Kendorski, F.S., and M.A. Mahtab. 1976. Fracture Patterns and Anisotropy of San Manuel Quartz Monzonite. Bulletin of Association of Engineering Geoloyists 13(1): 23-52.

Knill, J,. and K. Jones. 1965. "The Recording and Interpretation of Geological Conditions in the Foundations of the Roseires, Karifa, and Latiyan Dans. Geotechnique 15: 94-124.

Kurfurst, Pavel 3., T. Hugo-Persson, and G. Rudolf. 1978. Eorehole Drilling and Related Activities at the Stripa Mine. Lawrence Berkeley Laboratory report LBL-7080, SAC-05. Berkeley, CaTi fornia.

Nelson, P., B. Paulsson, R. Rachiele, L. Andersson, T. Schrauf, W. Hustrulid, 0 . Duran, and K. Magnusson. 1979. Prel ininary Report on Geophysical and Mechanjcal Borehole Measurements at Stripa. Lawrence Berkeley Laboratory report LBL-8280, SAC-16. Berkeley, Cal i fornia.

Office of Waste Isolation. 1977. Movement of Fluids in Largely Impermeable Rocks. Seminar held at University of Texas at Austin, January 27-29. 
01kiewicz, A. J., K. Hansson, K-E. Almen, and G. Gidlund. 1978. Geological and Hydroyeological Documentation of the Stripa Test Station. KBS Technical report 63. Stockholm, Sweden.

Press, F., and R. Siever. 1974. The Earth. San Francisco: W.H. Freeman and $\mathrm{Co}$.

Ramsay, J.G. 1967. Folding and Fracturing of Rocks. New York: McGrawHill, Inc.

Terzagni, R.D. 1965. Sources of Error in Joint Surveys. Geotechnique. 15:

Witherspoon, P.A., and O. Degeman. 1978. Swedish-American Cooperative Proyram on Radioactive Waste Storage in Mined Caverns. Lawrence Berkeley Laboratory report LBL-1049, SAC-01. Berkeley, California.

Wi therspoon, P.A., J. Gale, P. Nelson, T. Doe, R. Thorpe, C. Forster, and B. Paulsson. 1979. Rock Mass Characterization for Storage of Nuclear Waste in Granite. Proc. 4th ISRM Congress, Montreaux, Switzerland.

Wollenbery, H. 1979. Lawrence Berkeley Laboratory, Berkeley, California. Personal communication. 
10. APPENDICES

APPENDIX A. Borehole Fracture Logs for Time-Scale Experiment

\section{EXPLANATION OF FRACTURE LOGS}

DEPTH

- Represents depth to midpoint of fracture surface (nearest $\mathrm{cm}$ ).

ROCK TYPE

- The term "granite" is a general descriptor here, referring more specifically to quartz monzonite. Minor variations of this classification are not detailed. DISCONTINUITIES AND BREAN;

NATURAL

- Naturally occurring fracture; usually open in situ and containing some mineralization.

INDUCED - Break caused by drilling.

UNCERTAIN - May be a natural fracture; however, its openness in situ is very questionable.

OPEN/CLOSED - Refers to condition of fracture in core and, by inference, to its condition in situ.

OTHER - Refers to a discontinuity other than a fracture. ROUGHNESS - Amplitude of sinall-scale irregularities with wavelengths $<1-2 \mathrm{~cm}$. Larger scale roughness is denoted as "irregular."

WEATHERING - Degree of alteration of wall rock:

HW - Highly weathered

MH - Moderately weathered

SW - 51 ightly weathered

NW - Non-weathered 
MINERAL IZATION

TYPE

- Coded by occurrence, not predominance.

Hain types are chlorite (K), calcite (C), and epidote

(E). Others include:

iron pyrite (I)

mica (M)

fluorite ( $F$ )

quartz (Q).

COLOR - Black (BK), Bl ue (B), Brown (BN), Green (G), white (W), Yellow (Y).

THICKNESS - Very approximate; "hairlinie" fractures are about 1/2-mm thick.

HARDNESS - Soft $(S)$ - scratch with plastic

Moderateiy hard (MH) - scratch with iron

Hard $(H)$ - scratch with steel.

ORIENTATION

BETA ANGLE - Azinuth of apparent dip, looking down hole.

ALPHA ANGLE - Acute angle between fracture and core axis.

REMARKS

- Slickensiding (shearing) is indicated, along with

azimuth (B). 


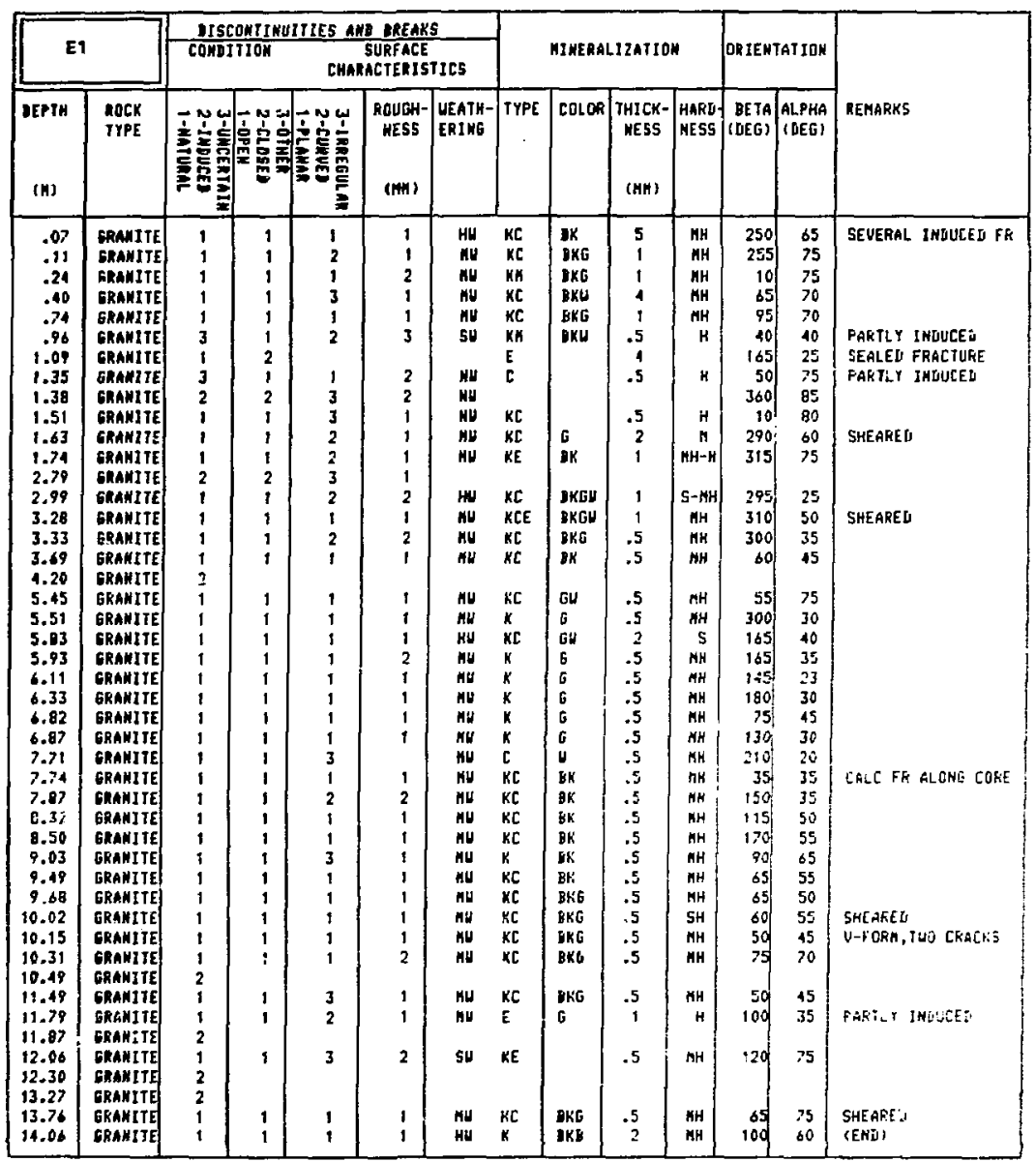




\begin{tabular}{|c|c|c|c|c|c|c|c|c|c|c|c|c|c|}
\hline & & DISCO & HIINU & IIES AV & D) REAKS & & & & & & & & \\
\hline & E2 & COMDT & TON & CHAS & $\begin{array}{l}\text { SURFACE } \\
\text { ACTERIST }\end{array}$ & IICS & & GIMERAL & L.J2ATIO & & DRIEWT & TATION & \\
\hline DEPIH & $\begin{array}{l}\text { RDCK } \\
\text { TYPEE }\end{array}$ & 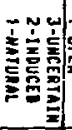 & 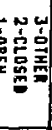 & 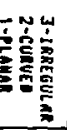 & $\begin{array}{c}\text { ROUGH- } \\
\text { WESS }\end{array}$ & $\begin{array}{l}\text { WEATH- } \\
\text { ERIKG }\end{array}$ & TYPE & COLOR & $\begin{array}{l}\text { THJEK- } \\
\text { MESS }\end{array}$ & 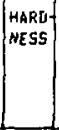 & $\begin{array}{c}B E T A \\
(D E G)\end{array}$ & $\begin{array}{l}\text { ALPHA } \\
\text { (DEE) }\end{array}$ & REMARKS \\
\hline .02 & GRANITE & 1 & 1 & t & 2 & su & CE & Gy & .5 & i & 270 & 10 & \\
\hline 1.09 & GRAYITE & $i$ & i & 1 & 1 & Fu & KC: & ov & .5 & 5 & 190 & 35 & BHEARED \\
\hline 1.21 & Gr.ANITE & ; & $i$ & $i$ & 2 & nu & $k$ & 6 & .5 & $\mathbf{s}$ & 300 & 55 & \\
\hline 1.20 & SRAMITE & 1 & 1 & 1 & 1 & Ku & $k$ & E & .5 & 5 & 300 & 45 & \\
\hline 1.31 & SRAMITE & 1 & 1 & 1 & 1 & nu & $k$ & 6 & .5 & 5 & 235 & 35 & \\
\hline $\begin{array}{l}2.14 \\
2.44\end{array}$ & $\begin{array}{l}\text { GMAG/PES } \\
\text { PEGMATJTE }\end{array}$ & 1 & $\begin{array}{l}1 \\
2\end{array}$ & $i$ & 2 & it & KCE & GH & 1 & $\mathbf{s}$ & 350 & so & \\
\hline 3.10 & [PEG/GRAT] & & & & & & & & & & & & \\
\hline 3.25 & PE6/GRA & 3 & & 1 & 3 & MW & kn & لله & .5 & 5 & 300 & 35 & PARTLYY INDUCED \\
\hline 3.44 & GRAMITE & 2 & & 3 & 3 & 54 & $k$ & 6 & .5 & s & 80 & 25 & PARTLY INGULEL \\
\hline 3.11 & GRAHITE & 1 & 1 & 1 & 2 & NG & $k[$ & G & .5 & $\mathbf{s}$ & 300 & 35 & \\
\hline 3.90 & GRANIIE & 1 & & 1 & $\mathbf{3}$ & su & KE & G & .5 & 5 & 300 & 40 & PARILY INDUCED \\
\hline 4.32 & Grani IE & $i$ & 1 & 2 & 3 & MU & $\mathrm{KE}$ & 6 & .5 & $s$ & 280 & 20 & \\
\hline 5.05 & GRAMITE & 1 & 1 & 1 & 1 & nu & $k$ & 5 & .5 & $s$ & 300 & 45 & \\
\hline 5.31 & GRANITE & 1 & 1 & 1 & 1 & $n:$ & k & 6 & .5 & 5 & 115 & 55 & SHEAKED \\
\hline 5.36 & GRAMITE & 1 & 1 & 1 & 1 & nu & $k$ & 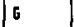 & .5 & $\mathbf{5}$ & 115 & 5s & SHEAREO \\
\hline 5.14 & GRAULTE & 1 & 1 & 1 & 1 & NG & KC & 64 & .5 & $\mathbf{s}$ & 20 & 35 & \\
\hline 5.57 & GGAMITE & 1 & 1 & 1 & 2 & $\mathrm{Hu}$ & $x$ & 6 & .5 & 5 & 300 & 45 & \\
\hline 5.94 & SRAMITE & 1 & 1 & 1 & 2 & Nu & k & 6 & .5 & 5 & 300 & 45 & \\
\hline 5.99 & GRANITE & 3 & & 1 & 2 & su & k & 5 & .5 & $\mathbf{s}$ & 110 & 50 & \\
\hline 6.40 & GRAMITE & 1 & $\mathbf{I}$ & 1 & $\mathbf{3}$ & it & k & 6 & .5 & $\mathbf{s}$ & 300 & 45 & \\
\hline 6.54 & GRANI TE & 1 & i & 1 & 2 & My & $k$ & G & .5 & $\mathbf{5}$ & 300 & 10 & SHEARED \\
\hline 6.62 & GREIITE & , & 1 & 1 & 2 & nU & $k$ & 6 & .5 & $\mathbf{s}$ & 140 & 75 & \\
\hline 6.67 & GRAMITE & 1 & 1 & $\mathbf{I}$ & 1 & ny & $\alpha$ & 6 & .5 & 5 & 80 & 40 & \\
\hline 6.94 & GRANIIE & 1 & 1 & 1 & 1 & N-HU & $k$ & 5 & .5 & s & 120 & 75 & SHEARED \\
\hline 7.15 & GRAMIIE & $i$ & i & i & 1 & $\mathrm{H}-\mathrm{HW}$ & $k$ & 6 & 1 & $\mathbf{s}$ & 110 & BO & SHEARED \\
\hline 7.30 & GRAMITE & 1 & 1 & 1 & 2 & in & $k$ & 0 & .5 & $s$ & 100 & 75 & PJRECTIOH UNCERTAIH \\
\hline 7.43 & ERANITE & $i$ & 1 & 1 & & su & $k$ & 6 & .5 & HK & 95 & 73 & \\
\hline 7.65 & ERAMITE & 1 & 1 & 1 & & HII & $k c$ & 64 & .5 & MH & 95 & 80 & \\
\hline 7.78 & GRANITE & 1 & $i$ & 1 & & & $k$ & 6 & .5 & s & 155 & 45 & \\
\hline $\begin{array}{l}7.98 \\
8.20\end{array}$ & $\begin{array}{l}\text { PEGHATIT } \\
\text { EEG/GRAR }\end{array}$ & 1 & 1 & i & & له. & KC & G & .5 & 5 & 80 & 85 & Yo FRACTURE \\
\hline 8.59 & GoaniJe & 1 & 1 & 1 & 4 & ny & kC & 6u & .5 & KH & 60 & 60 & \\
\hline 8.78 & $\therefore$ + IE & 2 & 2 & & & & & & & & & & \\
\hline & & & & & & & & & & & & & $\begin{array}{l}\text { FUEERQUS SEALED } \\
\text { T.HLOR FR } 9.00-9.30\end{array}$ \\
\hline 9.00 & $\mid \ldots$ IE & 1 & 1 & 1 & 2 & su & KC & 6 & 1 & 5 & 155 & 10 & \\
\hline 9.91 & I ERAHIIE & 1 & $i$ & 2 & 2 & WV & $k$ & 6 & $i$ & 5 & 300 & 55 & \\
\hline 10.10 & GRAM/PES & & & & & & & & & & & & NO FRACTURE \\
\hline 10.61 & PEGKATITE & 1 & 1 & 2 & 3 & Ku & KC & $6 v$ & .5 & HH & 260 & 25 & \\
\hline 10.63 & PEG/GRAI & & & & & & & & & & & & \\
\hline 11.32 & GRAWITE & 3 & 2 & 1 & & & ic & 4 & .5 & HH & & & \\
\hline $\begin{array}{l}11.48 \\
11.85\end{array}$ & $\begin{array}{l}\text { GRAWITE } \\
\text { GRAHITE }\end{array}$ & $\begin{array}{l}3 \\
1\end{array}$ & 1 & $i$ & 2 & sut & k & f & .5 & nh & 105 & 45 & \\
\hline 12.34 & GRAKIIE & i & $i$ & 2 & 2 & MU & $x$ & 6 & .5 & $\mathrm{MH}$ & 80 & 40 & \\
\hline 12.40 & GRAMITE & $i$ & $i$ & $i$ & 2 & MU & {$\left[\begin{array}{l}\mathrm{k} C \\
\mathrm{k}\end{array}\right.$} & 6u & .5 & MH & 85 & 45 & \\
\hline 12.45 & GRAMITE & $i$ & $i$ & $i$ & 3 & nu & $k$ & 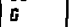 & .5 & KH & 85 & 60 & \\
\hline 12.49 & GRAHITE & 1 & 1 & 1 & 2 & at & $x$ & G & .5 & AH & 90 & 55 & SHEARED \\
\hline 12.54 & SRAHITE & 1 & 1 & 1 & 3 & No & $k$ & $\sigma$ & .5 & $\mathbf{s}$ & 75 & 50 & \\
\hline 12.79 & GRAMJTE & $i$ & $i$ & i & 3 & 5U & $\tilde{c}$ & $v$ & .5 & NH & 55 & 30 & \\
\hline 12.86 & GRAMITE & 1 & 1 & 1 & 2 & HU & $k$ & 6 & .5 & 5 & 175 & 50 & \\
\hline 13.41 & GRAMI TE & j & 1 & 2 & 3 & MU & $\mathrm{kC}$ & 64 & .5 & HH & 70 & 50 & \\
\hline 13.45 & GRANITE & 1 & 1 & 1 & i & MU & $\mathrm{KC}$ & 6V & .5 & 5 & 70 & 55 & JHEAR'.D \\
\hline 13.62 & GRAKITE & 1 & 2 & 1 & 3 & nu & $\mathrm{KC}$ & 64 & .5 & HH & 45 & 55 & \\
\hline 13.67 & GRAMITE | & 1 & 1 & 1 & 2 & nU & KC & 64 & $i$ & Мн & 55 & 60 & \\
\hline 14.03 & GRAN/PEE & 1 & 1 & 1 & 4 & 5H & $x$ & 6 & .5 & MH & 205 & 35 & \\
\hline
\end{tabular}




\begin{tabular}{|c|c|c|c|c|c|c|c|c|c|c|c|c|c|}
\hline \multicolumn{2}{|c|}{ E] } & \multicolumn{5}{|c|}{ 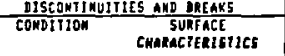 } & \multicolumn{4}{|c|}{ MJKEMALIZATIOY } & \multicolumn{2}{|c|}{ ORJEWTATISOK } & \multirow[b]{2}{*}{ IEMARKS } \\
\hline IEP IH & $\begin{array}{l}\text { ROCK } \\
\text { IYPE }\end{array}$ & 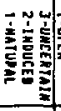 & 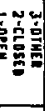 & 它卓 & $\begin{array}{c}\text { ROUCH- } \\
\text { RESE }\end{array}$ & $\begin{array}{l}\text { LEATH- } \\
\text { CHING }\end{array}$ & IYeE & $\cos 0$ & $\left\{\begin{array}{l}\text { THICN- } \\
\text { NESS }\end{array}\right.$ & HARS & $\left|\begin{array}{c}D E \\
C D E G\end{array}\right|$ & $\begin{array}{l}\text { ALPHA } \\
(D E G)\end{array}$ & \\
\hline .05 & Ganatite & 2 & & & & & & & & & & & \\
\hline .20 & GRANITE & 1 & 1 & 2 & 2 & MI & $x$ & 6 & .5 & MH & 85 & 20 & \\
\hline .51 & GRantite. & $t$ & 1 & 1 & 2 & AU & $\mathbf{k}$ & 0 & 1 & MH & 315 & 35 & \\
\hline .54 & GRANITE & 1 & 1 & 1 & 2 & HW & xc & fy & .5 & m. & 295 & 25 & SOHE CLAY FILLJWE \\
\hline .51 & Gnawtte & 1 & 1 & 1 & 2 & Al & $k c$ & Gu & .5 & : & 205 & 20 & \\
\hline 1.20 & GRaHLIJE & $\mathbf{I}$ & 1 & 1 & 3 & hl & KC & Ey & .5 & 5 & 310 & 45 & SOME CLAY FILLIMO \\
\hline 1.30 & GMANI TE & $t$ & $\mathbf{I}$ & 1 & $z$ & Hi & $k C$ & fon & .5 & 5 & 290 & 45 & \\
\hline 1.44 & GRANIIE & 2 & & & & & & & & & & & InDuCED \\
\hline 1.53 & SRAGITE & 1 & 1 & 1 & $z$ & NU & $k[$ & Ev & .5 & 5 & 340 & 10 & \\
\hline 1.97 & GRAMIIE] & 1 & 1 & 1 & $t$ & 5V & $\mathbf{k} \mathbf{c}$ & tou & .5 & 5 & 10 & 10 & \\
\hline 2.40 & ERAHIIE & 3 & & 3 & 1 & nit & & & .5 & & 150 & 60 & \\
\hline J.12 & GRANITE & 1 & 1 & 1 & 1 & uv & $\mathrm{c}$ & $n$ & .5 & & 20 & 65 & \\
\hline 3.47 & GRANIJE & 1 & 1 & 1 & 2 & nu & $k$ & 6 & .5 & 5 & 300 & 30 & \\
\hline 3.73 & BranIte & 1 & $\mathbf{I}$ & 3 & $i$ & Mu & $k$ & 6 & .5 & 5 & 300 & 20 & \\
\hline 3.81 & GRANITE & 1 & ? & 1 & 2 & nt & $k$ & 5 & .5 & $\mathbf{s}$ & 310 & 30 & \\
\hline 3.10 & CRANITE & 2 & 2 & & & & & & & & & & \\
\hline 1.16 & GRandIE & 1 & 1 & 1 & 1 & HW & $k t$ & ou & 1 & Het & 305 & 30 & SHEARED \\
\hline $\begin{array}{l}5.15 \\
5.19\end{array}$ & Otanste & $\frac{2}{1}$ & & 2 & 2 & ny & Ke & 64 & .5 & & 125 & 65 & \\
\hline $\begin{array}{l}5.19 \\
3.39\end{array}$ & $\begin{array}{l}\text { Ganmite } \\
\text { Seatilye }\end{array}$ & 1 & i & 1 & 2 & $n$ & $\mid \begin{array}{l}K E \\
K C\end{array}$ & av & .5 & $\begin{array}{r}2 \\
R\end{array}$ & $\begin{array}{r}125 \\
75\end{array}$ & $\begin{array}{l}65 \\
43\end{array}$ & \\
\hline 5.76 & GRAMIte & $i$ & I & $i$ & 3 & nit & $k C$ & $g$ & .5 & 5 & 160 & 70 & \\
\hline 5.92 & GRANItiE & 1 & 1 & i & 1 & niv & r. & g & .5 & 5 & $16 \%$ & 75 & SHEAKED \\
\hline 6.06 & GRAMI IE) & 1 & 1 & 1 & 2 & MU & $k C$ & bu & .5 & HH & 310 & 35 & \\
\hline 6.06 & ERAwt TE & 1 & 1 & 1 & 了 & $5 n$ & $k$ & $G$ & .5 & HH & 205 & 10 & IHeduON $3 / 2$ of cone \\
\hline 6.20 & GRANI IE & 2 & 2 & & & & & & & & & & JPIAKE DEPTH 8.30 \\
\hline 6.32 & SHANIIE) & 1 & 1 & 3 & 2 & su & $k c$ & Got & .5 & $\mathbf{H H}$ & 45 & 45 & \\
\hline 6.33 & Eranl If & 1 & 1 & 1 & 2 & nu & K & G & .5 & HA & 60 & 10 & \\
\hline 6.49 & GRanste & 1 & 1 & 1 & 3 & nu & Ke & 6u & .5 & $\mathbf{s}$ & 300 & 30 & \\
\hline 4.45 & ERhNIIE & 1 & 1 & $\mathbf{J}$ & 1 & nu & $k C$ & $6 u$ & .5 & MH & 23 & 40 & \\
\hline b.15 & GRand TE & 1 & 1 & $\mathbf{I}$ & 2 & MU & $k C$ & Gu & .3 & 5 & 85 & 40 & \\
\hline 6.87 & Granite & 1 & 1 & $\mathbf{I}$ & 3 & w & $k$ & $G$ & .5 & MH & 145 & 45 & \\
\hline 6.07 & granI Te & 2 & 2 & & & & & & & & & & SUDPARALLEL TO CARE \\
\hline 6.93 & GaviIt & 1 & 1 & 1 & 2 & su & $k$ & 0 & .5 & MH & 125 & 73 & \\
\hline 7.09 & GABuI IE: & 1 & 1 & 1 & 2 & HW & KC & 6u & .5 & $\mathbf{s}$ & 305 & 12 & continues ta 7.31 \\
\hline 7.09 & Grantre] & 1 & 1 & I & 2 & SN & kt & $5 y$ & .5 & MH & 130 & 70 & \\
\hline 7.75 & GRANIIE] & 1 & 1 & 1 & 1 & nu & $k$ & G & .5 & HH & 100 & 10 & \\
\hline 7,72 & GRAMI TE] & 1 & 1 & 1 & 2 & Su & $k$ & o & .3 & MH & 195 & 75 & THROUGH 1/2 CORE \\
\hline 7,75 & ERand If & 1 & 1 & 1 & 2 & nu & xt & & & AH & 300 & 15 & \\
\hline 7.86 & GRANITE & 2 & 2 & & & & & & & & & & \\
\hline B.10 & SRAM] IE & 1 & $i$ & J & $\mathbf{J}$ & MU & $n$ & $G$ & .5 & Mn & 80 & 70 & \\
\hline 6.42 & GRANITE? & 1 & 1 & 1 & 2 & W & kC & 54 & .5 & s & so & 25 & SHEARED \\
\hline 8.70 & GAhaj Te & 1 & 1 & 3 & 1 & 5U & $E$ & u & .5 & ma & 250 & 20 & \\
\hline 8.71 & shavite & 1 & 1 & 3 & $\mathbf{J}$ & su & $\mathrm{kC}$ & 65 & .5 & MH & 280 & 35 & \\
\hline 0.10 & GRAMITE & 1 & 1 & 1 & 3 & MU & kC & En & .5 & MH & 100 & 05 & \\
\hline 8.20 & Geant is & 1 & 1 & 1 & 2 & $\mathrm{NU}$ & $k C$ & 64 & .5 & 5 & 315 & 25 & IHROUGH $1 / 2$ CORE \\
\hline 6.65 & GRAMITE & 1 & 1 & 1 & 2 & H & Ke & 64 & .5 & $\mathbf{s}$ & 50 & 70 & \\
\hline 0.97 & GRAMITE & 1 & 1 & 1 & 2 & Nu & KE & of & & $\mathbf{s}$ & 155 & 30 & \\
\hline 9.10 & GRAMITE & 1 & 1 & 1 & 2 & Sw & $k$ & 6 & .5 & HH & 145 & 60 & \\
\hline 1.29 & GRANITE & 3 & & 1 & 2 & 5 & $x$ & 6 & .5 & H & 295 & 80 & \\
\hline 9.76 & GRAVITE & 1 & 1 & 1 & 3 & in & KC & Gy & .5 & $\mathbf{s}$ & 300 & 25 & \\
\hline 10.09 & GRALITE: & i & $i$ & 1 & 2 & nu & $\mathrm{kC}$ & 64 & .5 & MH & 195 & 65 & \\
\hline 10.21 & Gananite & $\mathbf{I}$ & 1 & $i$ & 3 & nt & KC & 64 & .5 & $\mathbf{s}$ & 300 & 30 & - \\
\hline$: 0.21$ & GRAMITE & 1 & 1 & 3 & 2 & nI & 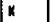 & 6 & .5 & $M H$ & & 90 & \\
\hline 10.34 & GINAITE & 1 & 1 & 1 & 2 & 5 & 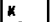 & 6 & .5 & NH & 145 & 10 & \\
\hline 10.39 & GRAMIJE? & 1 & 1 & 1 & 2 & w & ac & $5 u$ & .5 & nK & 100 & 45 & \\
\hline 10.64 & GRAWITE & 1 & 1 & 1 & 3 & nu & Kc & EH & 1 & Ha & 180 & 45 & \\
\hline 11.17 & SRAHI IE & 1 & 1 & I & 2 & $w$ & KCI & mav & .5 & MH & 190 & 75 & \\
\hline 11.40 & BRAMITE & 1 & 1 & 2 & 2 & w & ke & 64 & .5 & MF & 75 & 45 & \\
\hline 11.63 & GRAwITE & 1 & 1 & 3 & 3 & 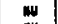 & KCt & Dnar & .5 & $\mathrm{mH}$ & 10 & 60 & \\
\hline 11.83 & senulitg & 1 & 1 & 1 & 2 & an & $x$ & 6 & .5 & GH & 285 & 55 & \\
\hline 11.00 & GRANITA & 1 & 1 & 1 & 3 & WI & kc & GU & .5 & 5 & 65 & 45 & \\
\hline 12.22 & Ganuite & 1 & $i$ & $i$ & 3 & at & $x$ & 6 & .5 & s & 130 & 20 & \\
\hline 12.25 & gramite & 1 & $i$ & $i$ & 2 & u & KC & 64 & .5 & 5 & 320 & 20 & \\
\hline 12.31 & Ganite & 1 & $i$ & $i$ & $i$ & 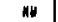 & $k$ & i & .5 & $\mathbf{s}$ & 160 & 55 & \\
\hline 12.35 & Gtaulre & 1 & 1 & i & $i$ & HU & $x$ & i & 2 & 5 & 175 & is & \\
\hline 12.51 & Grawtre & 1 & $t$ & 3 & 2 & an & ne & $6 y$ & .5 & 5 & 75 & 50 & PATIRY INOUEED \\
\hline 13.27 & GRAMIIE & 1 & 1 & $\mathbf{3}$ & 2 & nt & KCIn & INEN & .5 & s & 175 & 35 & I IMOUCED \\
\hline 13.00 & SRAdira & 1 & 1 & 1 & $i$ & BN & KI & ING & .5 & n & 90 & 65 & \\
\hline 53.94 & GRAAITH & 1 & 1 & 3 & 3 & 5V & $k C$ & 64 & .5 & $\mathbf{s}$ & 105 & 55 & \\
\hline 19.01 & GRAMIYG & 1 & 1 & 3 & 2 & 54 & CI & Bus & .5 & $\mathbf{s}$ & 155 & 75 & \\
\hline 14.07 & GRAuite & 1 & 1 & 3 & 2 & iu & $\mathbf{k}$ & 6 & .5 & $\mathbf{s}$ & 305 & 10 & 1 Inouces \\
\hline 14.67 & ckanite & 1 & i & $i$ & $\mathbf{r}$ & id & Ke & 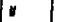 & & s & 110 & 50 & (EMP) \\
\hline
\end{tabular}




\begin{tabular}{|c|c|c|c|c|c|c|c|c|c|c|c|c|c|}
\hline \multirow{2}{*}{\multicolumn{2}{|c|}{ E4 }} & \multicolumn{5}{|c|}{ 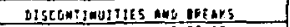 } & \multirow{2}{*}{\multicolumn{4}{|c|}{ nInEhaldinilor }} & \multirow{2}{*}{\multicolumn{2}{|c|}{ QRSETATION }} & \multirow[b]{3}{*}{ IEnakess } \\
\hline & & \multicolumn{2}{|c|}{ COMDition } & \multicolumn{3}{|c|}{ chanacteoistics } & & & & & & & \\
\hline DEPIn & tiock & 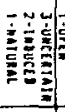 & 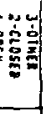 & 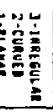 & acote- & $\begin{array}{l}\text { Dethe- } \\
\text { Eoinc }\end{array}$ & $3 \mathrm{PP}$ & COI Do ? & $\left\{\begin{array}{c}\text { JHICX- } \\
\text { MES5 } \\
\text { (nn) }\end{array}\right.$ & $\begin{array}{l}\text { moks: } \\
\text { wiss: }\end{array}$ & 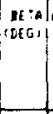 & $\begin{array}{l}\text { lairma } \\
\text { floEG }\end{array}$ & \\
\hline .13 & Geanste & 1 & 1 & 1 & 2 & 54 & res & 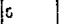 & 1.5 & $\mu$ & $\because$ & $2 t$ & \\
\hline 25 & GRAWIIE & 1 & & $?$ & 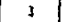 & nu & "n & fo & & 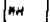 & $10 \%$ & go & \\
\hline 3 & Grantul & 1 & 1 & 2 & 3 & Au & ir & o & 1 & HH & $"$ & 7 & I FHI AVtS \\
\hline .91 & Ckanel II & & 1 & & & $m$ & & a & & $\omega$ & 174 & ys & \\
\hline 1.14 & Enawifl & 1 & $i$ & 1 & 1 & nit & r. & to & 1.5 & s & 35: & s: & MECAGICRLLI JHEUEL \\
\hline 1.30 & shanith & 1 & 1 & 1 & 3 & u & & ! & & n & $17 \%$ & $6^{5}$ & \\
\hline 1.94 & Ghand ti & 1 & 1 & 1 & 1 & 56 & $k$ & {[} & $\therefore$ & nn & is: & It & fanc rs = InOUCE: \\
\hline 2.16 & Ghand It & 1 & 1 & 1 & ; & 54 & $\ddot{r}$ & 6 & $\therefore$ & 5 & 14"s & 15 & SHE AEES \\
\hline 2.64 & Ekand It & 1 & 1 & 1 & $z$ & \$u & kt & $c$ & .3 & 5 & $13 \%$ & $5:$ & SMEAKED \\
\hline 2.39 & ERand If & 1 & $i$ & 1 & $i$ & su & $k$ & $\mathrm{c}$ & & MH & 240 & 15 & 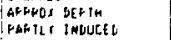 \\
\hline 3.37 & Genaste & 2 & & & & & & & & & & & icohe L05: $3.3,-3,11$ \\
\hline 3.41 & Gkarlite & : & & & & & & & & & & & ICHAHGE TO OZAM COHE \\
\hline 3.86 & Ghanlti & 1 & $!$ & 1 & 3 & su & $x$ & 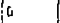 & $\therefore$ & 5 & 150 & 50 & ENG GEEO \\
\hline 4.11 & skawift & 1 & 1 & 2 & 2 & su & $r$ & i & .3 & 5 & 140 & $s e$ & SHEABED, CUEMEL \\
\hline 9.19 & GRautite & 1 & $i$ & 1 & 3 & & r.c & a & 1 & 5 & 120 & 40 & SMEAFED \\
\hline 9,76 & Ekand te & 1 & 1 & 2 & 2 & su & r. & ou & 2 & 5 & 135 & 40 & BOTY SHEARED,ONE \\
\hline 4.28 & GRANITf & 1 & 1 & 1 & 1 & 54 & $n c$ & an & $\div$ & 5 & 120 & 50 & $\begin{array}{l}\text { OF FUD FRACIUAES } \\
\text { IN GE TUEEN THESE }\end{array}$ \\
\hline 4.89 & Ekenile & 1 & 1 & 1 & 1 & & $*$ & 6 & $\therefore$ & $n$ & 190 & 50 & \\
\hline 5.07 & Ganastit & $?$ & 1 & 1 & 3 & nu & k. & 6 & .5 & 5 & 9 & 25 & \\
\hline 3.34 & Genatite & 1 & 1 & 1 & 2 & MU & $\left\{\begin{array}{l}* \\
K h\end{array}\right.$ & 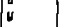 & .5 & 5 & 290 & $x$ & \\
\hline 5.57 & Gkandte & 1 & 1 & 1 & 2 & nu & $k$ & 0 & .5 & 5 & 116 & 30 & SHE ARED \\
\hline 5.65 & Grani If & 1 & $t$ & 3 & 3 & nu & 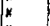 & 6 & .5 & s & 265 & 10 & \\
\hline 5.74 & Ghand tE & 1 & 1 & 1 & 2 & Su & $k$ & 0 & .5 & 5 & 340 & 42 & \\
\hline 3.80 & GRANIIE & 1 & 1 & 3 & 2 & nu & $k c$ & Gu & .5 & 5 & 115 & 30 & \\
\hline 6.11 & Ghans IE & 1 & 1 & 1 & 2 & MU & $k$ & 0 & .5 & 5 & 18 & 30 & 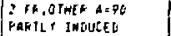 \\
\hline 6.40 & Elktulte & 1 & 1 & 1 & 1 & NU & $k$ & 6 & .5 & 5 & 345 & 30 & \\
\hline 6.50 & GRANI IE & 1 & 1 & 3 & 3 & 54 & k. & E & $\therefore$ & 5 & 270 & BO & \\
\hline 6.82 & GRahlte & 1 & 1 & 1 & 2 & $\omega$ & $x$ & b & .5 & 5 & 145 & 25 & FART IMDUEEQ.V-FOVA \\
\hline 6.85 & GEANJTE & 1 & 1 & 1 & 3 & nu & $k$ & G & .3 & 5 & 335 & to & \\
\hline 6.93 & Eranile & 1 & 1 & 3 & 2 & nu & $k$ & c &.$\$$ & 5 & 340 & 45 & \\
\hline 7,32 & GRAMITE & 1 & 1 & 1 & 1 & nل & $k$ & o & .5 & 5 & 150 & 40 & \\
\hline 2.51 & GRANIIE & 1 & 1 & 3 & 2 & nu & $k$ & 0 & .5 & $\mathbf{s}$ & 20 & Bs & \\
\hline 7.65 & GRAUITE & 1 & 1 & $\mathrm{~J}$ & 2 & ns & $r$ & 6 & .5 & 5 & 300 & 70 & \\
\hline 7.87 & GkANItE & 1 & 1 & 3 & 2 & Wh & $k$ & 0 & .5 & $\mathbf{s}$ & 270 & 55 & $v=$ FORM \\
\hline 7.24 & GRANITE & 1 & 1 & 3 & ? & AI & $x$ & 5 & .5 & 5 & 280 & so & \\
\hline $\begin{array}{l}9.40 \\
9.00\end{array}$ & $\begin{array}{l}\text { GKAMITE } \\
\text { GRAMIIE }\end{array}$ & 1 & 1 & 1 & 3 & M & $k$ & 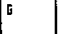 & .5 & s & 270 & 60 & \\
\hline 9.08 & ERAMITE & $i$ & 1 & 1 & $t$ & MU & $k$ & G & .5 & 5 & 300 & 15 & \\
\hline 7.30 & GRARITE & 1 & 1 & 1 & 1 & Nit & Kc & Gu & .5 & 5 & 200 & 80 & \\
\hline $9.6 \mathrm{~J}$ & GRanjte & 1 & $i$ & 3 & ; & at & $k E$ & Gu & .5 & $s$ & 100 & 60 & V-Fakn \\
\hline 9.73 & GRAni IE & 1 & 1 & 1 & 1 & NH & $k$ & 6 & -5 & s & 300 & 80 & \\
\hline 10.16 & Geantre & $i$ & $i$ & 2 & 2 & ny & $k$ & a & .5 & 5 & 270 & 70 & \\
\hline 10.35 & Granite & 3 & & & & & & & & & & & \\
\hline $\begin{array}{l}10.72 \\
10.77\end{array}$ & SRMUIIE & i & 1 & 1 & 2 & ne & $k$ & a & .5 & 5 & 290 & 40 & J CH PEEMAIITE \\
\hline 13.26 & Gkawite & 1 & 1 & 1 & 3 & nu & kC & 60 & .5 & 5 & 65 & 20 & J CA PEEHATMTE \\
\hline 11.26 & GRAMITE & $i$ & i & $z$ & 2 & su & $k$ & 6 & .5 & 5 & 70 & 55 & \\
\hline 11.62 & GaAlite & 1 & 1 & $\mathbf{3}$ & 3 & s-wu & KC & Ge & .5 & HH & 20 & 55 & SAK1 IWDUCE : \\
\hline 11.79 & Ghawite & $i$ & $i$ & 1 & 2 & 5H & KC & IKG & .5 & HH & 260 & 50 & SHEARED \\
\hline 12.30 & GRAWITE & $i$ & 1 & 1 & 2 & iv & $x$ & ik & .5 & MH & 245 & 65 & SHEARE \\
\hline 32.94 & SRAMITE & 1 & 1 & 1 & i & sH & c & 6 & .5 & $\mathrm{H}-\mathrm{H}$ & 250 & 60 & SHEARED \\
\hline 13.14 & GRAMITE: & 1 & 1 & I & 2 & ne & $k$ & IXE & .3 & | $\mathrm{KH}$ & 250 & 30 & SHEARED \\
\hline 13.03 & GRAG]TE & 1 & 1 & 1 & 1 & su & KI & OKBY & .5 & MH & 200 & 60 & \\
\hline 13.97 & GRANIIE & 1 & 1 & 3 & 2 & su & $x \in 1$ & bx & .5 & H & 279 & 50 & \\
\hline 14.02 & GhANITE & $i$ & $i$ & 1 & 3 & $\mathbf{K H}$ & kI & BKBWU & .5 & $H-5$ & 275 & 30 & \\
\hline 14.60 & shamtin & 1 & 1 & 3 & 2 & ny & $\mathbf{k}$ & ok & .5 & | $\mathrm{AH}$ & 290 & 60 & \\
\hline 14.17 & GRanire & $i$ & 1 & 3 & 2 & $\mathrm{~ms}$ & $\mathbf{k}$ & BK & .5 & HH & 310 & 60 & SHEARED \\
\hline 14.24 & GKAHITE) & 1 & 1 & 1 & 2 & ny & 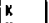 & DK & .5 & 4 & 300 & 65 & SHEARED \\
\hline 14.32 & GRAMJIE & 1 & 1 & 3 & 1 & II & $\boldsymbol{k}$ & sk & .5 & HH & 280 & 30 & SHEARED (EMD) \\
\hline
\end{tabular}




\begin{tabular}{|c|c|c|c|c|c|c|c|c|c|c|c|c|c|}
\hline E & & $-\frac{z: s:}{i w^{\prime}: !}$ & 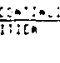 & $\frac{1 \times A}{C E A}$ & 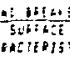 & & & $\operatorname{nintbit}$ & 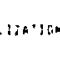 & & Obil $L$ & 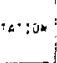 & \\
\hline DEtim & $\begin{array}{l}\text { hotr } \\
\text { tems }\end{array}$ & 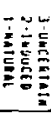 & 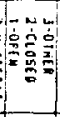 & 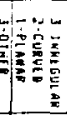 & $\begin{array}{c}\text { EOUGM- } \\
\text { ME } 55\end{array}$ & $\begin{array}{l}\text { UeAm-i } \\
\text { Ifing }\end{array}$ & $i_{i}+106$ & tco. ok & $\begin{array}{l}\text { YNoto- } \\
\text { MEss }\end{array}$ & $\begin{array}{l}\text { Wht } \\
\text { m! } 55\end{array}$ & 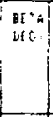 & 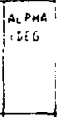 & IEMARKS \\
\hline .24 & $G=4 n \geq t=$ & 1 & . & $\therefore$ & - & $\therefore$ & . & Eo. & $\therefore$ & $\mathrm{nm}$ & $\therefore$ & $d i$ & \\
\hline $.3:$ & coniti & 1 & 1 & : & : & h. & 1 & b+o & $\therefore$ & $m$ & $3:-1$ & $\ddot{q}$ & \\
\hline se! & GoLIIIE) & 1 & $:$ & $=$ & 1 & mis & 1 & $1+0$ & $\therefore$ & ar & $\therefore$ & of & $5 \mathrm{UL}: \mathrm{dt}$ \\
\hline$\therefore t$ & Gesin:10! & ; & $\cdot$ & ' & $\cdot$ & $m$ & .1 & $5+6$ & $\therefore$ & + & $\therefore \because !$ & $\because$ & \\
\hline$\because$ & $\operatorname{cstan}[1: 1$ & i & $\cdot$ & ; & 1 & n. & if & m & $\therefore$ & nm & $\therefore$ & $1:$ & FAF:i: OHIn \\
\hline et & totandit! & i & : & $:$ & : & b* & $1:$ & ir & $\therefore$ & $m$ & $\cdot$ & $\therefore$ & GFowiti rl, inE \\
\hline 酯 & Gohmilis & $!$ & ; & $\vdots$ & & 5* & ' & ". & $\therefore$ & $=m$ & $\therefore:$ & $\therefore$ & ghtha]fl \\
\hline$\therefore$ & 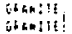 & $\vdots$ & $i$ & $\vdots$ & $:$ & *. & $1:$ & $k$. & $\therefore$ & $\cdots$ & $\because \because$ & $c:$ & 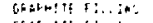 \\
\hline 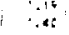 & $\begin{array}{l}\text { of hallit! } \\
\text { othen:lit }\end{array}$ & $!$ & 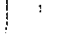 & 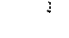 & $:$ & nt & $\because$ & F" & $\therefore$ & $r$ & $\because$ & is & Gothim::t $1: \ldots:=1$ \\
\hline $\begin{array}{l}\therefore x \\
\therefore 15\end{array}$ & $\begin{array}{l}\text { iksaily! } \\
\text { ibcollft }\end{array}$ & $\vdots$ & & & & & & & & & & & \\
\hline & & & : & ' & $\cdot$ & $n 6$ & $\therefore$ & $i \cdot 6$ & $\therefore$ & b An & $\because "$ & $\because:$ & \\
\hline$\therefore$ & Gren:le & 3 & & $\vdots$ & : & $5-4$ & ' & bi. & $\therefore$ & 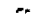 & 4 & $\because$ & Abs:d, induit: \\
\hline & the $=$ : : I & $:$ & · & 3 & : & s. & + & H: & $\therefore$ & ar & 16. & st & \\
\hline $\begin{array}{l}3.4 \div 5 \\
3.48\end{array}$ & 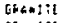 & t & 1 & ; & . & $5 \mathbf{b}$ & . & bis & $\therefore$ & $M-$ & & & FaFs, Inisute: \\
\hline $\begin{array}{l}3.48 \\
3.62\end{array}$ & 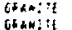 & $:$ & $:$ & ' & $:$ & $m$ & $\because$ & $t=b$ & $\therefore$ & $E m$ & oc & Jc & \\
\hline $3 ; 8$ & Giant: & $\vdots$ & i & $:$ & $:$ & sth & , & f. & $\dot{0}$ & (n.. & $\because$ & $\because$ & \\
\hline 1.13 & Gtan:?ti & . & . & $i$ & $\vdots$ & is. & : & $i_{4}$ & $\therefore$ & n. & $\because:$ & $\mathrm{E}$ & \\
\hline A. Fe & Grak:it & - & $:$ & . & : & $5 \mathrm{~s}$ & $\therefore$ & F" & & mm & $\because$ & $\because 6$ & \\
\hline 4.02 & Ghak! It & . & - & $\cdot$ & . & $\sin$ & is & $\therefore$ & • & w & $a:$ & $\because$ & \\
\hline 4.17 & lbandiE & $:$ & & . & & $" *$ & , & $\vdots$ & & $\rightarrow$ & j & $8:$ & \\
\hline+34 & Ghawlit & : & + & ' & : & +4 & r: & $i n_{n}$ & & ar & b. & $\because$ & \\
\hline 4.06 & GFan!it: & 1 & : & : & $\cdot$ & nv & ic & jo & $\therefore$ & ni. & 4 & $\therefore$ & \\
\hline 4.9 & Gran:tif & : & $:$ & - & $\cdot$ & $a_{0}$ & $\therefore$ & $\dot{r} \cdot=$ & $\cdot$ & an & $\because$ & 4. & \\
\hline $\begin{array}{c}3.03 \\
5.03\end{array}$ & $\begin{array}{l}\text { Ghan:it } \\
\text { Gham:it }\end{array}$ & ! & $i$ & - & , & nw & $\therefore$ & $\therefore$ & & nm & - & $\cdot 1$ & STin:Ant: \\
\hline$\$ .34$ & ERAN:T & $i$ & . & $\because$ & . & $\therefore$ & $\cdot:$ & the & $\therefore$ & n. & $\because$ & 6. & \\
\hline$\therefore .44$ & Ghat:? & $i$ & + & : & . & $r$ & i: & 䀡 & $\therefore$ & Are & $M C$ & $4:$ & PARILT INDUCE: \\
\hline 3.53 & GFAN:If & 1 & 3 & 1 & : & n. & it & in & $\therefore$ & A.. & 6.. & 40 & \\
\hline $3.60 !$ & DFAn:iE & : & $i$ & 3 & r & $n$ & $\cdot$ & g & $\therefore$ & i pen & 7 & $"$ & \\
\hline 9.621 & THANIIE & 1 & 1 & 3 & $\vdots$ & $m_{*}$ & $r$ & G & : & nH & is: & 35 & \\
\hline 5.63 & GRANIIE & . & 1 & $\vdots$ & $:$ & st & $\therefore$ & $:$ & $\therefore$ & $n$ & $\therefore$ & $\therefore$ & FakTLI IN!. \\
\hline$\therefore 24$ & GRas: ti & 1 & $:$ & $\vdots$ & $:$ & s. & i. & $3+6$ & .3 & $9 r$ & 85 & $\because:$ & IREILY IMLUEEJ. \\
\hline 0.04 & GRHEITE & 1 & 1 & 3 & $i$ & n. & - & is & $\therefore$ & nN & & & \\
\hline 0.25 & Gokanili & $:$ & 1 & 2 & 1 & $n_{6}$ & • & Et & $\therefore$ & 4 & $\because$ & : : & \\
\hline 2.45 & GKAMIIE & & & & $i$ & & & & & & & 1: & PIGHLY FKAL TLAE \\
\hline 0.80 & Gian:lif & 1 & 1 & $z$ & $\vdots$ & 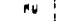 & ' & is & $\therefore$ & nr & Eo & $\because$ & SHEARL L' \\
\hline 2.04 & Gkanite & i & $:$ & : & : & $\mathrm{rb}$ & t & 6 & .5 & HM & EQ & 50 & \\
\hline 7.11 & GFANTIL & i & : & 1 & : & si. & ' & 6 & $\therefore$ & Nn & ג' & $\Delta \mathrm{i}$ & raEt, ; InbluClo \\
\hline 2.34 & [han:? :e & 1 & 1 & 1 & ' & m. & r & *. & $\therefore$ & $\pi$ & â & $\therefore$ & SHEÄt \\
\hline $7.4 !$ & GHARIIE. & 1 & 1 & i & ! & n. & , & E & $\therefore$ & No & Eखi। & e! & \\
\hline$\therefore \because$ & Than: 1t & 1 & ; & · & : & 5. & 1 & $\mathrm{i}$ & $\therefore$ & : & $50^{\circ}$ & 43 & \\
\hline 2.73 & GeandiE. & 1 & $:$ & 1 & : & n: & - & $\because$ & $\therefore$ & $\operatorname{mr}$ & $\therefore$ & es & \\
\hline 7.87 & GGAM:IE & $i$ & 1 & · & $\vdots$ & no & $\therefore$ & 6. & $\therefore$ & Nr: : & $66^{\circ}$ & 4 & \\
\hline E.13 & GEANDIE. & 1 & ; & : & 1 & mb & $r$ & C & .5 & $\mathrm{k+N}$ & $s_{i}$ & 15 & \\
\hline E.26 & GRANIIE & $i$ & & & & & & & & & & & \\
\hline E.50 & GRANIIE, & $t$ & 1 & $\vdots$ & $\because$ & AL & $\because 4$ & Git & $\because$ & nth & 40 & 5 & \\
\hline $\begin{array}{l}8.081 \\
9.6\end{array}$ & Gkanditi & 1 & i & $i$ & 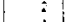 & a & $r i$ & 6 & .5 & NH & 501 & sis & \\
\hline 9.16 & GRALISE & 1 & 11 & 2 & $:$ & $\mathrm{nit}$ & '. & 6 & .5 & ne & 20 & 4: & \\
\hline $\begin{array}{l}9.18 \\
3.22\end{array}$ & [atand]1 & 1 & 1 & 2 & 1 & KL & : & 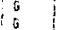 & .5 & ${ }_{\mathrm{NH}}^{\mathrm{HH}}$ & 40 & 55 & \\
\hline $\begin{array}{l}3.22 \\
0.21\end{array}$ & Ghanili & 1 & $\vdots !$ & 2 & 1 & NU & r. & 0 & & AH & 50 & ss & \\
\hline 9.27 & $\begin{array}{l}\text { GhanlTE } \\
\text { [ThatiJTE }\end{array}$ & $?$ & 1 & i & & nu & p. [ & 64 & $\therefore$ & MH & 70 & & \\
\hline 9.961 & GTANITEE & $i$ & i & 2 & $i$ & As & h & 6 & .5 & $\mathrm{AH}$ & 180 & $3 c$ & \\
\hline $\begin{array}{l}19.69 \\
10.46\end{array}$ & $\begin{array}{l}\text { GKANITE' } \\
\text { GRAMITE }\end{array}$ & $\begin{array}{l}2 \\
z\end{array}$ & 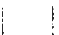 & 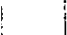 & & & & & & & & & EHDS RDTATEV \\
\hline 10.64 & GEAMIIE & 3 & 3 & 1 & 2 & Su & E & 0 & .5 & $n$ & 150 & Is & FARI IKDUCED \\
\hline $11.0 \bar{c}$ & GRARITE & $i$ & $i$ & 3 & 2 & Aw & $\begin{array}{l}k i \\
i\end{array}$ & G. & .5 & 5 & 255 & 10 & \\
\hline 11.28 & ORAMIIS & 1 & 1 & 2 & 2 & S山 & $\mathrm{E}$ & G & .5 & $n$ & $2+1$ & is & \\
\hline 11.80 & ERakits & 2 & ? & & & & & & & & & & \\
\hline 12.80 & Ghantid & 2 & 2 & & & & & & & & & & \\
\hline$: 3.19$ & GRantid & 1 & $\mathfrak{t}$ & 2 & 2 & SL & REEOO & Giv & .5 & $\mathrm{~N} \cdot \mathrm{HS}$ & $160:$ & 25 & \\
\hline 13.34 & GRANETL & 1 & $i$ & 1 & 2 & MU & s & 6 & $\therefore$ & 5 & 2301 & 25 & \\
\hline 13.45 & GRAMITE & 1 & 1 & 2 & 2 & 56 & E & 5 & $\therefore$ & nn" & 29 & 36 & \\
\hline 13.46 & GRANITE & 1 & $i$ & 3 & 3 & SU & $k$ & G & .5 & $s$ & 120 & 40 & \\
\hline 13.70 & GRAMITE & 1 & I & 1 & 2 & my & $\mathrm{kC}$ & Ev & s. & S-P. & 205 & J5 & \\
\hline 13.86 & GKanIt] & 1 & ' & 3 & 2 & D & KCE & E & $\therefore$ & $n-5$ & 220 & 30 & \\
\hline 13.96 & GRALITE & 1 & 1 & 3 & 3 & Su & [ & 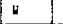 & .5 & N & 290 & 40 & \\
\hline
\end{tabular}




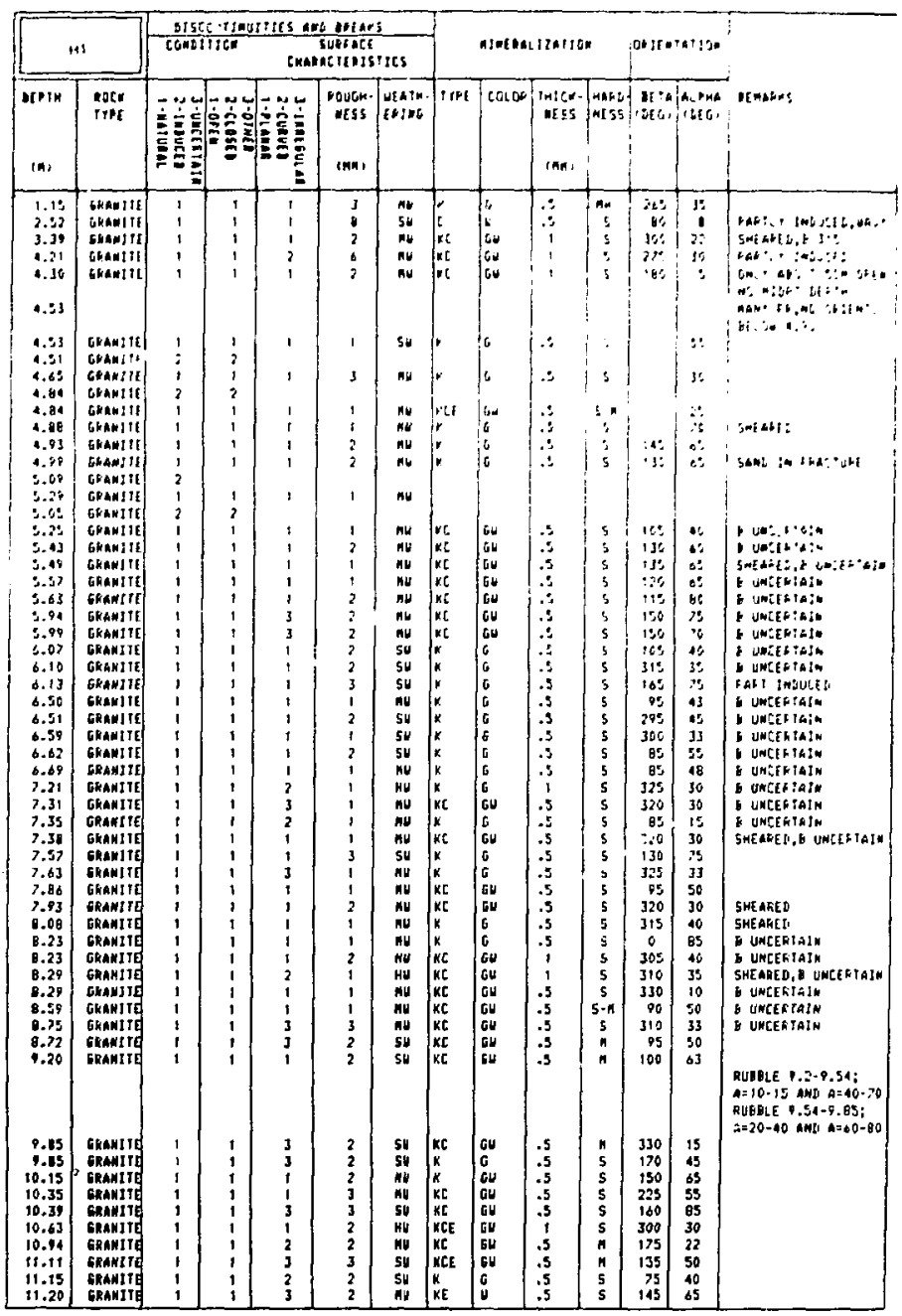




\begin{tabular}{|c|c|c|c|c|c|c|c|c|c|c|c|c|c|}
\hline \multicolumn{2}{|c|}{$\mathrm{H} 2$} & \multicolumn{2}{|c|}{ COMOLIIOH } & \multicolumn{3}{|c|}{$\begin{array}{c}\text { SURFACE } \\
\text { CHARACTERISTICS }\end{array}$} & \multicolumn{4}{|c|}{ Hiweratizarion } & \multicolumn{2}{|c|}{ JORIEMTATION } & \multirow[b]{2}{*}{ AENARKS } \\
\hline DEPTH & $\begin{array}{l}\text { OOCK } \\
\text { IPPE }\end{array}$ & 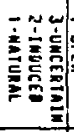 & 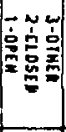 & 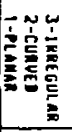 & $\begin{array}{c}\text { ROUGH- } \\
\text { MESS }\end{array}$ & $\begin{array}{l}\text { ULATH- } \\
\text { ERIAL }\end{array}$ & IYPE & COLOR & $\left\{\begin{array}{c}\text { IHICK- } \\
\text { MESS } \\
\text { (nN) }\end{array}\right.$ & HARI & $\mid \begin{array}{l}\text { BCTA } \\
\text { IDEG }\end{array}$ & $\left\{\begin{array}{l}\text { ALPHA } \\
\text { (LEG) }\end{array}\right.$ & \\
\hline+10 & GkanIte & 2 & 2 & 1 & $?$ & $\mathrm{Nu}$ & & & & & 284 & צ'י & \\
\hline 1.00 & GRANSTE & 1 & 1 & 1 & 2 & su & $c$ & $v$ & $\therefore$ & NH & $20 j$ & 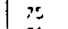 & \\
\hline 1.42 & GRamite & 2 & : & ' & 3 & No & & & & & $: 30$ & OC & \\
\hline$\therefore 60$ & GRAMITE & 2 & 2 & 1 & 3 & Mu & & & & & 300 & 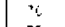 & \\
\hline$\therefore \& 1$ & GRAHITE, & 2 & 2 & 1 & 2 & MU & & & & & 310 & צ & \\
\hline$\therefore 80$ & GRAMI IE & ? & 2 & 2 & 2 & Mu & & & & & 146 & $\Rightarrow$ & \\
\hline 3.10 & GRAKITE & i & 1 & 1 & i & no & $x c$ & Gu & .5 & NH & 300 & 29 & \\
\hline 3.23 & GRAWITE & 2 & 2 & $t$ & 3 & $*$ & & & & & 300 & 80 & \\
\hline 3.21 & GRAMITE & 1 & i & 1 & 2 & hu & $x \in E]$ & BNGL & .5 & 5 & BO & $?$ & \\
\hline 4,36 & GRAMITE & 2 & 2 & 3 & 2 & nu & & & & & 320 & QS & \\
\hline 4,63 & GRAHITE & $i$ & $=1$ & 1 & 2 & nv & $k c$ & $5 *$ & .5 & 5 & 330 & 15 & \\
\hline 5.21 & GKaHIIE & 1 & 1 & 1 & 3 & hu & $k$ & G & 1 & NH & 105 & 55 & SHEARED \\
\hline 6.01 & GKAN]TE & $i$ & 1 & 1 & 2 & Mis & $k L$ & G & .5 & AH & 105 & 30 & \\
\hline 7,27 & GRANITE & $z$ & & & & & & & & & & & \\
\hline$\therefore 45$ & GKANJTE] & 1 & 2 & & & & K & G & & & 330 & 25 & SEALEU \\
\hline 7.02 & GKANITE & 1 & i & 1 & $t$ & nu & KC & Go & .5 & HH & 280 & 36 & \\
\hline 8.21 & GKANIIE & 1 & 1 & 1 & 2 & 54 & $\mathrm{Kt}$ & GLBK & .5 & AH & 100 & bo & SHEAFEIU ANULLE $=323$ \\
\hline 6.35 & GKANITE & 2 & & & & & & & & & & & \\
\hline 8.43 & GRAMITE & 1 & 1 & 1 & 2 & su & $k$ & $8 \times 6$ & .5 & KH & 280 & 25 & \\
\hline 8.73 & GKANITE] & 1 & 1 & $i$ & 2 & hH & Kc & BKGU & .5 & HH & 210 & 50 & \\
\hline 8.79 & GKANITE & $i$ & $i$ & $i$ & & nu & KE & BKE & .5 & WH-H & 195 & 75 & \\
\hline 8.92 & GRAHITE & 1 & 1 & 1 & 2 & hu & $k$ & BKG & .5 & $\mathrm{MH}$ & 205 & 45 & SHEAKEU AHGLE = 326 \\
\hline 8.99 & GRAHIIE & 1 & 1 & 3 & 2 & Su & $k$ & 3KG & .5 & MH & 115 & 75 & PAFTLY INILUCE II \\
\hline 9.12 & GKANIIE & 1 & 1 & 3 & 2 & su & $k$ & BKG & .5 & NH & 170 & 70 & FAKTLY INLIULEW \\
\hline 9.21 & GRANITE & 1 & 1 & 1 & 1 & กט & KCE & BKUE & .5 & WHH-H & 275 & 25 & \\
\hline 9.37 & GRAMITE & $i$ & 1 & 1 & 1 & su & $k[$ & BKG & .5 & NH & 65 & 50 & SHEAFE $\triangle$ ANGLE $=335$ \\
\hline 9.54 & GRANITE & 1 & i & 1 & $i$ & nu & KC & UKEV & .5 & $\mathrm{HH}$ & 65 & 55 & SHEAKE $\mathrm{I}=335$ \\
\hline 9.85 & GRAMBTE & 1 & 1 & 1 & 2 & su & $k E$ & BKG & .5 & NH & 270 & 75 & \\
\hline 9.86 & GRANITE & 1 & 1 & 1 & 2 & su & $k C$ & BKL & .5 & MH & 115 & 55 & \\
\hline 9.98 & GRANITE & 1 & 1 & $t$ & $i$ & nu & KE & BKG & .5 & $\mathrm{KH}+\mathrm{H}$ & 170 & 25 & PAKTLY SEALED \\
\hline 10.25 & GRANITE & 2 & & & & & & & & & & & \\
\hline 10.27 & GRAHITE & 2 & & & & & & & & & & & \\
\hline 10.40 & GRAMITE & 1 & 1 & 1 & 1 & su & KE & BKG & .5 & HH-H & 80 & 30 & SOHE FEGMATITE \\
\hline 10.56 & GRANITE] & 1 & 1 & 3 & 3 & su & $k$ & DKG & .5 & HH & 220 & 10 & \\
\hline 10.66 & URANITE & 1 & 1 & 1 & 3 & su & Kn & BKGW & .5 & KH-S & 340 & +5 & \\
\hline 10.70 & GRAMITE & 1 & 2 & & & & $k$ & Bk & & & & & FR. 20 OME $10.68-10.25$ \\
\hline 10.87 & GRAKITE & 2 & & & & & & & & & & & \\
\hline 11.10 & GRAMITE & 2 & & & & & & & & & & & \\
\hline $\begin{array}{l}11.44 \\
11.77\end{array}$ & GRAHITA & 2 & & & & & & & & & & & ENU OF HOLE \\
\hline
\end{tabular}




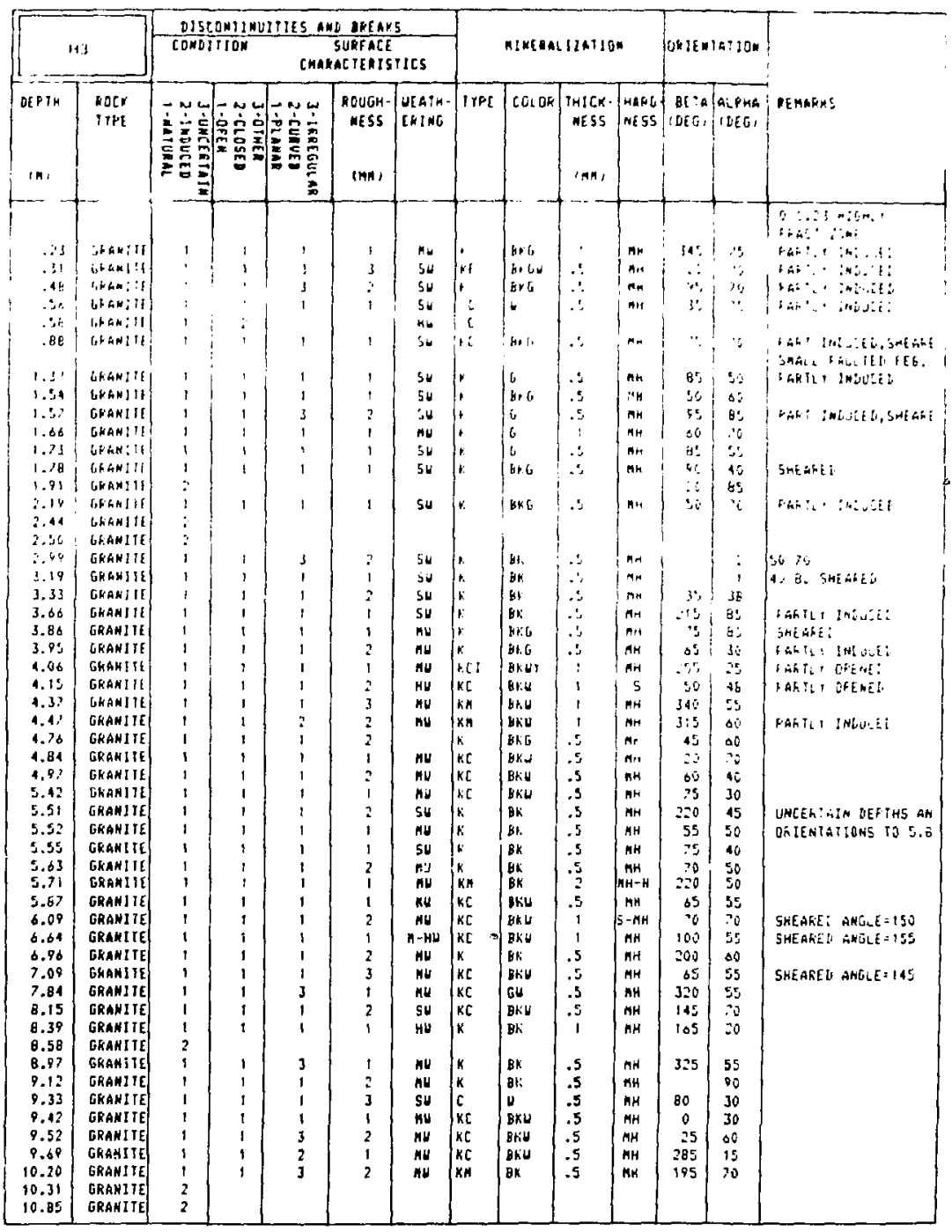




\begin{tabular}{|c|c|c|c|c|c|c|c|c|c|c|c|c|c|}
\hline \multicolumn{2}{|c|}{$+i 4$} & \multicolumn{5}{|c|}{$\frac{\text { DISCONIINULiIES AMV OREAKS }}{\text { CONDITION }}$} & \multicolumn{4}{|c|}{ MI HERALIZATTOON } & \multicolumn{2}{|c|}{ LOF IENTATION } & \multirow[b]{2}{*}{ REMAKKS } \\
\hline DEPTH & $\begin{array}{l}\text { ROCK } \\
\text { IIPE }\end{array}$ & 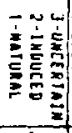 & 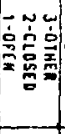 & 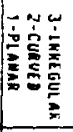 & $\begin{array}{l}\text { ROUGH- } \\
\text { NESS }\end{array}$ & WEATH & IYPE & COLOF & $\begin{array}{l}\text { THICK- } \\
\text { WESS }\end{array}$ & $\begin{array}{l}\text { Haht } \\
\text { MESS }\end{array}$ & 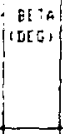 & $\begin{array}{l}\text { ALFHA } \\
\mid \text { DEGI }\end{array}$ & \\
\hline$b=$ & & 3 & & & & & & & & & & & \\
\hline$\therefore$ & Uhaw: T! & 3 & & $:$ & 3 & 56 & 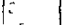 & b. & $\therefore$ & Mи & $2: 4$ & of & \\
\hline$\because$ & than: $E$ & 1 & 1 & $\cdot$ & $:$ & $5-n_{b}$ & 10 & ist & $\therefore$ & ar & $8:$ & $a$ & SHTAFE I $b=135$ \\
\hline$\therefore 8$ & Gothiti & $\vdots$ & 1 & 1 & 1 & nu & $1+i$ & Hit. & $\therefore$ & nte & 10 & 3 & FAFTL, INDUCED \\
\hline$\therefore \therefore$ & $\begin{array}{l}\text { linatits } \\
\text { gingutitis }\end{array}$ & $i$ & 1 & 1 & : & nu & $1 i$ & Ex & .3 & $\operatorname{An}$ & $30:$ & $1:$ & 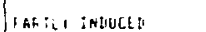 \\
\hline$\therefore t$ & Gret: : & 1 & 1 & $t$ & 3 & nu & 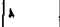 & DE: & .3 & $\mathrm{AH}$ & $18:$ & d & rakil, IN DUECE! \\
\hline $1.7 *$ & Gfak! i & $?$ & & & & & & & & & & & \\
\hline 1.74 & Letolit & 2 & & & & & & & & & & & \\
\hline 3.34 & Cinand Ti & 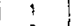 & ! & $t$ & ; & at & $\times 5$ & Hed & .5 & AH & 125 & EU & HGHIL :HUUEE: \\
\hline 3.14 & CFightile & 2 & & & & & & & & & & & \\
\hline 2.25 & GFANITE & $=$ & & & & & & & & & & & \\
\hline $3.4 t$ & GKAH:TE & 2 & & & & & & & & & & & \\
\hline 3.95 & GRAW!TI & 1 & 1 & $t$ & 1 & 54 & $k[$ & Bi: & .5 & ntr & 100 & 45 & \\
\hline+.22 & Gunallit & 1 & 1 & 1 & 1 & Ha & $n c 1 \pi$ & $\begin{array}{ll}5 \\
a\end{array}$ & 3 & $5-M_{n}$ & IDS & 20 & SHEAKE \\
\hline 4.37 & GKanile & 1 & 1 & 1 & 3 & in & $K C$ & BR:GU & 1 & Nin & 335 & 70 & \\
\hline 4.69 & GEAW:TE & 2 & & & & & & & & & & & \\
\hline 4.85 & GKhN: TE & 1 & 1 & 1 & 1 & HL & $r$ & bl: & 10 & $S-\pi H$ & 290 & 2ir & $\begin{array}{l}\text { SHEGKED } \\
\text { FF.2DNE } 0.69 .4 .89\end{array}$ \\
\hline 5.21 & Gian] & 1 & 1 & 3 & 3 & 54 & i. & EKU & .5 & AH & 345 & 70 & \\
\hline 5.56 & GKaWlite & $i$ & 1 & i & $i$ & 5 & h [ & Bría & .5 & $\mathrm{nk}$ & 310 & ES & BHEAKEO $\$=1 . \bar{O}$ \\
\hline 5.97 & GESNIIE & 1 & 1 & $\mathbf{i}$ & 2 & Sid & $1 \mathrm{C}$ & ERG & .5 & HH & 50 & 80 & $5 \mathrm{HEAFEl} \quad \mathrm{H}=150$ \\
\hline 0.36 & GKANITE & 1 & 1 & 1 & 2 & su & $k$ & blig & $\therefore$ & $M H$ & 220 & 50 & FAKT JHIULEF \\
\hline 0.26 & GRANITE & 2 & & & & & & & & & & & \\
\hline 6.10 & GFAHITE & 1 & 1 & 1 & 1 & SW & $k$ & $61: 6$ & 1.5 & nH & 15 & 13 & SHEAFEU, FAFT IHJUCEU \\
\hline 0.14 & GZANITE & 1 & 1 & : & 3 & SH & kic & Ghigy & .5 & $\mathrm{AHH}$ & 25 & 80 & SHEAFED E $=170$ \\
\hline 0.72 & GFGAIIE & 1 & 1 & 1 & 3 & 54 & $k=$ & Bkus & .5 & $\mathrm{Mm}$ & Ps & 78 & SHEAFEJ \\
\hline $0.8 \mathrm{i}$ & GKGHITE & 1 & $t$ & 2 & 1 & nu & $K E$ & GN & 1 & $\mathrm{MH}$ & 290 & 22 & \\
\hline 7.13 & GKANITE & 2 & & & & & & & & & 80 & 88 & \\
\hline 7.23 & GKANITE & 1 & 1 & 3 & 1 & Al & $\mu C$ & 6 & $\therefore$ & $\mathrm{HH}$ & 300 & 30 & \\
\hline 7.47 & GKAHITE & 1 & 1 & 2 & 2 & SU & i.c & BKG & .5 & Nili & 10 & 85 & SHEAKE [ $B=160$ \\
\hline 7.51 & GKANITE & 1 & 1 & 1 & 2 & $5 \psi$ & k. & WNE & .5 & AH & 270 & 25 & \\
\hline 8.23 & GKAHIYE & 1 & 1 & 1 & 3 & Si & KCH & DKG & .5 & $\mathrm{HH}$ & 195 & Eo & \\
\hline 8.50 & GRANIIE & $i$ & 1 & 3 & 2 & SH & $k$ & BKG & .5 & hK & 320 & 30 & PAF: IMUULELU \\
\hline 0.82 & GKANI IE & 1 & 1 & $t$ & 2 & SH & $k$ & EKG & .5 & HH & 330 & 35 & SHEAAE I $E=120$ \\
\hline 9.12 & GKANITE & 1 & 1 & 1 & 1 & SW & $k$ & $B K^{\prime} G$ & .5 & HH & 240 & 12 & \\
\hline 9.32 & GRAHITE & 1 & 1 & 1 & 2 & HU & CE & EKWE & 3 & HH-H & 215 & 33 & \\
\hline 9.59 & GRAHITE & 1 & 1 & 1 & 2 & $5 v$ & $K C$ & on & .5 & HH & 210 & 55 & \\
\hline 9.95 & GKANIIE & 1 & 1 & 1 & 2 & MU & $K C$ & Gu & 1 & $\mathrm{HH}$ & 285 & 22 & \\
\hline 10.21 & Dratite & 1 & 1 & 3 & 2 & SH & $k C$ & 66 & .5 & HH & 300 & 15 & PARTLY CLOSED \\
\hline
\end{tabular}




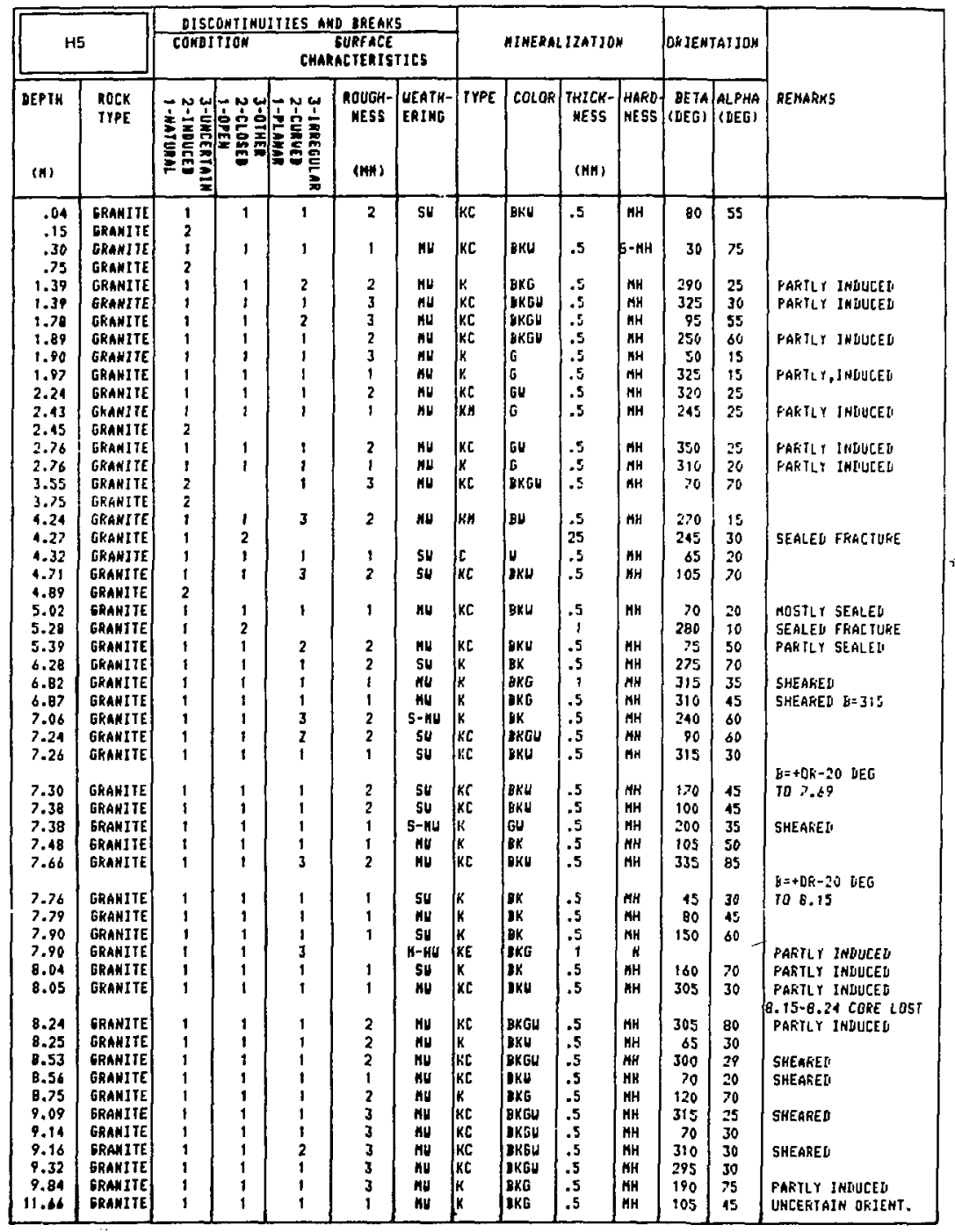




\begin{tabular}{|c|c|c|c|c|c|c|c|c|c|c|c|c|c|}
\hline \multicolumn{2}{|c|}{ H6 } & \multicolumn{5}{|c|}{$\frac{\text { DISCONTJUUTTIES AND MREAKS }}{\text { CONDITIOA }} \frac{\text { SUAFACE }}{\text { CHARACTERISTICS }}$} & \multicolumn{4}{|c|}{ MIMERALIZATIOH } & \multicolumn{2}{|c|}{ ORIEHTATION } & \multirow[b]{2}{*}{ REMARKS } \\
\hline DEPTH & $\begin{array}{l}\text { ROCK } \\
\text { TrPE }\end{array}$ & 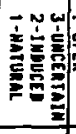 & & 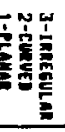 & $\begin{array}{l}\text { ROUGH- } \\
\text { HESS }\end{array}$ & $\begin{array}{l}\text { WEATH- } \\
\text { ERINE }\end{array}$ & IYPE & COLOR & $\left\{\begin{array}{c}\text { THICK- } \\
\text { MESS } \\
\text { (NA) }\end{array}\right.$ & - $\begin{array}{l}\text { HARD } \\
\text { HESS }\end{array}$ & $\begin{array}{c}\text { DETA } \\
\text { (DEG) }\end{array}$ & $\begin{array}{l}\text { ALPHA } \\
\text { (DEG) }\end{array}$ & \\
\hline .10 & GRAMIIE & 1 & 1 & 3 & 1 & HW & $k$ & G & 1 & $\mathbf{5}$ & 55 & 65 & $1 / 2$ OFEWES BY HAMG \\
\hline .29 & GRANITE & $i$ & 1 & i & 2 & HW & $k$ & 6 & .5 & $\mathbf{s}$ & 40 & 70 & SHEARED \\
\hline .39 & GRAMIIE & $i$ & 1 & 1 & 1 & HW & $k$ & 0 & .5 & $s$ & 335 & 55 & \\
\hline .52 & GRAMITE & 1 & 1 & 1 & 1 & HU & k & b & .5 & $\mathbf{s}$ & 335 & 55 & \\
\hline .69 & GRAMITE] & 1 & 1 & 1 & 2 & mu & $k$ & E & .5 & s & 10 & 70 & \\
\hline 3 & GRANITE & 1 & 1 & 1 & 1 & HU & kL & 6U & 1 & 5 & & 79 & \\
\hline 1.08 & GRANITE & 1 & 1 & 2 & 1 & HU & $k$ & 0 & .5 & s & & 80 & \\
\hline 1.18 & GRANITE & 1 & 1 & 1 & 1 & HU & $k$ & 0 & .5 & 5 & & 67 & FAFTLY INDUCED \\
\hline 1.49 & ERANITE & 1 & 1 & 1 & 1 & nU & KC & GU & .5 & $\mathbf{s}$ & & 85 & \\
\hline 1.58 & GRANITE & 1 & 1 & J & 1 & HI & KC & Gy & .5 & $\mathbf{s}$ & & 75 & \\
\hline 1.64 & GRANITE & 1 & 1 & 3 & 1 & 46 & KC & bu & .5 & $\mathbf{s}$ & & 75 & \\
\hline 2.24 & GRAMUTE, & 1 & 1 & i & 2 & NU & $k$ & 0 & .5 & $\mathbf{s}$ & & 60 & \\
\hline 2.48 & GRANITE & 1 & 1 & J & 1 & HU & KC & G & .5 & $\mathbf{s}$ & & 65 & \\
\hline 2.97 & GRAMITE & 1 & 1 & 2 & 1 & MU & $k$ & 6 & .5 & $\mathbf{s}$ & & 50 & \\
\hline 2.24 & GRANITE & 1 & 1 & 3 & 2 & $\mathrm{ML}$ & $k$ & 0 & .5 & $\mathbf{s}$ & & 60 & \\
\hline 2.48 & GRAMITE & 1 & 1 & 3 & 1 & HU & KC & 64 & .5 & 5 & & 65 & \\
\hline 2.77 & GRAKITE & 1 & 1 & 2 & 1 & nu & r. & 6 & .5 & s & & so & \\
\hline 3.18 & GRANITE & 1 & 1 & 3 & 1 & HU & $k C$ & 64 & .5 & 5 & & 65 & \\
\hline 4.15 & GRAHITE & 1 & 1 & 3 & 1 & HW & $k C$ & GU & .5 & $\mathbf{s}$ & & & SHEARE I \\
\hline 4.38 & GRAWITE & $t$ & 1 & $i$ & 1 & Hy & KE & Iikg & 2 & HH & 90 & 55 & SHEAKED \\
\hline 4.50 & GRAHITE & 1 & 1 & $\mathbf{J}$ & 2 & I & KCF & BKG & 1 & HH & 80 & 80 & 2 SHEARED FF, $\quad B I=60$ \\
\hline 4.51 & GKAMITE & 1 & 1 & 3 & 2 & Al & KC & BW & & & 190 & 40 & $A 1=80 ; B 2=190, A 2=10$ \\
\hline 4.65 & GRAHITE & 1 & 1 & 1 & 2 & 5-4U & kC & BKGU & 1 & ин & 100 & do & SHEARED \\
\hline 1.72 & GRAWITE & 1 & 1 & 2 & 2 & מע & KC & JKGL & 1 & HH & 90 & Bo & SHEAKE U \\
\hline 5.19 & GRAWITE & 1 & 1 & 2 & 2 & nu & KC & JKG & 1 & MH & 120 & 55 & \\
\hline 5.30 & GRaWJiE & 1 & 1 & 1 & 1 & HW & KC & Jjkging & 2 & HH & 100 & 65 & \\
\hline $5.5 t$ & GRANIIE & & & & & & & & & & & & FR.2ONE 5.51-.77 \\
\hline 5.77 & GRANIIE & 2 & & & & & & & & & & & \\
\hline 6.09 & GRAHITE & 2 & & & & & & & & & & & RUDBLE TO 6.2 \\
\hline 6.25 & GRAKITE & 1 & 1 & 1 & $?$ & nu & $\left.\right|_{X C} ^{X C}$ & $\int_{0}^{3 K G}$ & $\cdot 3$ & HH & 120 & 80 & \\
\hline 6.61 & GRANITE & 1 & 1 & $\begin{array}{l}1 \\
2\end{array}$ & 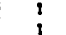 & mo & KC & 16 & $\begin{array}{l}2 \\
1\end{array}$ & $\begin{array}{l}\text { MH } \\
\text { HH }\end{array}$ & 65 & 80 & \\
\hline 6.92 & GRAMITE & 1 & 1 & 2 & 1 & wa & $x_{n e}^{x}$ & 6 & $\mathbf{1}$ & $\begin{array}{l}\mathrm{HH} \\
\mathrm{HH}\end{array}$ & 0 & 85 & SHEARED, PART INDUCE \\
\hline $\begin{array}{l}7.04 \\
7.16\end{array}$ & $\begin{array}{l}\text { GRANITE } \\
\text { GRANITE }\end{array}$ & 1 & $i$ & i & $\vdots$ & WH & $\begin{array}{l}k 6 \\
k\end{array}$ & $a_{0}^{64}$ & .5 & $\begin{array}{l}\text { AH } \\
\text { HH }\end{array}$ & $\begin{array}{l}170 \\
265\end{array}$ & $\begin{array}{l}2.7 \\
70\end{array}$ & PARTL: IMDUCEU \\
\hline 7.48 & GRAMIIE & 1 & & & & & & & & & & & PERCUS. HOLE IN CORE \\
\hline 7.55 & GRAHIIE & 1 & 1 & 3 & 2 & su & $k c$ & IXKG & .5 & HH & 150 & 32 & \\
\hline 7.61 & GRAHIIE & 1 & 1 & I & 1 & su & KC & GW & .5 & MH & 95 & 25 & \\
\hline 7.66 & GRAHITE & 1 & 1 & 1 & 2 & 5u & KC & IKGU & .5 & HH & 295 & 50 & \\
\hline 8.12 & GRAHITE & 1 & 1 & 1 & 3 & nu & $k c$ & DKeU & 1 & HH & 35 & 75 & \\
\hline 8.19 & GRAHITE & I & 1 & 1 & 2 & SU & KC & IKGU & .5 & & 270 & 9 & \\
\hline $\begin{array}{l}8.36 \\
8.51\end{array}$ & GRAHITE & 1 & 1 & 2 & 2 & 5H & $\mathrm{xC}_{\mathrm{c}}$ & 6U & .5 & МH & 210 & 75 & \\
\hline $\begin{array}{l}8.51 \\
8.60\end{array}$ & $\begin{array}{l}\text { GRANITE: } \\
\text { GRANITE }\end{array}$ & i & 2 & & & & la & & $\begin{array}{l}20 \\
20\end{array}$ & & & & $\begin{array}{l}\text { UEATHERE I CALCIIE } \\
\text { UEATHEREI CALCITE }\end{array}$ \\
\hline 0.64 & GRANITE & $i$ & 1 & 1 & 2 & 5u & KCEF & Bkag & .5 & HH-H & 25 & 85 & $\begin{array}{l}\text { SHEARED SEVERAL } \\
\text { UEATHERED CALCITE } \\
\text { FRAC TURES }\end{array}$ \\
\hline 9.10 & GRAHITE & $\mathbf{I}$ & 1 & 1 & 1 & Nat & KC & 6u & 1 & MH & 10 & 85 & \\
\hline 9.32 & GRAMITE & 1 & 1 & 1 & 1 & no & $k$ & 6 & 1 & HA & 195 & 15 & \\
\hline & & & & & & & & & & & & & $\begin{array}{l}\text { 9.70-0.90 SEVERML } \\
\text { EF IDOTi-SEALEI FRAC }\end{array}$ \\
\hline 9.90 & GRAMITE & 2 & & & & & & & & & & & \\
\hline 9.99 & GRAMITE & 1 & $\mathbf{I}$ & 1 & 2 & su & c1 & $\boldsymbol{U}$ & .5 & HH & 00 & Bo & \\
\hline 10.10 & GRAHITE & 2 & & & & & & & & & & & \\
\hline $\begin{array}{l}10.20 \\
10.19\end{array}$ & GRAMITE & 1 & 1 & 3 & 2 & SII & K & BK & .5 & HI & 170 & 50 & \\
\hline $\begin{array}{l}10.49 \\
10.69\end{array}$ & $\begin{array}{l}\text { GRAWITE } \\
\text { GRAKITE }\end{array}$ & $i$ & 1 & 1 & 1 & su & KC & DKG & .5 & MH & 195 & 40 & \\
\hline
\end{tabular}




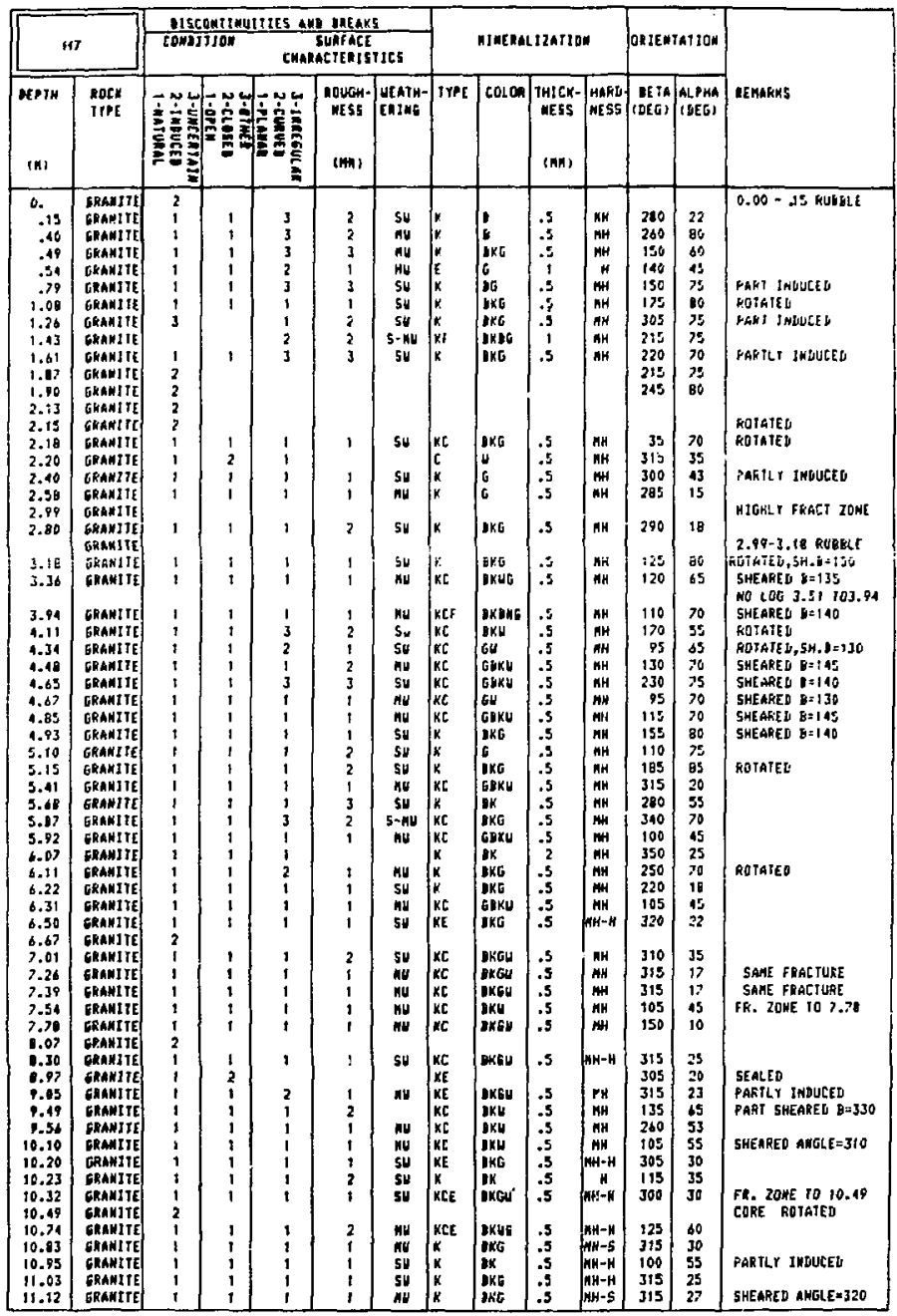




\begin{tabular}{|c|c|c|c|c|c|c|c|c|c|c|c|c|c|}
\hline \multicolumn{2}{|c|}{18} & \multicolumn{5}{|c|}{$\frac{\text { DISCONTIWUITIES AMD LREAKS }}{\text { COMDITIOH }}$} & \multicolumn{4}{|c|}{ MIKERAL ITATIOH } & \multicolumn{2}{|c|}{ ORIENTATIOH } & \multirow[b]{2}{*}{ REKARKS } \\
\hline IH: & $\begin{array}{l}\text { ROCK } \\
\text { TYPE }\end{array}$ & 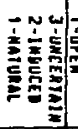 & 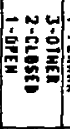 & 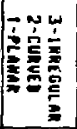 & $\begin{array}{c}\text { RDUGH- } \\
\text { NESS }\end{array}$ & $\begin{array}{l}\text { UEATH- } \\
\text { ERIHE }\end{array}$ & TYPE & COLOR & $\begin{array}{c}\text { THICK- } \\
\text { HESS }\end{array}$ & $\begin{array}{l}\text { HARES } \\
\text { NESS }\end{array}$ & $\begin{array}{c}\text { AETA } \\
\text { (DEG) }\end{array}$ & $\begin{array}{l}\text { ALPHA } \\
\text { (DEG) }\end{array}$ & \\
\hline 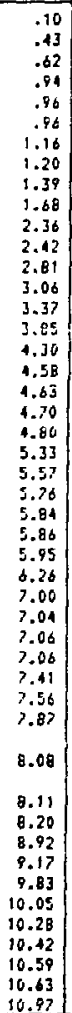 & 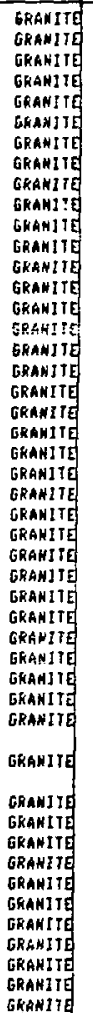 & $\begin{array}{l}1 \\
1 \\
1 \\
1 \\
1 \\
1 \\
1 \\
1 \\
2 \\
1 \\
1 \\
1 \\
1 \\
1 \\
3 \\
2 \\
1 \\
1 \\
1 \\
1 \\
1 \\
1 \\
1 \\
1 \\
1 \\
1 \\
2 \\
2 \\
2 \\
2 \\
1\end{array}$ & $\begin{array}{l}1 \\
1 \\
1 \\
1 \\
1 \\
1 \\
1 \\
1 \\
1\end{array}$ & $\begin{array}{l}1 \\
3 \\
1 \\
1 \\
2 \\
2 \\
1 \\
1 \\
3\end{array}$ & $\begin{array}{l}3 \\
3 \\
3 \\
1 \\
1 \\
2 \\
2 \\
1 \\
3\end{array}$ & 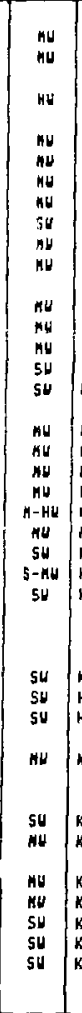 & $\begin{array}{l}K \\
K C \\
E \\
C \\
K E \\
K C \\
K C \\
K C \\
K \\
K C \\
K C \\
K C \\
K \\
K \\
K C \\
K C \\
K C \\
K C \\
K C \\
K C \\
K C \\
K C \\
K C \\
K C \\
K C \\
K C \\
K C \\
K C\end{array}$ & 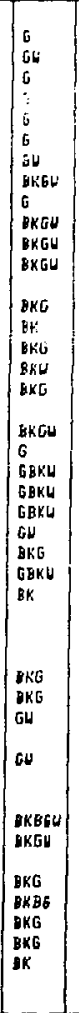 & \begin{tabular}{|c}
1 \\
1 \\
1 \\
1 \\
1 \\
2 \\
1 \\
.5 \\
1 \\
1 \\
2 \\
1 \\
1 \\
.5 \\
.5 \\
1 \\
1 \\
1 \\
.5 \\
2 \\
3 \\
.5 \\
.5 \\
.5
\end{tabular} & $\begin{array}{c}\mathrm{NH} \\
\mathrm{HH} \\
\mathrm{H} \\
\mathrm{H} \\
\mathrm{HH} \\
\mathrm{HH} \\
\mathrm{S}-\mathrm{MH} \\
\mathrm{KH} \\
\mathrm{HH} \\
\mathrm{HH} \\
\mathrm{HH} \\
\mathrm{HH} \\
\mathrm{HH} \\
\mathrm{HH} \\
\mathrm{HH} \\
\mathrm{HH} \\
\mathrm{KH} \\
\mathrm{HH} \\
\mathrm{HH} \\
\mathrm{NH} \\
\mathrm{HH} \\
\mathrm{NH} \\
\mathrm{NH} \\
\mathrm{HH} \\
\mathrm{HH}\end{array}$ & $\begin{array}{r}285 \\
325 \\
200 \\
170 \\
0 \\
0 \\
20 \\
195 \\
170 \\
147 \\
75 \\
170 \\
310 \\
65 \\
60 \\
270 \\
270 \\
310 \\
320 \\
75 \\
260 \\
220 \\
230 \\
115 \\
80 \\
180\end{array}$ & $\begin{array}{r}75 \\
5 \\
28 \\
55 \\
35 \\
35 \\
20 \\
35 \\
30 \\
65 \\
30 \\
\\
80 \\
55 \\
50 \\
15 \\
20 \\
55 \\
10 \\
20 \\
42 \\
50 \\
33 \\
25 \\
50 \\
47 \\
10\end{array}$ & $\begin{array}{l}\text { PAFTLY INIUUCED } \\
\text { PARTLY INDUCED; } \\
\text { SHEAFEI } \\
\text { PARTLY INULCED; } \\
\text { SHEAREU }\end{array}$ \\
\hline
\end{tabular}




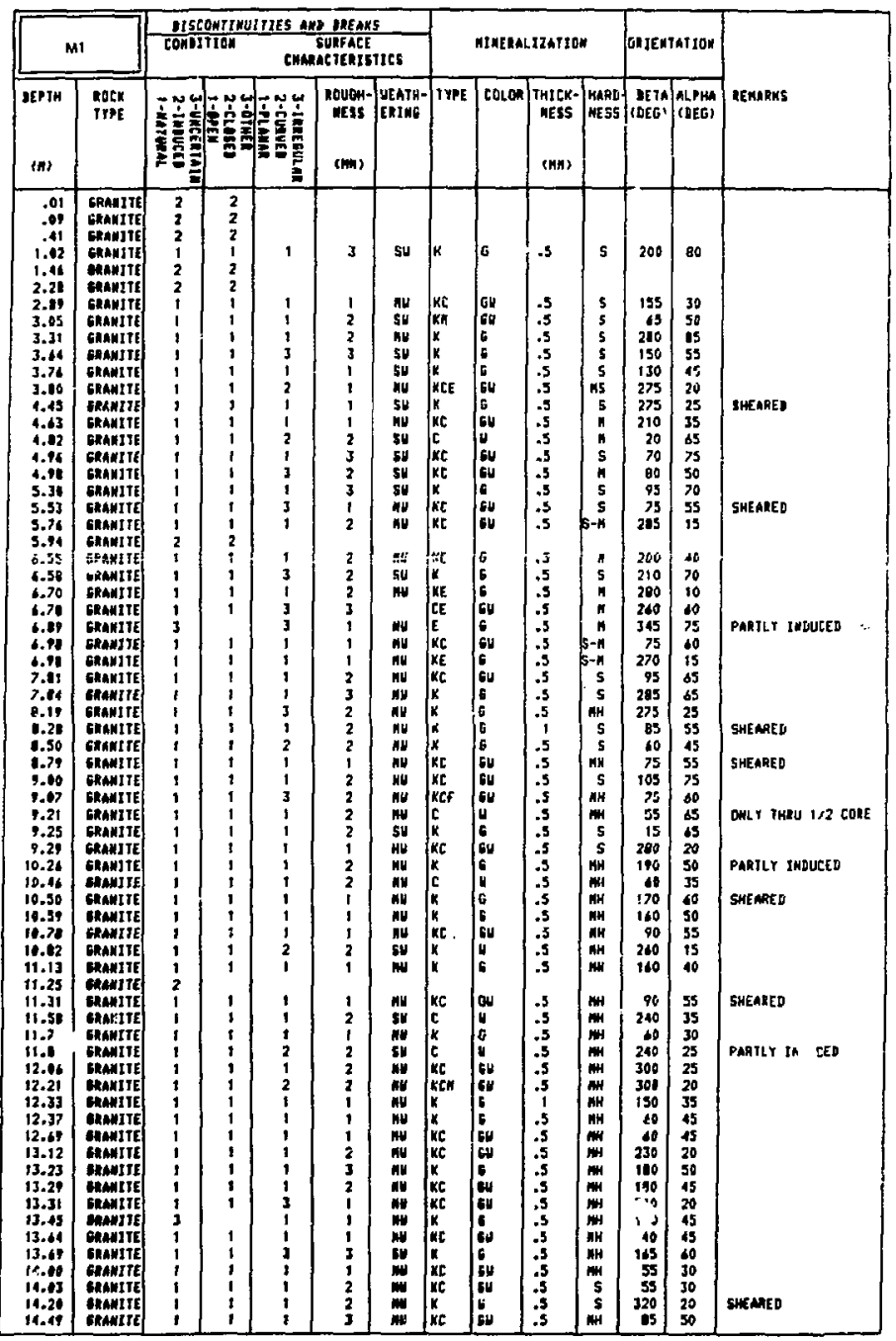




\begin{tabular}{|c|c|c|c|c|c|c|c|c|c|c|c|c|c|}
\hline \multicolumn{2}{|c|}{$M 2$} & \multicolumn{5}{|c|}{$\frac{\text { DJSCONTINUITIES AND IAEAKS }}{\text { CONDJJIOA }}$} & \multicolumn{4}{|c|}{ MIHERALIZATIOH } & \multicolumn{2}{|c|}{ DRIENTATION } & \multirow[b]{2}{*}{ IERARKS } \\
\hline (M) & $\begin{array}{l}\text { ROCK } \\
\text { TYPE }\end{array}$ & 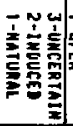 & 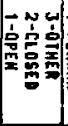 & 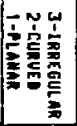 & $\begin{array}{c}\text { ROUGH- } \\
\text { HESS }\end{array}$ & $\begin{array}{l}\text { UEATH- } \\
\text { ERIMG }\end{array}$ & IYPE & COLOR & $\begin{array}{c}\text { THICK- } \\
\text { NESS } \\
\text { (NK) }\end{array}$ & HARI & $=\begin{array}{c}\text { DETA } \\
(D E G)\end{array}$ & $\begin{array}{l}\text { ALPHA } \\
\text { SDEGI }\end{array}$ & \\
\hline $\begin{array}{l}.08 \\
.24 \\
.61 \\
.70 \\
1.38 \\
1.43 \\
1.59 \\
2.73 \\
2.83 \\
3.06 \\
3.23 \\
3.25 \\
3.41 \\
3.77 \\
4.14 \\
4.24 \\
4.70 \\
4.71 \\
4.99 \\
5.50 \\
5.75 \\
5.81 \\
5.81 \\
5.98 \\
5.59 \\
6.13 \\
6.27 \\
6.58 \\
6.59 \\
6.75 \\
6.83 \\
6.87 \\
6.89 \\
6.91 \\
6.91 \\
6.93 \\
7.03 \\
7.03 \\
7.14 \\
7.15 \\
7.37 \\
7.59 \\
7.93 \\
8.21 \\
8.21 \\
8.49\end{array}$ & 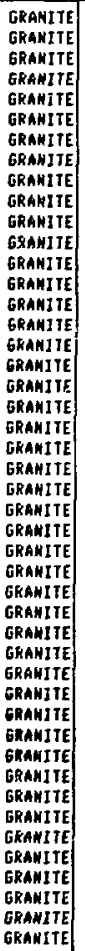 & $\begin{array}{l}2 \\
2 \\
1 \\
2 \\
1 \\
2 \\
1 \\
1 \\
1 \\
1 \\
1 \\
1 \\
1 \\
1 \\
1 \\
2 \\
1 \\
1 \\
1 \\
1 \\
2 \\
1 \\
1 \\
1 \\
1 \\
2 \\
1 \\
2 \\
1 \\
1\end{array}$ & $\begin{array}{l}2 \\
2 \\
1 \\
2 \\
1 \\
2 \\
1 \\
1 \\
1 \\
1 \\
1 \\
1 \\
1 \\
1 \\
1 \\
1 \\
1 \\
2 \\
1 \\
1 \\
1 \\
1 \\
1 \\
2 \\
1 \\
1\end{array}$ & $\begin{array}{l}1 \\
1 \\
3 \\
1 \\
3 \\
2 \\
2 \\
1 \\
1 \\
3 \\
2 \\
1 \\
1 \\
1\end{array}$ & $\begin{array}{l}2 \\
2 \\
4 \\
1 \\
2 \\
2 \\
2 \\
2 \\
1 \\
2\end{array}$ & $\begin{array}{l}\text { GU } \\
\text { SU } \\
\text { SU } \\
\text { HU } \\
\text { SU } \\
\text { HU } \\
\text { NU } \\
\text { SU } \\
\text { Wu }\end{array}$ & $\begin{array}{l}E \\
C \\
K \\
K \\
E \\
K C \\
K C \\
K C \\
\\
E \\
K \\
K \\
K C \\
C \\
C \\
K \\
K C \\
K \\
K \\
K C \\
K C \\
K C \\
K C \\
K\end{array}$ & $\begin{array}{l}60 \\
6 \\
6 \\
6 \\
0 \\
4 \\
6 \\
6 \\
6 \\
64 \\
64 \\
84 \\
6 \\
6 \\
64 \\
4 \\
4 \\
6 \\
64 \\
6 \\
6 \\
60 \\
60 \\
64 \\
6\end{array}$ & $\begin{array}{l}.5 \\
.5 \\
.5 \\
.5 \\
.5 \\
.5 \\
.5 \\
.5 \\
20 \\
.5 \\
.5 \\
.5 \\
.5 \\
.5 \\
.5 \\
.5 \\
.5 \\
.5 \\
.5 \\
1 \\
.5 \\
.5 \\
.5 \\
.5 \\
1\end{array}$ & $\begin{array}{r}5 \\
5 \\
n \\
5 \\
5 \\
5-H \\
n+1 \\
n H \\
5 \\
5 \\
5 \\
n H \\
n+1 \\
5 \\
\text { HN } \\
5\end{array}$ & $\begin{array}{r}45 \\
255 \\
60 \\
280 \\
150 \\
0 \\
100 \\
110 \\
70 \\
285 \\
160 \\
270 \\
270 \\
290 \\
330 \\
210 \\
180 \\
240 \\
180 \\
\\
300 \\
130 \\
20 \\
280 \\
350 \\
275 \\
35 \\
80 \\
100 \\
280 \\
250 \\
360 \\
25 \\
300 \\
\end{array}$ & $\begin{array}{l}65 \\
60 \\
20 \\
85 \\
85 \\
85 \\
20 \\
50 \\
40 \\
15 \\
\\
60 \\
20 \\
40 \\
50 \\
40 \\
10 \\
45 \\
25 \\
30 \\
30 \\
5 \\
10 \\
30 \\
15 \\
90 \\
10 \\
50 \\
35 \\
30 \\
25 \\
20 \\
60\end{array}$ & $\begin{array}{l}\text { SEALED EF ZONE } \\
\text { MAHY FR, } 6.83-6.91 \\
\text { DNEY JHRU } 1 / 2 \text { CORE } \\
\text { PARTLY JUDUCED }\end{array}$ \\
\hline
\end{tabular}




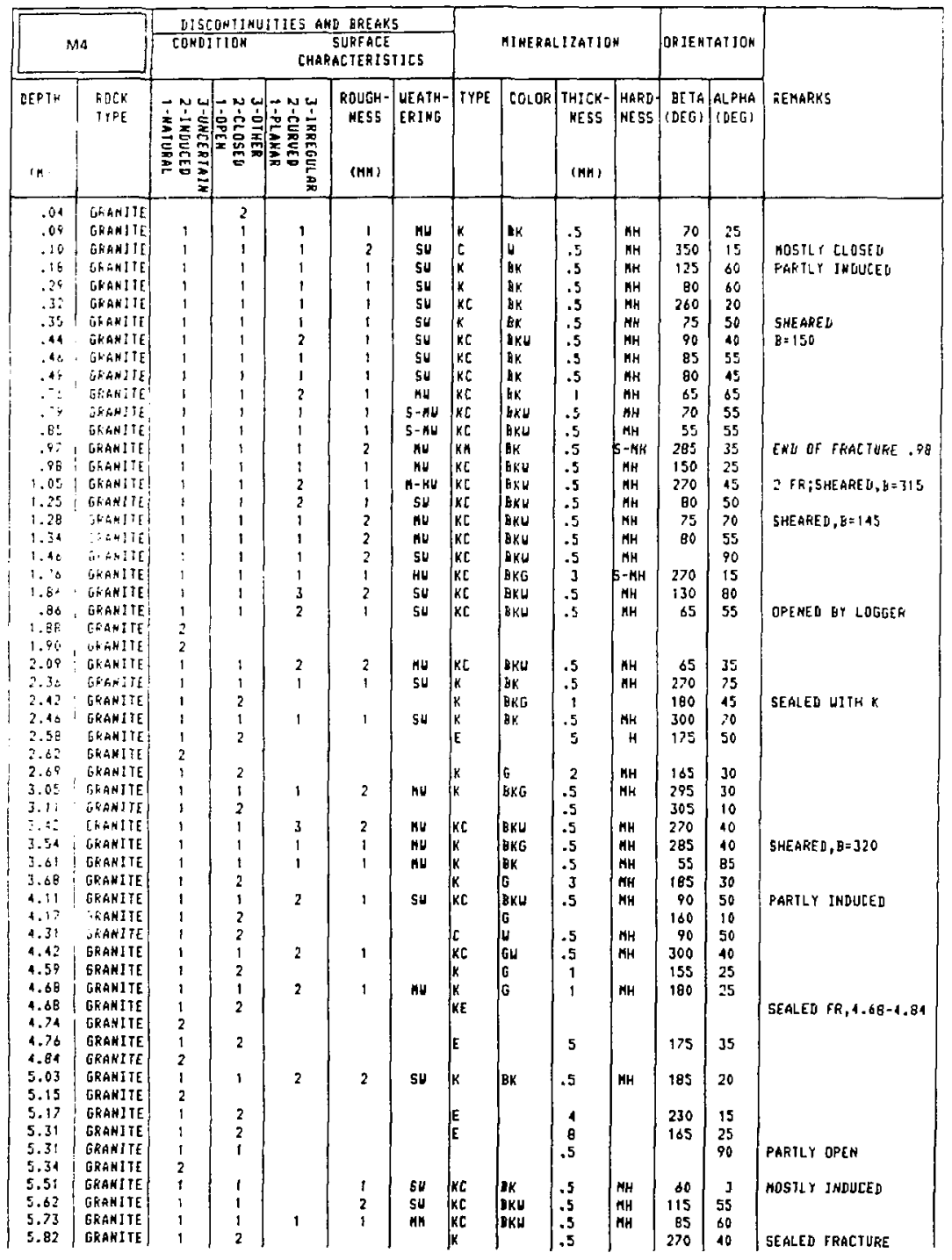




\begin{tabular}{|c|c|c|c|c|c|c|c|c|c|c|c|c|c|}
\hline \multicolumn{2}{|c|}{ his } & \multicolumn{5}{|c|}{$\begin{array}{c}\text { SURFACE } \\
\text { CDMLITION }\end{array}$} & \multicolumn{4}{|c|}{ AI HERALIZATIION } & \multicolumn{2}{|c|}{ OKIEKTATION } & \multirow[b]{2}{*}{ REMARMS } \\
\hline DEPIH & $\begin{array}{l}\text { AOCS } \\
\text { TYPE } \\
\end{array}$ & 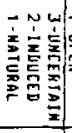 & 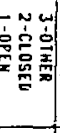 & 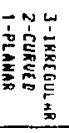 & $\begin{array}{l}\text { ROUGH- } \\
\text { MESS }\end{array}$ & $\begin{array}{l}\text { WEATH- } \\
\text { ERING }\end{array}$ & IYPS & $\cos 0 \cos ^{\prime}$ & THICK- & $\begin{array}{l}\text { HAFI } \\
\text { jEESS }\end{array}$ & $\left\{\begin{aligned} B E T A \\
(D E G)\end{aligned}\right.$ & $\begin{array}{c}\text { ALPHA } \\
\text { (IEG) }\end{array}$ & \\
\hline 5.84 & GRAKITE & 1 & 2 & & & & $\mathrm{k}$ & & .5 & & 279 & $s$ & SE PLLEU FFACTUKE \\
\hline $5.8^{4}$ & GRAMITE & 1 & $i$ & 1 & 2 & Al & $\mathrm{kc}$ & bou & .3 & ha & $B \dot{0}$ & 55 & \\
\hline 0.01 & GRANIIE & $i$ & 2 & & & & & & .5 & & $1: 5$ & 40 & Ulitk of it \\
\hline 6.18 & GRANIIE & 1 & 1 & 1 & 1 & nU & kC & ghu & .5 & MH & 250 & 78 & SHEAKES \\
\hline 0.20 & GRANITE & 1 & 1 & i & 1 & nu & $k 6$ & BKu & .5 & $\mathrm{nH}$ & Q: & 4 & SHE HAHCLI, F fiC \\
\hline 0.35 & GSANI? & . & 2 & & & & i & & 1 & & & & SLALCG FRAGTUAR \\
\hline $\begin{array}{l}6.15 \\
0.54\end{array}$ & : Grantie & 1 & 1 & $\mathbf{I}$ & 1 & su & $k$ & H. & .5 & $M H$ & $2 \mathrm{si}$ & 06 & \\
\hline 0.54 & GRANITE & 1 & 2 & & & & k & & 1 & & $1: 0$ & $a$ & $\triangle E A L E L I K, A=E S \quad \theta$ \\
\hline 1.00 & GRAMITE! & 1 & 1 & 3 & 1 & no & kic & EKW & 12 & $\mathrm{AH}_{H}$ & di & sit & \\
\hline 7.01 & GKaWIIT & 1 & $i$ & 1 & $i$ & su & $k E$ & Brigu & 1.5 & MH & 110 & as & \\
\hline 7.10 & I GRANITE & 1 & 1 & 1 & $:$ & su & $k \mathrm{c}$ & $E \times G$ & .5 & KH & x: & 45 & \\
\hline 7.18 & GRANITE & 1 & 1 & 2 & 1 & $s-m_{k}$ & $k[$ & BKU & $\therefore$ & NH & $9 \dot{u}$ & $4 i$ & \\
\hline $7.2 i$ & GRANIII & i & 1 & $i$ & 1 & ny & $\operatorname{lin} c$ & Bru & $\therefore$ & 5 An & Q5 & - & SHLAFE $U, \mathrm{H}=120$ \\
\hline-.31 & GRANIIE I & 1 & 2 & & & & $k$ & & & & $8:$ & $3^{x}$ & SE HLI V FFAG TUKE \\
\hline$? .35$ & GRANITE & i & $i$ & 1 & 1 & mu & KC & Bku & .3 & MN & 90 & 16 & SHEAFED, $b=105$ \\
\hline 7.48 & GRAMITE & 1 & 1 & 1 & 1 & nit & $k c$ & tent & $i$ & AH & 1.5 & a: & \\
\hline 7.51 & GRAKITE & 1 & 1 & 1 & 1 & 56 & kc & br.u & .5 & at: & $105 !$ & 5 & SREAKED $D, H=165$ \\
\hline 7.57 & GRAKITE & i & 1 & 1 & $\mathrm{i}$ & st & $\mathrm{KC}$ & FKu & .5 & $\mathrm{rH}_{\mathrm{H}}$ & $10 \%$ & 30 & \\
\hline$\therefore .65$ & GRANIIE & 1 & 1 & 1 & 1 & SW & $\mathrm{kC}$ & BriL L & .5 & HH & $: 6$ & $\therefore$ & SHEAFEO, $\mathrm{B}=1 \mathrm{\Delta O}$ \\
\hline 7.71 & GKAN:TE & 1 & 1 & 1 & 2 & St & KC & Ekw & .9 & Mn & $: 110$ & A6 & SHEAKFT, $\mathrm{E}=180$ \\
\hline 7.68 & GFanite & 1 & 1 & 2 & 1 & no & bic & itr & .5 & Nh & 1110 & is & \\
\hline 2.97 & GRAMITE & 1 & 2 & & & & k & 16 & 4 & & 326 & 05 & DEALEU EFACIUKE \\
\hline E.14 & GRAMITE & 1 & 1 & 1 & 1 & miv & $x$ & GK & .5 & AM & 105 & $\therefore$ & SHE AKE: , $F=155$ \\
\hline 8.35 & GRANITE & ; & 1 & 1 & $i$ & Au & $k$ & lok & .3 & th & 25 & $\therefore$ & \\
\hline 8.40 & JKAMITE & 1 & 1 & 1 & 1 & S-mu & knc & EKL & .5 & MH & 85 & 46 & \\
\hline 8.45 & GEAH]TE & 1 & 1 & 3 & 2 & 54 & k & Ek: & .5 & $M H$ & $\therefore$ & 120 & \\
\hline B.4: & ERAN!TE & 1 & 1 & 2 & 1 & Mis & k & Ex: & .5 & $\mathrm{AH}$ & 35 & (j) & 1 \\
\hline 8.53 & GRanite & 1 & 1 & 3 & 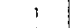 & $5 k$ & is & En & is & : m & B: & 5 & \\
\hline 601 & Gkasitic & 1 & 1 & 2 & 1 & L & kL & $B \times 54$ & .5 & an & 105 & $\because$ & SHE ARE I , $B=1: 5$ \\
\hline 8.70 & GRANIIE & 1 & 2 & & & & k & & & & & & $\begin{array}{l}\text { KANY SEALE: HSAL!; } \\
\text { G=7B-90,A=59-:: }\end{array}$ \\
\hline 8.80 & GKANITE & 1 & 1 & 3 & 2 & 50 & $k$ & B: & .5 & M & 128 & $\therefore$ & \\
\hline 8.85 & GRANIIE & 1 & 2 & & & & $k$ & & 1 & & & & $\begin{array}{l}\text { MARY SEALED FE.TLi. } \\
8, B 5-8,8 B ; \\
B=110-115, A=45-5 E\end{array}$ \\
\hline 9.43 & GRAMIIE & 1 & 1 & 1 & 1 & Sw & c & w & .5 & AH & $\therefore$ & 80 & \\
\hline Q.5t & GRANITE & 1 & 1 & 3 & 2 & si & is & lish & -5 & NH & $\varphi_{i}$ & 05 & \\
\hline 9.54 & GRAHIJE & 1 & 1 & i & 2 & su & $k$ & BK & . & kH & 4i & $\because$ & $!$ \\
\hline 9.27 & GRAHIJE & 1 & 1 & 1 & 2 & su & $k$ & ak & .5 & $\mathrm{AH}$ & 35 & 6 & $\grave{i}$ \\
\hline 10.05 & GRANITE & 2 & & & & & & & & & & & \\
\hline 10.09 & GRAN17E & 1 & 2 & & & & KE & & 1 & & go & 50 & : SEALEL FFACTURE \\
\hline 10.83 & GKaHJIE & 1 & 2 & & & & $k E$ & & 1 & & 75 & so & $\begin{array}{l}10 \text { SEALEU FFALTUKES } \\
\text { tU. } 0 \div-10.23 ; A=50-60\end{array}$ \\
\hline 10.8. & GRAHIIE & 1 & 1 & 1 & 2 & nV & $k$ & Bk & .5 & AH & 75 & 45 & \\
\hline 10.81 & GRAHITE & $i$ & i & $i$ & $i$ & ne & KC & $B K G$ & 2 & MH & 320 & 45 & SHEARE $[1, b=3: 5$ \\
\hline 11.04 & GRAHITE & 1 & $i$ & I & 1 & nN & ke & $B K H$ & .5 & $M N$ & 80 & 55 & \\
\hline $1 i .08$ & PEgKatita & & & & & & & & & & 300 & 65 & $30 \mathrm{BS}$ \\
\hline 11.12 & GRAHITE & & & & & & & & & & & & \\
\hline 11.23 & GRAKIIE & 1 & 1 & 1 & 1 & 56 & $k$ & $B k$ & .5 & $\mathrm{HH}$ & 05 & as & \\
\hline 11.30 & GKANITE & 1 & 2 & & & & E & & 1 & & 285 & 45 & I SEALED FRACTURE \\
\hline 11.46 & GKAHIIE & 1 & $i$ & 1 & 2 & H. & Kᄃ & fEKS & .5 & nH & ds & $00^{\circ}$ & \\
\hline 11.50 & GRAHIJE & 1 & 1 & 1 & 2 & su & $k$ & Bk & .5 & HA & 50 & 50 & PARTLY INDUCEU \\
\hline 11.88 & GRAMITE & 1 & 1 & 2 & 2 & HW & $k \varepsilon$ & $8 \mathrm{~kW}$ & .5 & $n H$ & 275 & 25 & \\
\hline 12.55 & GKANITE & 1 & 1 & $i$ & 2 & S-Mu & $*$ & $B K$ & .5 & nH & 320 & Bo & FARTLY INDUCED \\
\hline 12.82 & GRAHIIE & $i$ & $i$ & 1 & $i$ & nis & $\mathrm{kC}$ & BkE & .5 & HE & 75 & 70 & SHEARE $D, B=130$ \\
\hline 12.88 & GRANIIE & $i$ & 1 & 3 & 2 & ע & $\mathrm{kC}$ & $B \times H$ & 1.5 & HH & p.5 & 29 & \\
\hline 12.94 & GRAHITE & 1 & $i$ & 3 & 3 & St & $k$ & $E K^{\circ}$ & .5 & $\mathrm{HH}$ & 270 & 60 & \\
\hline 13.09 & GRAHI TE & 1 & 1 & 2 & 2 & HW & $\mathrm{k}$ & BBKG & 1 & $\mathrm{HH}$ & 285 & 30 & \\
\hline 13.58 & GRAMITE & 1 & 2 & & & & k & & 1 & & $\$ 10$ & 60 & SEALED FRAC TURE \\
\hline
\end{tabular}




\begin{tabular}{|c|c|c|c|c|c|c|c|c|c|c|c|c|c|}
\hline \multicolumn{2}{|c|}{ M5 } & \multicolumn{5}{|c|}{$\begin{array}{l}\text { COHOITION SURFACE } \\
\text { CHARACTERISTICS }\end{array}$} & \multicolumn{4}{|c|}{ MINERALIZATIOH } & \multicolumn{2}{|c|}{ DORIENTATIOH } & \multirow[b]{2}{*}{ REKARKS } \\
\hline DEPTH & $\begin{array}{l}\text { RDCK } \\
\text { TYPE }\end{array}$ & 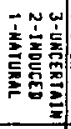 & 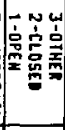 & 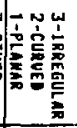 & $\begin{array}{l}\text { ROUGH- } \\
\text { HESS }\end{array}$ & $\begin{array}{l}\text { UEATH - } \\
\text { ERING }\end{array}$ & $-\int$ TYPE & COLOF & $\begin{array}{l}\text { THJCK- } \\
\text { MESS } \\
\text { (MA) }\end{array}$ & $\begin{array}{l}\text { HARU } \\
\text { NESS }\end{array}$ & $\left\{\begin{array}{r}\text { BETA } \\
\text { (DEG) }\end{array}\right.$ & $\begin{array}{l}\text { ALPHA } \\
\text { (DEG) }\end{array}$ & \\
\hline .03 & GRANITE & 3 & & $\mathbf{J}$ & 2 & Su & $x$ & BHG & $\therefore$ & $\mathbf{H H}$ & 220 & 35 & \\
\hline .13 & GRAHITE & 1 & 1 & 2 & 2 & Ku & $k$ & $2 k$ & 2 & HH & 295 & 65 & \\
\hline .56 & GRAMITE & $i$ & $i$ & 2 & 2 & $5-54$ & $k$ & $6 k$ & .5 & $\mathrm{HH}$ & 200 & 60 & \\
\hline .79 & 6RANJTE & 1 & $i$ & 1 & 2 & 54 & i & Bk & .5 & HH & 325 & 55 & \\
\hline .84 & GRANITE & 1 & 1 & 2 & 2 & SU & $k$ & EK & .5 & HH & 270 & 50 & \\
\hline .93 & $\begin{array}{l}\text { GRANITE } \\
\text { GRAHITE }\end{array}$ & 1 & & & & & & & & & 345 & 55 & \\
\hline 1.34 & GRAMITE & $i$ & 1 & 1 & 1 & HW & $\mathrm{kC}$ & BKW & .5 & MH & 180 & 2 & \\
\hline 1.52 & GRAHITE & 1 & 1 & 2 & 2 & nu & $k C$ & BKOU & .5 & HH & 215 & ts & \\
\hline 1.58 & GRANIIE & 1 & $i$ & $i$ & 2 & SU & $k$ & GK & .5 & MH & 180 & 85 & \\
\hline 1.59 & GRAHITE & $i$ & $i$ & 1 & 2 & Nu & $k$ & ok & .5 & KH & 170 & 65 & \\
\hline 1.61 & GRANIIE & 1 & 1 & 1 & 1 & ni & $k$ & BK & .5 & $\mathrm{HH}$ & 180 & 65 & SHEARE $D, B=130$ \\
\hline 1.65 & GRANITE & 1 & 1 & 1 & : & Nu & $k$ & $g K$ & .5 & HH & 190 & 50 & SHEARE $D, E=135$ \\
\hline 1.70 & GKAHITE & $t$ & 1 & 1 & 1 & ab & $x$ & BK & .5 & $\mathrm{NH}$ & 225 & 50 & $\begin{array}{l}\text { THO SUEFARALLEL } \\
\text { TRAC TURES }\end{array}$ \\
\hline 1.74 & GRAHITE & 1 & 1 & $\mathbf{1}$ & 2 & $\mathrm{HW}$ & $k$ & BKG & .5 & HH & 75 & 10 & SHEARE $D=155$ \\
\hline 1.80 & GRANITE & 1 & $i$ & $:$ & 2 & $\mathrm{HW}$ & $K$ & BK & .5 & HH & 160 & $5 n$ & \\
\hline $\begin{array}{l}2.00 \\
2.21\end{array}$ & GRAHITE & 1 & 1 & 1 & 1 & Ho & $K C$ & BK & .5 & HH & 80 & 40 & \\
\hline $\begin{array}{l}2.21 \\
2.26\end{array}$ & $\begin{array}{l}\text { GAAHITE } \\
\text { GRAN11E }\end{array}$ & $?$ & 1 & 1 & 1 & HU & K & BKG & .5 & HH & 165 & 26 & \\
\hline 2.33 & GRAWIIE & $i$ & $i$ & 3 & 2 & su & $x$ & bX & .5 & MH & 215 & 75 & \\
\hline 2.50 & GRANITE & 2 & & & & & & & & & & & \\
\hline 2.87 & GRANITE: & 1 & 1 & 1 & 1 & su & $k$ & $8 K$ & .5 & MH & 70 & 50 & \\
\hline 3.33 & GRANITE & $i$ & 1 & 2 & 2 & nu & KC & BK & 1 & MH & 315 & 45 & SHEARE $U, B=300$ \\
\hline 3.41 & GRANITE & $i$ & $i$ & 1 & 2 & nu & $k$ & $\mathrm{BK}$ & .5 & $\mathrm{MH}$ & 315 & 60 & SHEAKE $\mathrm{D}, \mathrm{B}=310$ \\
\hline 3.47 & GRANITE & $i$ & 1 & 1 & 2 & su & $k C$ & BK & .5 & NH & 65 & 40 & \\
\hline 3.54 & GRAHIIE & 1 & 1 & 2 & 1 & HU & $k$ & G & .5 & $\mathbf{H H}$ & 30 & 35 & SHEAREO $B=310$ \\
\hline 3.58 & GRANITE & 1 & 1 & 1 & 1 & SU & KC & BK & .5 & HH & 70 & 50 & \\
\hline 3.58 & GRANIYE & 1 & 1 & 2 & $i$ & 54 & $k$ & $B K$ & .5 & HH & 235 & 65 & \\
\hline 3.69 & GRANITE & 1 & 1 & 3 & & nu & $K E$ & $8 K G$ & .5 & H & 230 & 75 & PAKTLY LOST \\
\hline 3.69 & GRAKITE & 1 & 1 & 3 & 2 & su & $k$ & $B K$ & .5 & HH & & 90 & \\
\hline 3.95 & GRANITE & 1 & 1 & 1 & 1 & su & $k$ & BK & .5 & MH & 65 & 35 & PAFT INDUCED \\
\hline 4.09 & GRAHITE & 1 & 1 & 1 & 1 & nu & $K C$ & BKU & .5 & HH & 80 & 35 & SHEARED, B $=160$ \\
\hline 4.29 & GRAHITE & 1 & 1 & 1 & 2 & su & $K$ & BK & .5 & $\mathbf{M H}$ & 230 & 65 & \\
\hline $4.3:$ & BRANIJE & 9 & 1 & 1 & 1 & Su & $k$ & $B K$ & .5 & $\mathrm{HH}$ & 80 & 40 & SHEARED, $B=155$ \\
\hline 4.43 & GRANITE & 1 & 2 & & & & $k$ & & 1 & & 75 & 45 & SEALED FRAC TURE \\
\hline 4.53 & GRANITE & 1 & 2 & & & & $k$ & & $i$ & & 270 & 15 & SEALED FRACTURE \\
\hline 4.55 & GRANITE & 1 & 2 & & & & $\mathbf{k I}$ & & $i$ & & 95 & 45 & SEALED FRAC TURE \\
\hline 4.69 & GRAHITE & $i$ & 1 & $\mathbf{1}$ & 2 & su & $k$ & BK & .5 & $\mathrm{HH}$ & 250 & 65 & \\
\hline 4.70 & GKAKIIE & $i$ & $i$ & $i$ & $i$ & Sy & $k$ & BK & .5 & $\mathrm{HH}$ & 90 & 10 & \\
\hline 4.81 & GRANIIE & 1 & 1 & 2 & 1 & $\mathrm{H}-\mathrm{HN}$ & i & RU & 1 & $\mathbf{H H}$ & 35 & 75 & HICROCLJHE \\
\hline 4.88 & GRANITE & 1 & 2 & & & & E & & 2 & & 315 & 50 & SEALED FR; HICROCLIH \\
\hline 4.98 & GRAN $1 \mathrm{TE}$ & 1 & 1 & 1 & 2 & HU & $k$ & BKG & .5 & $\mathrm{HH}$ & 295 & 25 & SHE AREL, $B=0$ \\
\hline 5.07 & GRANITE & 1 & 1 & 1 & J & MU & KC & BKGU & .5 & HH & 35 & 20 & \\
\hline 5.11 & GRANITE & 1 & 1 & 1 & 1 & S-nu & $k i$ & BKU & .5 & $\mathrm{HH}$ & 85 & 40 & \\
\hline 5.11 & GRAHITE & 1 & 1 & 2 & 1 & nu & $k$ & G & .5 & MH & 360 & 50 & SHEAKE \\
\hline 5.12 & GRANITE & 1 & 1 & 1 & , & WN & $K C$ & G & .5 & $\mathrm{HH}$ & 310 & 40 & SHEAKE $\|, B=320$ \\
\hline 5.18 & GRAHITE & 1 & 1 & 1 & 2 & su & $k$ & BK & .5 & AH & 90 & & \\
\hline 5.29 & GRANITE & 1 & 1 & $i$ & 2 & 5u & KC & OKW & .5 & HH & 60 & 65 & \\
\hline 5.44 & GRANIYE & 1 & $i$ & $i$ & $i$ & sy & $x$ & JK & .5 & $\mathrm{HH}$ & 280 & 85 & \\
\hline 5.70 & GRAHITE & $i$ & $i$ & i & $i$ & SU & K & IK & .5 & NH & 255 & 75 & \\
\hline 5.85 & GRAHITE & 1 & 1 & $i$ & 1 & su & KC & IKU & .5 & HH & 240 & 70 & \\
\hline 5.93 & GRAHI?E & 1 & 1 & $i$ & 1 & SU & $x$ & $\mathrm{KK}$ & .5 & HH & 250 & 70 & \\
\hline 5.98 & GRAHITE| & 1 & $i$ & i & 2 & SU & KC & DKU & .5 & HH & 230 & 75 & PARTLY INDUCED \\
\hline
\end{tabular}




\begin{tabular}{|c|c|c|c|c|c|c|c|c|c|c|c|c|c|}
\hline \multirow{2}{*}{\multicolumn{2}{|c|}{ M5 }} & \multicolumn{5}{|c|}{ DISCONIINUITIES AHO OREAKS } & \multirow{2}{*}{\multicolumn{4}{|c|}{ AI HERAL IZATIOH }} & \multirow{2}{*}{\multicolumn{2}{|c|}{ OR JEKTATIOH }} & \multirow[b]{3}{*}{ REHARKS } \\
\hline & & \multicolumn{2}{|c|}{ CONDITIOA } & \multicolumn{3}{|c|}{$\begin{array}{c}\text { SURFACE } \\
\text { CHARACTERISTICS }\end{array}$} & & & & & & & \\
\hline DEPTH & $\begin{array}{l}\text { ROCK } \\
\text { TYPE }\end{array}$ & 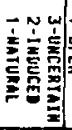 & 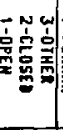 & 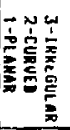 & $\begin{array}{c}\text { ROUGH- } \\
\text { MESS }\end{array}$ & $\begin{array}{l}\text { UEATH- } \\
\text { ERING }\end{array}$ & IYPE & COLOA & $\begin{array}{c}\text { THICK- } \\
\text { MESS } \\
\text { (MN) }\end{array}$ & $\begin{array}{l}\text { HARO } \\
\text { MESS }\end{array}$ & $\left\{\begin{array}{r}B E T A \\
\text { (LEGT) }\end{array}\right.$ & $\begin{array}{l}\text { ALPHA } \\
\text { (DEG) }\end{array}$ & \\
\hline 0.12 & GRANITE & 1 & 1 & 1 & 2 & su & [ & 5 & .5 & HH & 335 & 75 & \\
\hline 6.14 & GRAHIYE & 1 & 1 & 1 & 1 & Su & $k$ & 8K & .5 & HH & 250 & 65 & \\
\hline 0.36 & GRAMITE & 1 & 2 & & & & $k$ & $8 x$ & 1 & & 80 & 50 & SEALED FRACTI RE \\
\hline 0.39 & GRANITE & 1 & 1 & 2 & 1 & Su & kC & BKH & .5 & HH & 335 & Bo & \\
\hline 0.51 & GRaKITE & 1 & 2 & 3 & & & c & & 3 & & & & \\
\hline$\delta .78$ & GRAN17E & 1 & 2 & & & & $k$ & & 1 & & 230 & 40 & \\
\hline$\therefore$. & GAANITE & 1 & 1 & 2 & 2 & SU & k & IK & .5 & HA & 295 & 50 & \\
\hline 2.55 & GHANITE & 1 & $i$ & 1 & 1 & 54 & $x$ & ok & .5 & MH & 355 & 65 & \\
\hline 3.55 & GRAHITE] & 1 & 1 & 1 & 1 & SH & kic & IXW & .5 & NH & 110 & 60 & \\
\hline$\therefore .64$ & GRAMITE & 1 & 1 & 1 & 2 & su & kC & 8KH & .5 & AH & 25 & 60 & \\
\hline$\therefore .64$ & GRAMITE: & 1 & 1 & 1 & 1 & 5H & $x$ & BK & .5 & MH & 190 & 25 & PARPLY INDUCED \\
\hline 7.74 & GRANITE] & 1 & 2 & & & & & Bk & 1 & $\mathrm{H}$ & 200 & 25 & SEALED FRACIURE \\
\hline 8.23 & GRAMITE & 1 & 1 & 2 & 1 & SU & KC & BKU & .5 & MH & 100 & 10 & \\
\hline 8.51 & GRANITE & 1 & 2 & & & & $\mathrm{k}$ & & 1 & & 270 & 15 & \\
\hline 8.61 & GRANITE] & 1 & 1 & 3 & 2 & لاs & $k$ & $3 \mathrm{k}$ & .5 & HH & 250 & 15 & $\begin{array}{l}\text { PARTLY CLOSEO } \\
\text { FR ZOME, B.59-9.61; } \\
\text { PARALLEL TO } 8.61 \mathrm{FR} \text {. }\end{array}$ \\
\hline 8.76 & GRANITE' & 2 & & & & & & & & & & & \\
\hline 8.94 & GRANITE] & 1 & 1 & 2 & 2 & 54 & KC & JKU & .5 & HH & 95 & 35 & \\
\hline 10.10 & GRANITE & 2 & & & & & & & & & & & \\
\hline 10.88 & GRAHITE & 1 & 1 & 1 & 2 & 5y & k & $8 x$ & .5 & MHH & 120 & 50 & \\
\hline $1 t .32$ & GRANITE & 1 & 1 & 3 & 2 & 54 & $k$ & IK & .5 & HH & 125 & 55 & \\
\hline $1: .54$ & GRANITE: & 1 & 1 & 1 & 1 & \$u & $k$ & BK & .5 & HH & 230 & 25 & MOSILY CLOSED \\
\hline 11.62 & GRAWITE & 2 & & & & & & & & & & & \\
\hline 12.04 & GRANITE & 2 & & & & & & & & & & & \\
\hline 12.04 & GRANITE & 1 & 2 & & & & E & & 2 & & 175 & 30 & SEALED FRAC TURE \\
\hline 12.23 & GRANITE & 1 & 2 & 3 & & & E & & 2 & & & & SEALED FRACTURE \\
\hline 12.27 & GRAKITE] & 1 & 1 & 2 & 1 & U & E & 0 & 1 & H & 325 & & PARTLY INDULED \\
\hline 12.31 & GRANI TE: & 1 & 2 & & & & $\bar{\varepsilon}$ & & 2 & & 210 & 55 & \\
\hline 12.31 & GRAMITE & 1 & 2 & & & & KE & & 1 & & & & $\begin{array}{l}\text { SEALED F RAC TURE } \\
:=165-170, A=30-35\end{array}$ \\
\hline 13.11 & GRAN!TE\} & 2 & & & & & & & & & & & \\
\hline 13.23 & GKBKITE & 1 & 2 & & & & E & & 3 & & 175 & 30 & SEALED FRAC TURE \\
\hline 13.23 & GRANITE & 1 & 2 & & & & $\varepsilon$ & & 2 & & & & SEALED FR, 13.23-79 \\
\hline 13.75 & GRAHIIE] & 1 & ? & & & & KC & & 1 & & 325 & 15 & SEALED FRACTURED \\
\hline $\begin{array}{r}13.79 \\
\text { SBOTION }\end{array}$ & $\begin{array}{l}\text { GRANITE } \\
\text { OF FILE) }\end{array}$ & $i$ & 1 & 2 & 1 & 5ע & E & 6 & .5 & H & 210 & 55 & \\
\hline
\end{tabular}


APPENDIX B. Photographs of Time-Scale Experinent Core Samples 


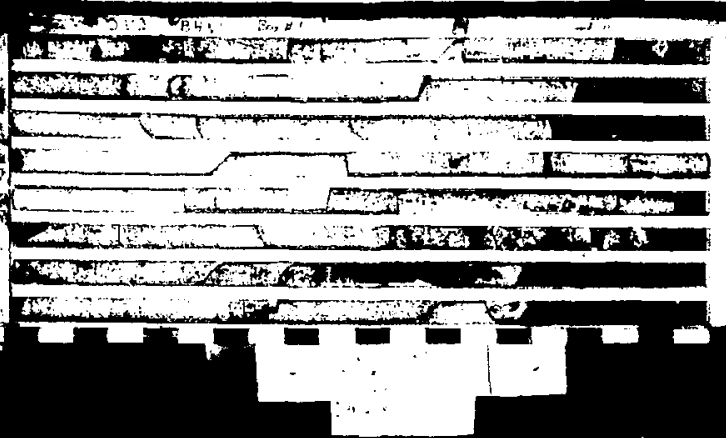

Borehole N1, $0-6.75$ m (CBB 796-8615)

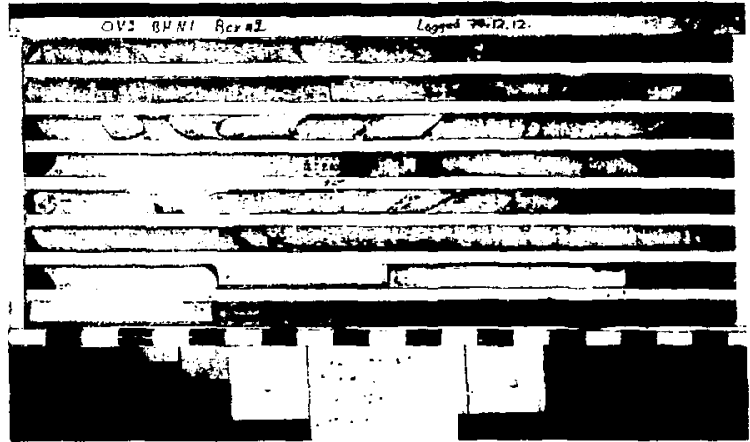

Borehole N1, $6.75-12.80 \mathrm{~m}$ (CBB 796-8528)

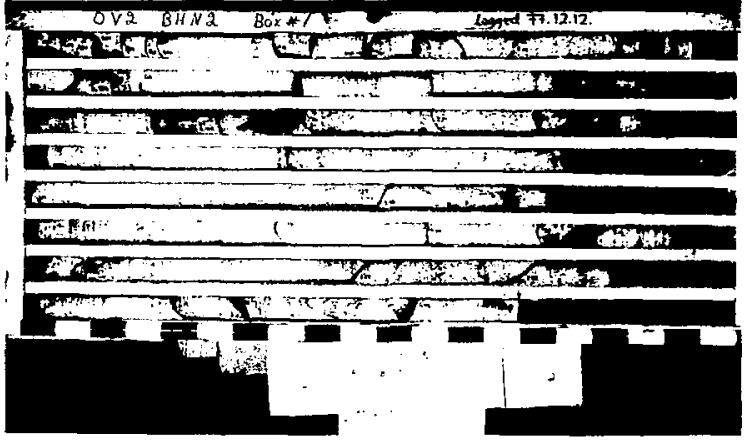

Borehole N2, $0-6.60 m$ (CBB 796-8530)

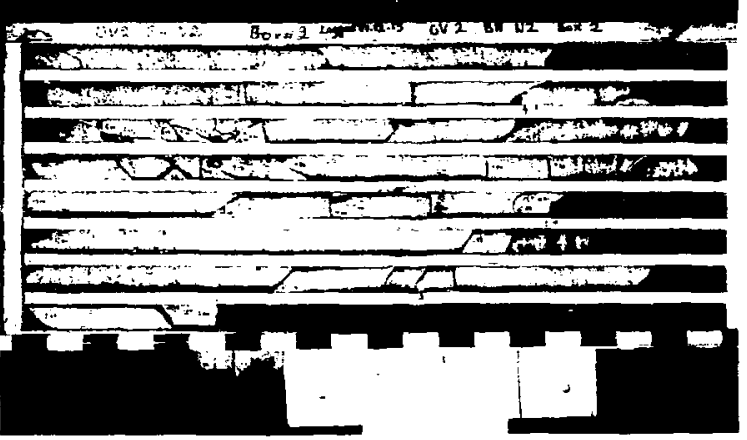

Borehole N2, $6.60-12.84$ m (CBB 796-8613) 


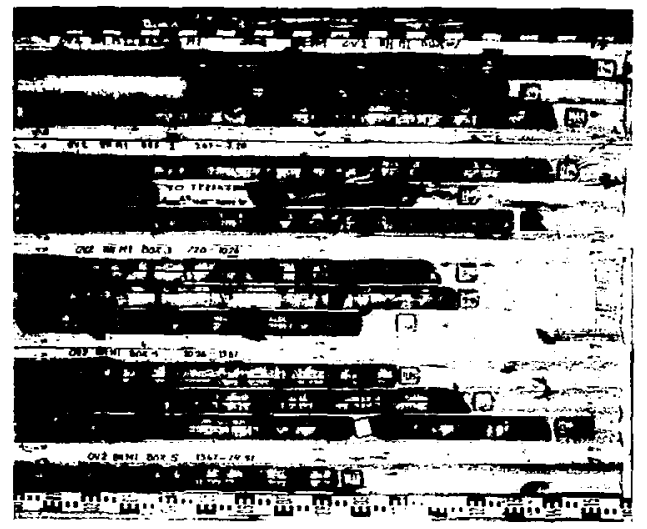

Borehole M1, 0 - $14.51 m$ (XBC 784-3865)

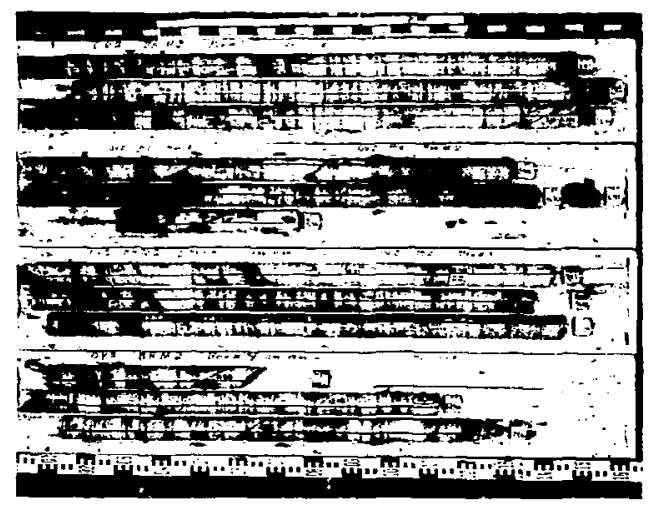

Borehole M2, 0 - 14.01 m (XBC 784-3875) 


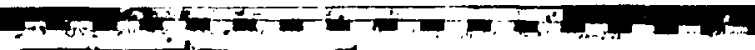

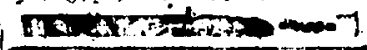

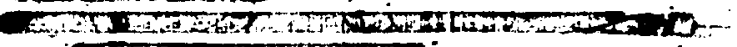

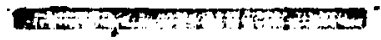

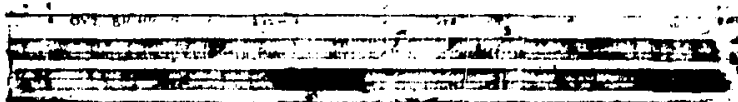

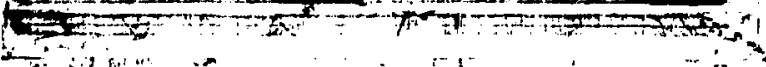

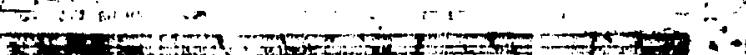

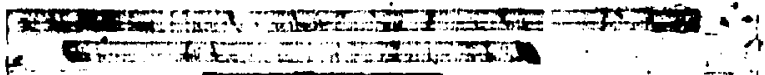

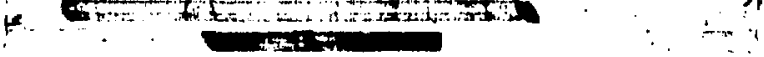
-

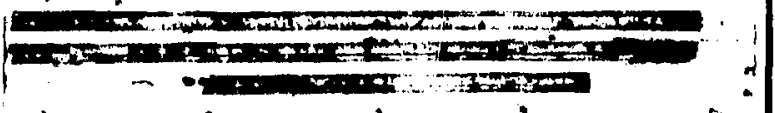

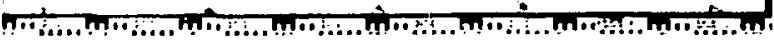
Borehole M4, 0 - 13.76 m (XBC 784-4012)

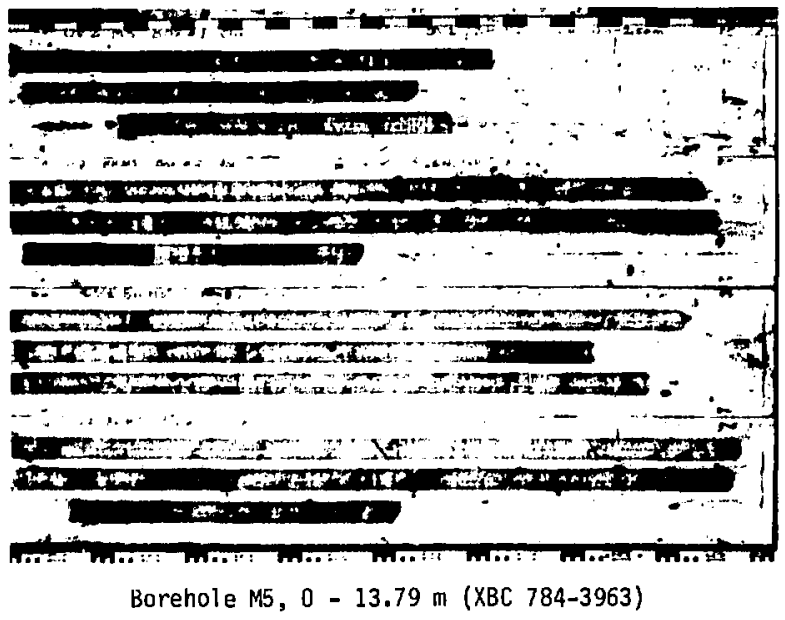




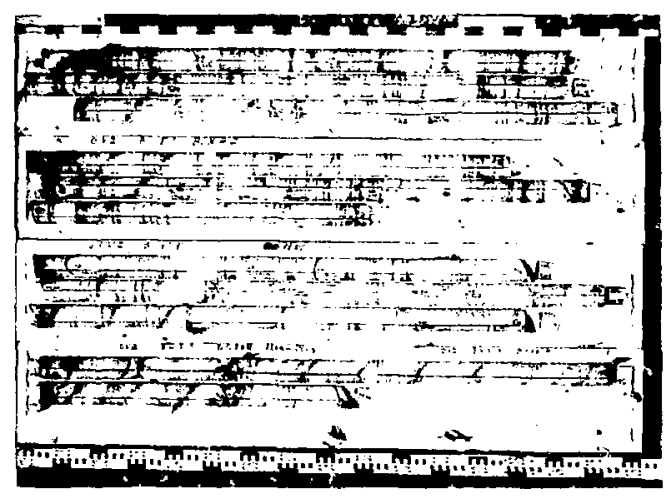

Borehole E1, 0 - 14.08 m (XBC 784-3871)

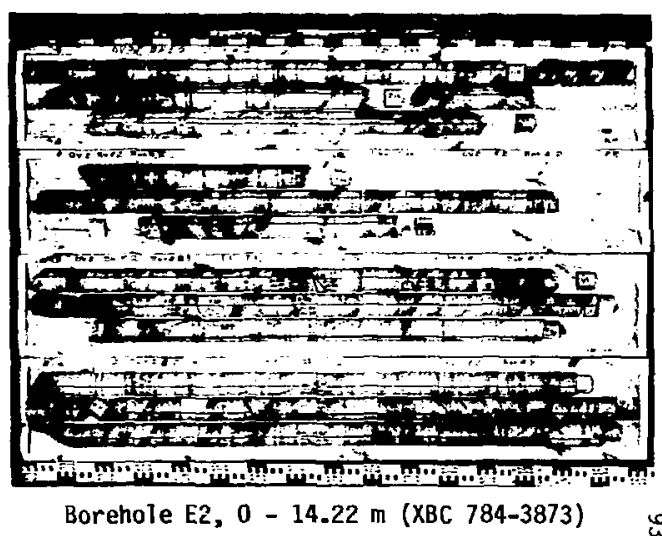

Borehole E2, 0 - $14.22 \mathrm{~m}$ (XBC 784-3873)

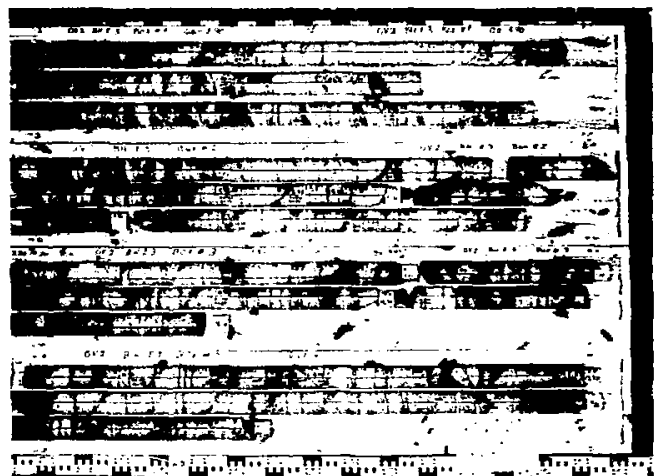

Fin

Borehole E3, 0 - $14.67 \mathrm{~m}$ (XBC 784-3874) 


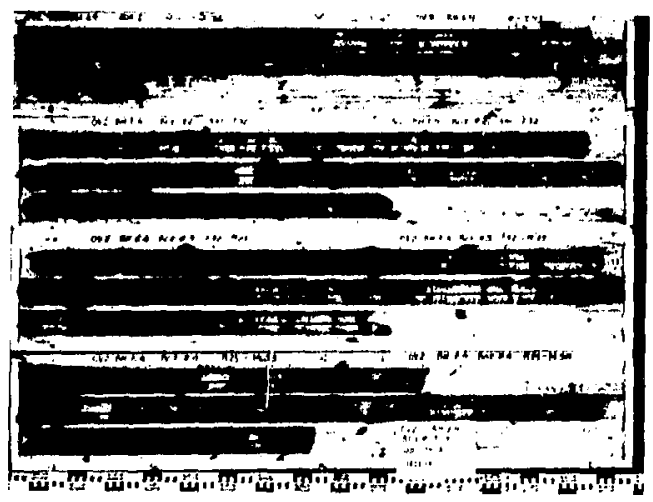

Borehole E4, 0 - 14.58 m (XBC 784-3877)

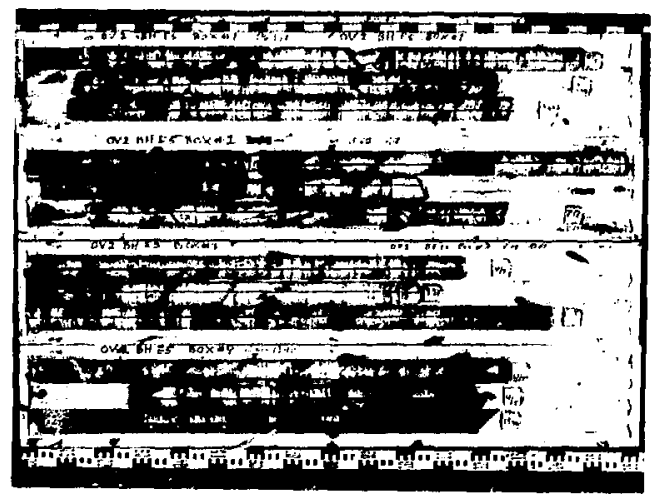

Borehole E5, $0-13.90 \mathrm{~m}$ (XBC 784-3876) 


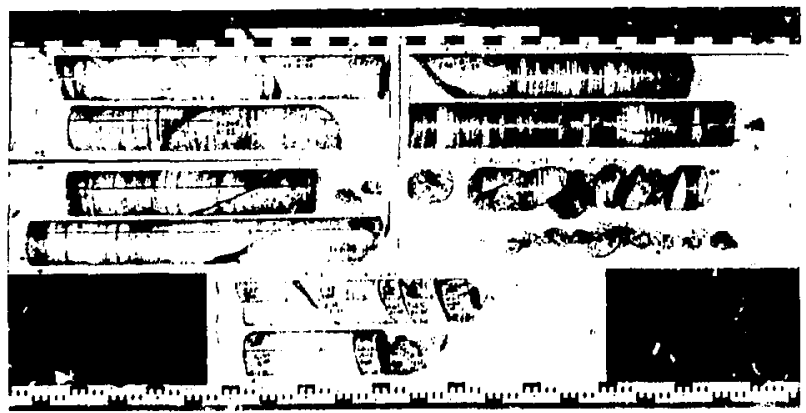

Borehole H1, 0 - $6.07 \mathrm{~m}$ (XBC 784-3881)

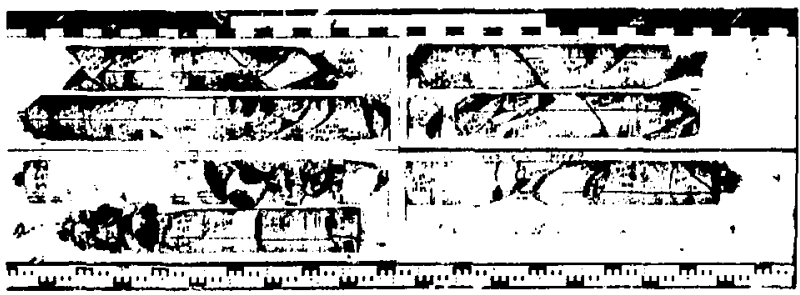

Borehole H1, 6.07 - 11.18 in (XBC 784-3882)

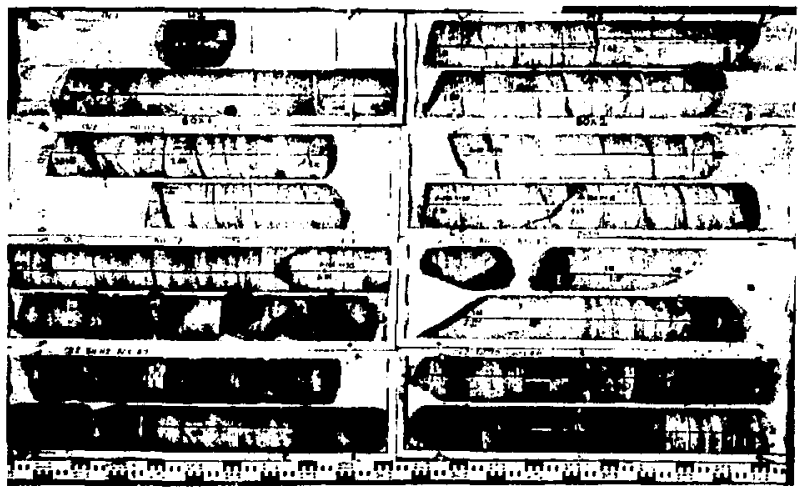

Borehole H2, 0 - 11.77 in ( $\mathrm{XBC} 784-3870$ ) 


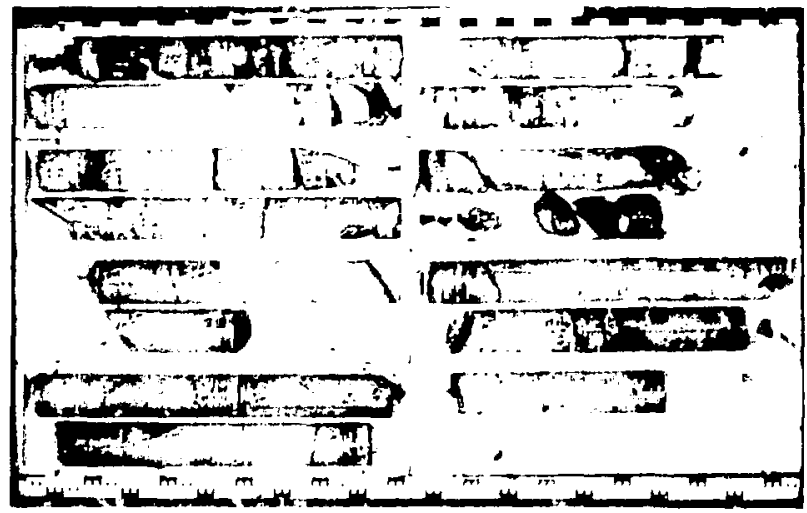

Borehole H3, O - 10.85 m (XBC 784-3879)

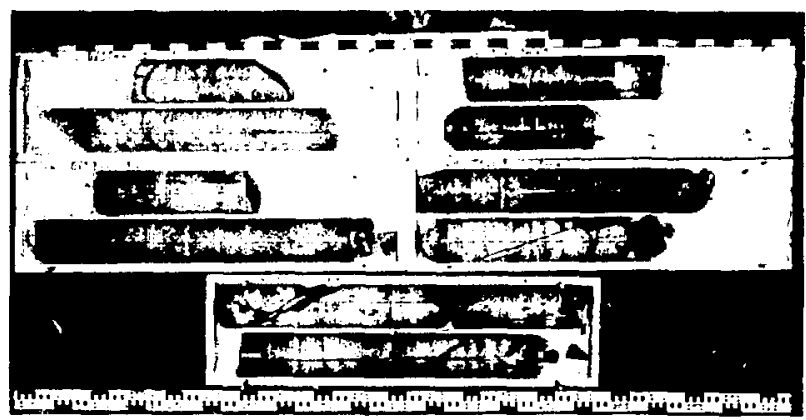

Borehole $\mathrm{H4}, 0-6.28 \mathrm{~m}$ (XBC 784-3890)

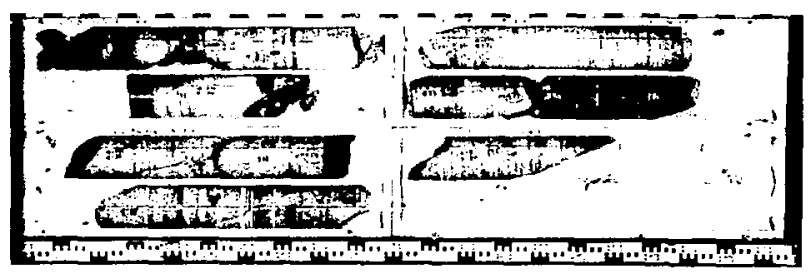

Borehole H4, 6.28 - 10.48 m (XBC 784-3891) 


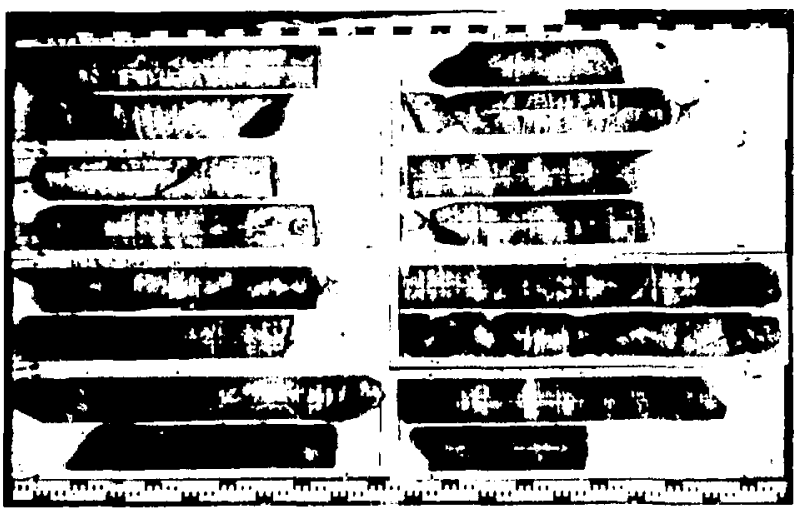

Borehole H5, $0-11.07$ n1 (XBC 784-3889)

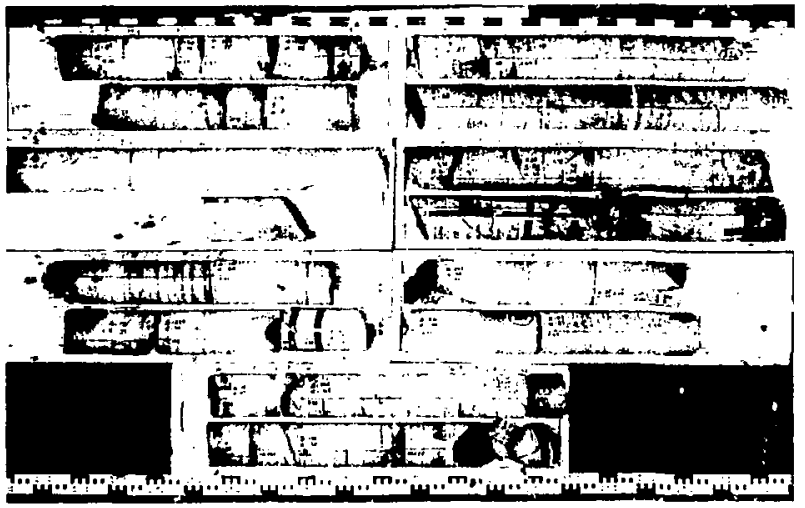

Borehole H6, $0-10.82$ m (XBC 784-3880) 


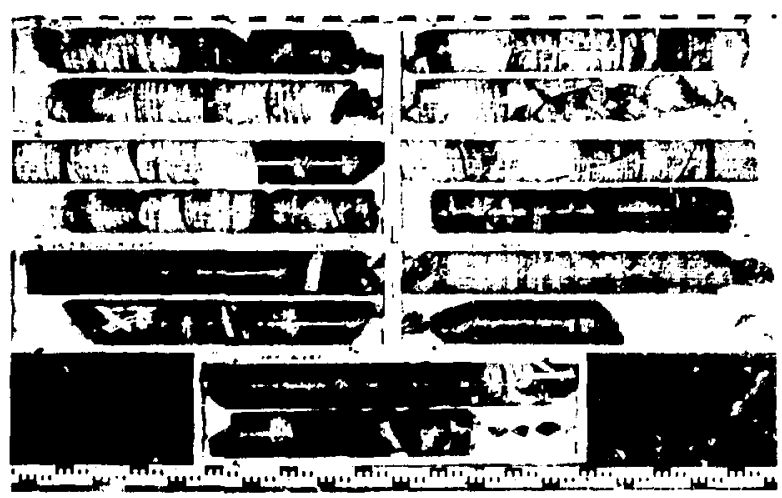

Borehole H7, $0-11.18 \mathrm{~m}$ (XBC 784-3894)

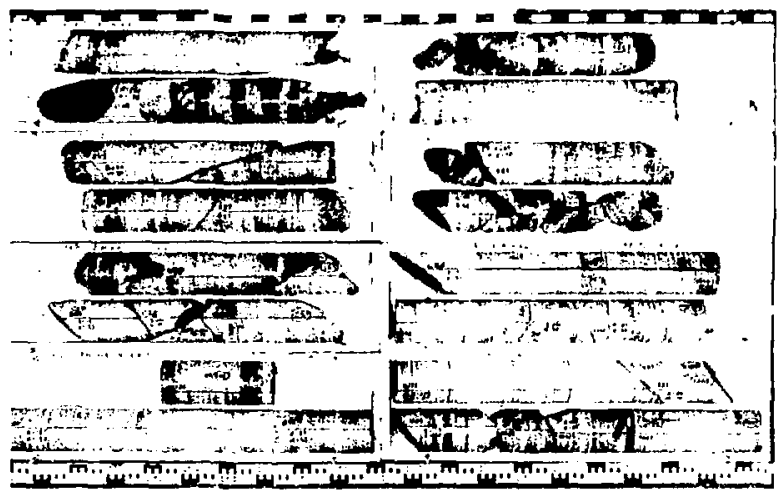

Borehole H8, 0 - $10.97 \mathrm{~m}$ (XBC 784-3888) 
APPENDIX C. Stereonet Plots of Fracture Poies for Time-Scale Experiment Bureholes

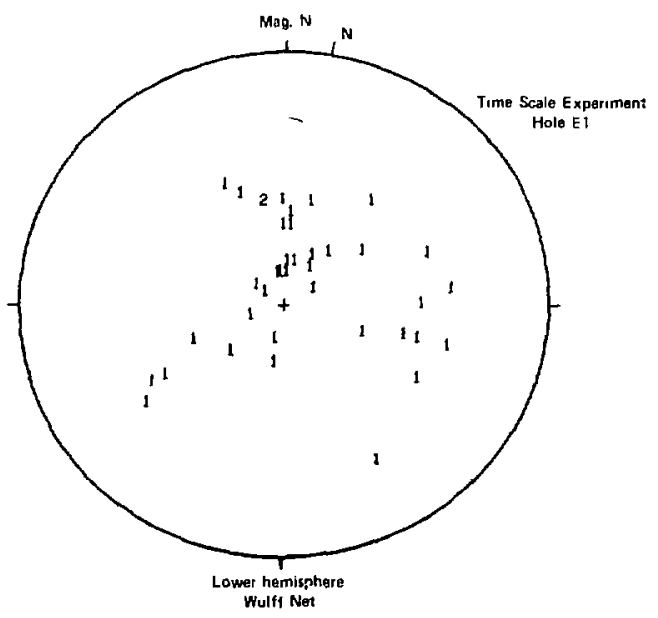

XBL $798-11224$ 

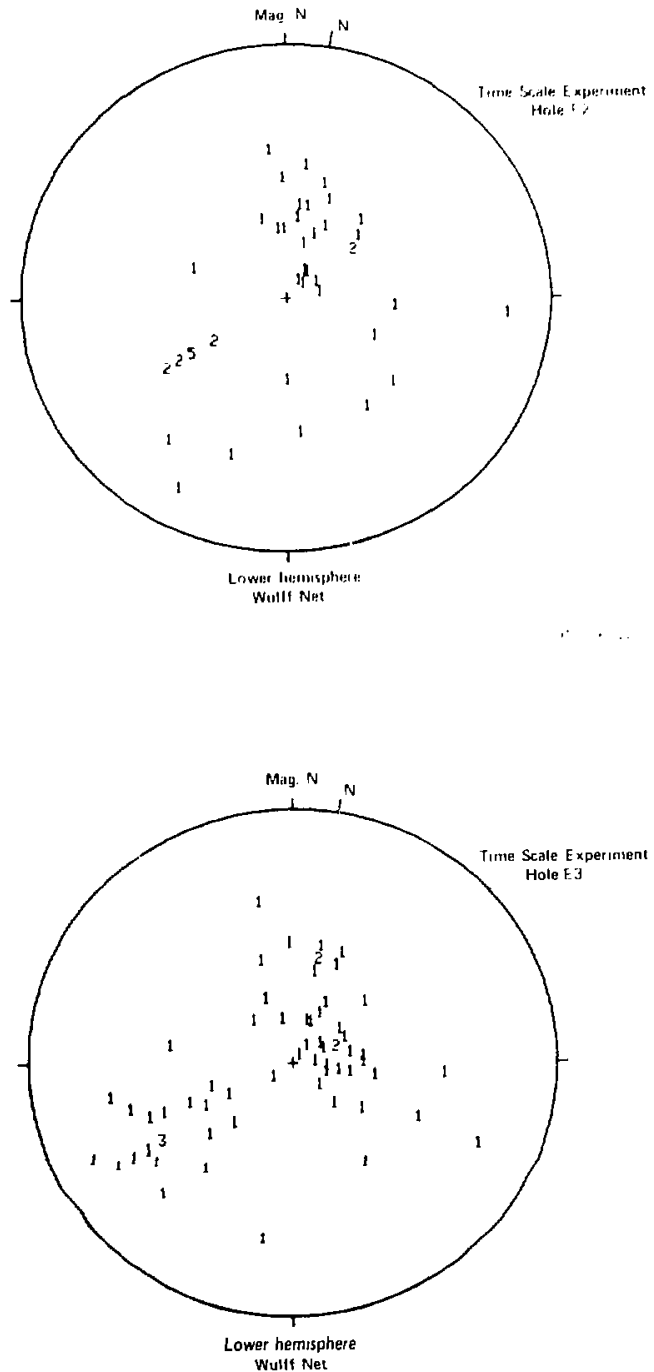

ite $; 3$ r.112e6 


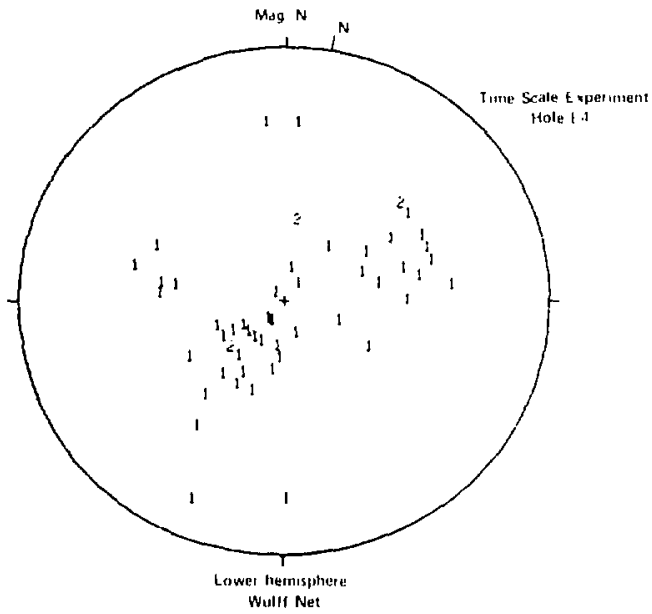

$\therefore \quad, \cdots$

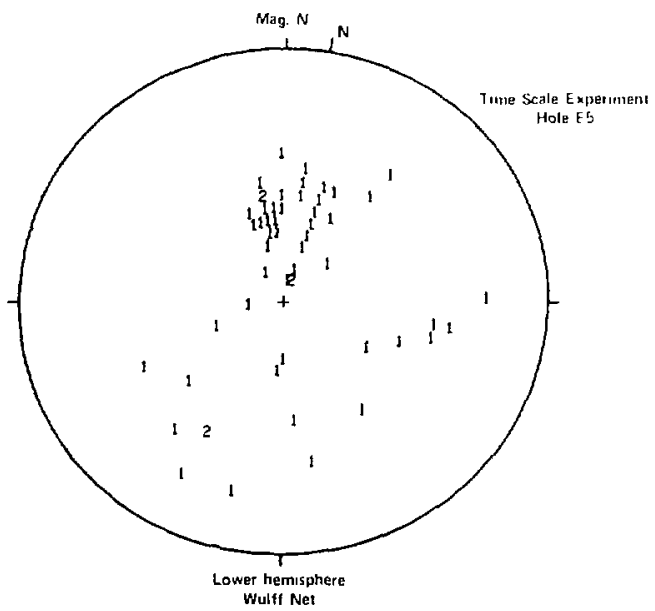




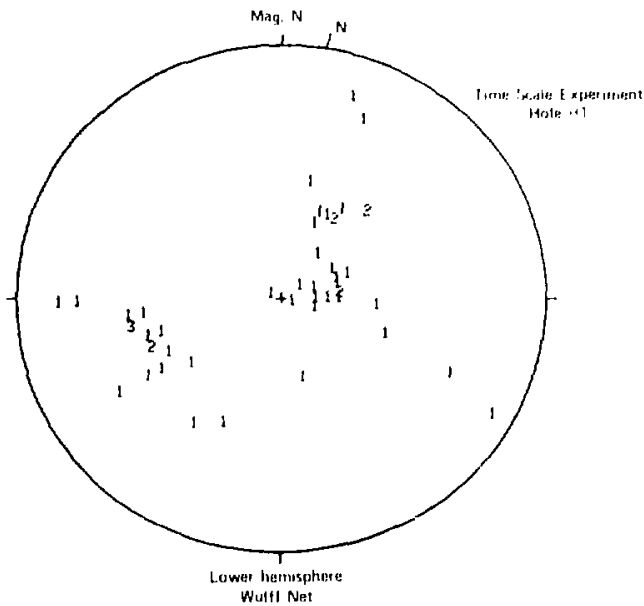

is $\because \quad \therefore$

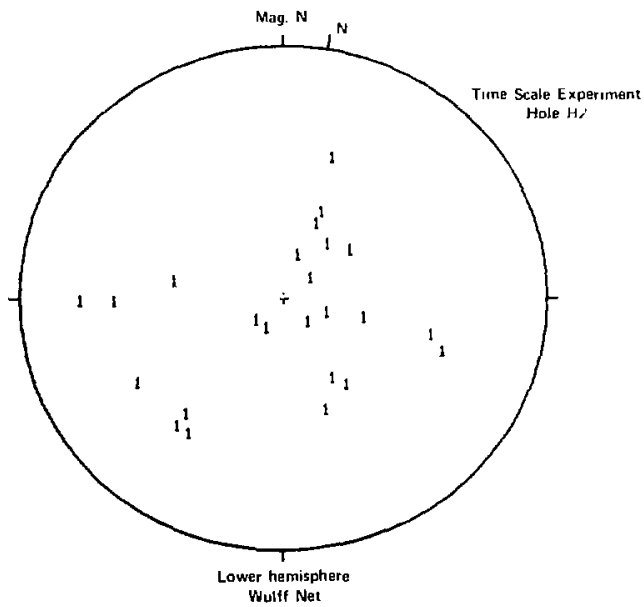

XBL $798-11230$ 


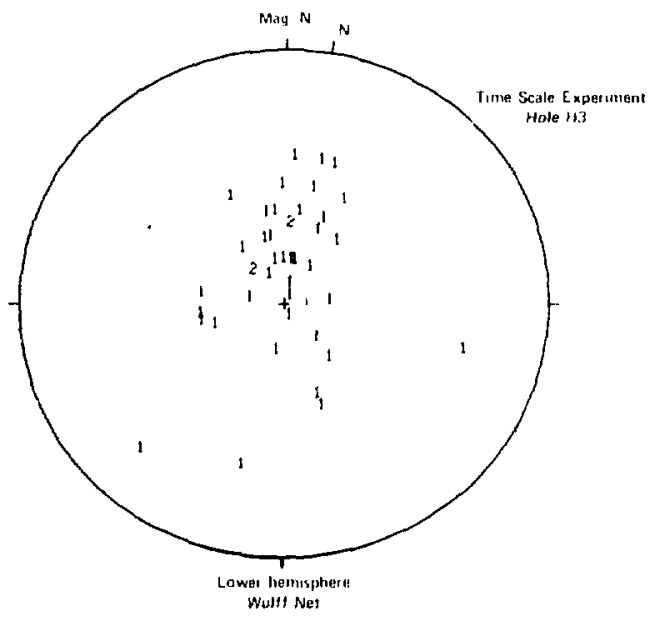

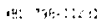

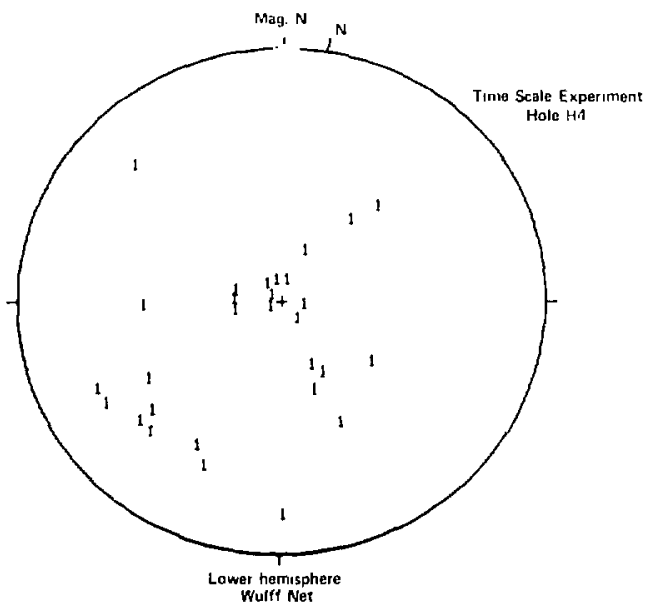


104

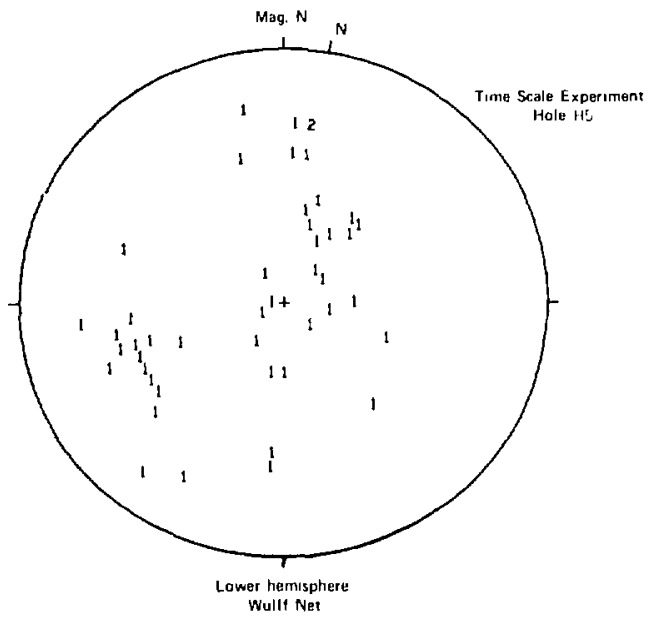

14. 90. 1:-

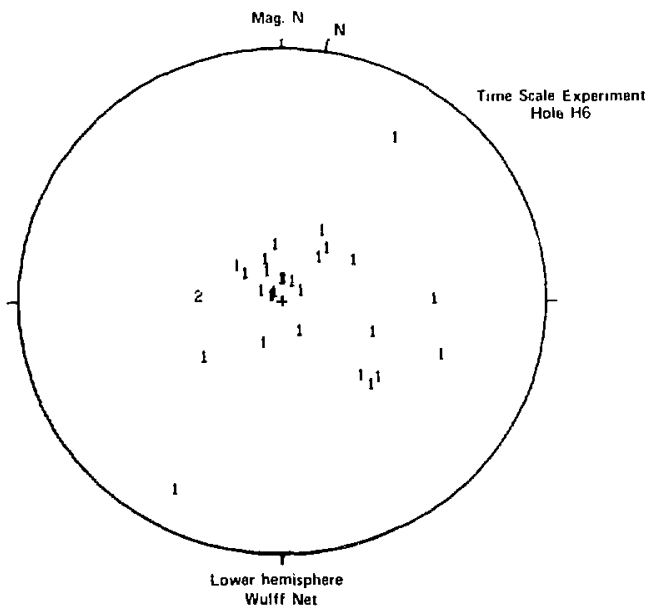

MEL ?98-11233 


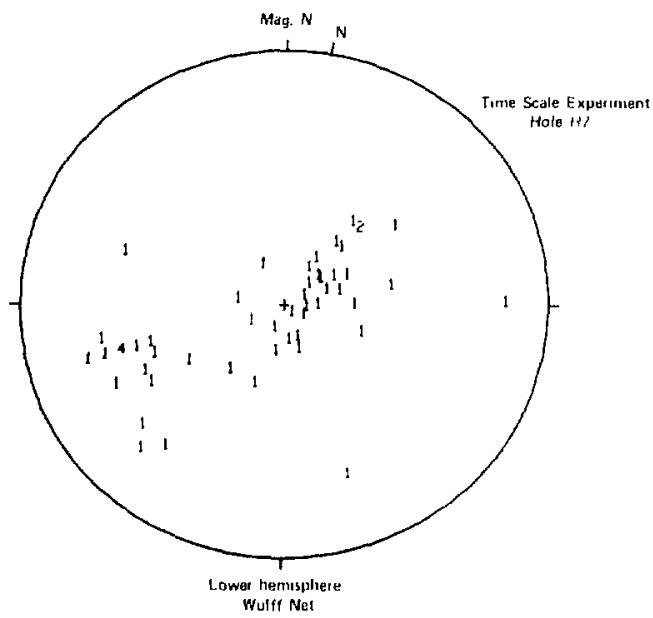

$\therefore \quad \cdots$

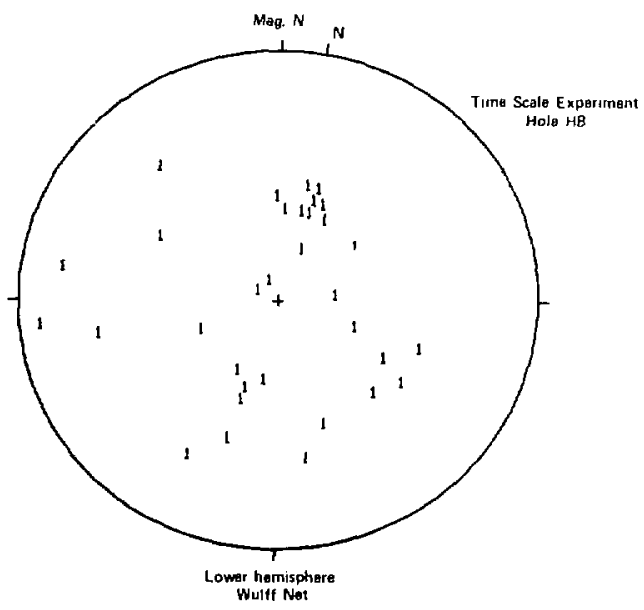

x嘈 79A-11219 


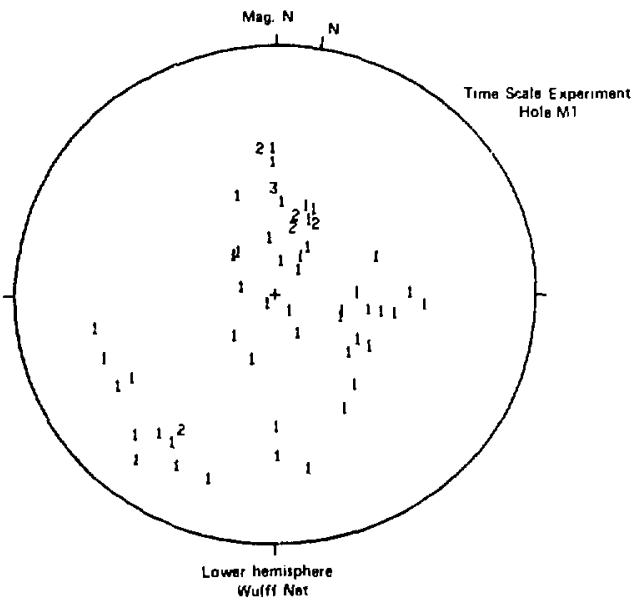

\&EL 798.11223

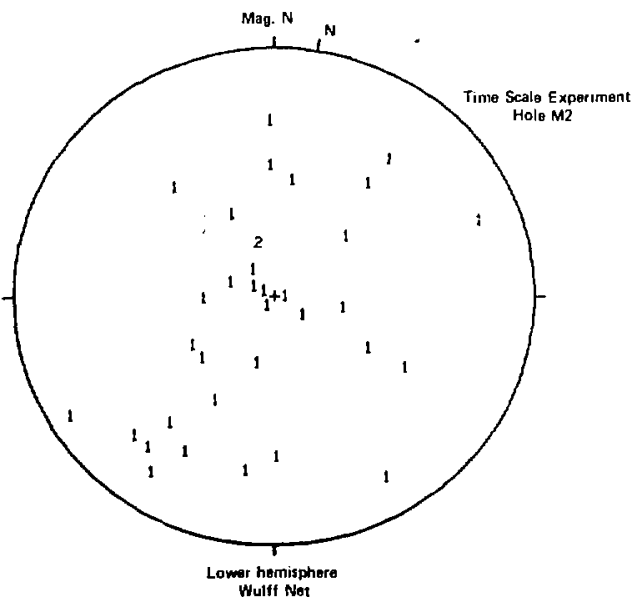

KBL 79B-11221 


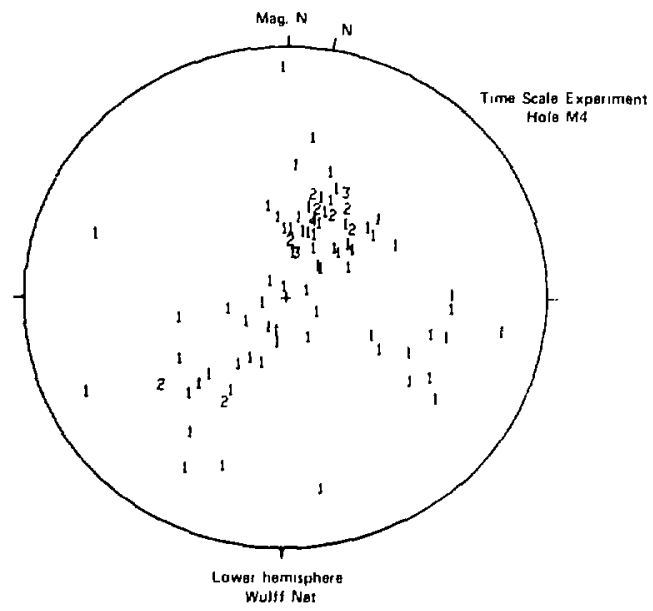

4.9. 74.1228

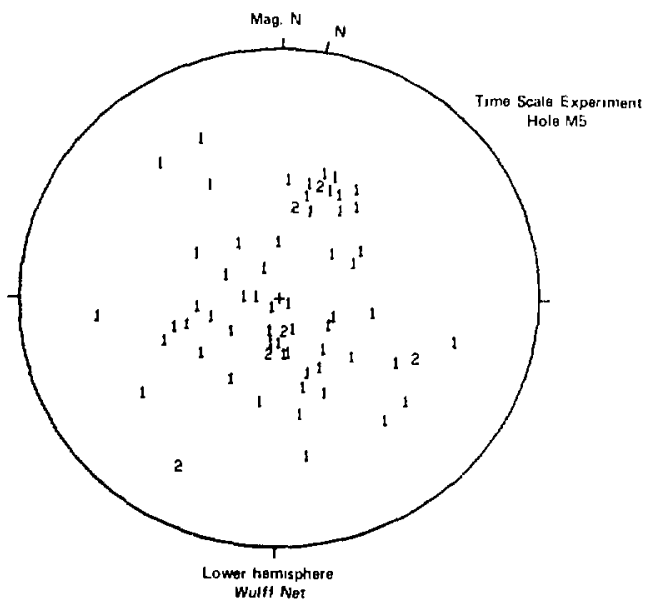

xaเ $798-11223$ 